\title{
Mapping An Information Architecture's Scent: \\ Evaluating the Effects of Task and Context \\ on Judgments of Relevance
}

\author{
Mark A. Game, B.A.
}

\author{
A thesis submitted to \\ The Faculty of Graduate Studies and Research \\ in partial fulfillment of the \\ requirements for the degree of \\ Master of Arts \\ Department of Psychology \\ Carleton University \\ Ottawa, Ontario, Canada
}

December, 2004

Copyright (C2004 Mark A. Game 


$\begin{array}{ll}\begin{array}{l}\text { Library and } \\ \text { Archives Canada }\end{array} & \begin{array}{l}\text { Bibliothèque et } \\ \text { Archives Canada }\end{array} \\ \begin{array}{l}\text { Published Heritage } \\ \text { Branch }\end{array} & \begin{array}{l}\text { Direction du } \\ \text { Patrimoine de l'édition }\end{array} \\ \begin{array}{l}\text { 395 Wellington Street } \\ \text { Ottawa ON K1A ON4 } \\ \text { Canada }\end{array} & \begin{array}{l}\text { 395, rue Wellington } \\ \text { Ottawa ON K1A ON4 } \\ \text { Canada }\end{array}\end{array}$

Your file Votre référence ISBN: 0-494-00720-6

Our file Notre référence

ISBN: 0-494-00720-6

NOTICE:

The author has granted a nonexclusive license allowing Library and Archives Canada to reproduce, publish, archive, preserve, conserve, communicate to the public by telecommunication or on the Internet, loan, distribute and sell theses worldwide, for commercial or noncommercial purposes, in microform, paper, electronic and/or any other formats.

The author retains copyright ownership and moral rights in this thesis. Neither the thesis nor substantial extracts from it may be printed or otherwise reproduced without the author's permission.
AVIS:

L'auteur a accordé une licence non exclusive permettant à la Bibliothèque et Archives Canada de reproduire, publier, archiver, sauvegarder, conserver, transmettre au public par télécommunication ou par l'Internet, prêter, distribuer et vendre des thèses partout dans le monde, à des fins commerciales ou autres, sur support microforme, papier, électronique et/ou autres formats.

L'auteur conserve la propriété du droit d'auteur et des droits moraux qui protège cette thèse. $\mathrm{Ni}$ la thèse ni des extraits substantiels de celle-ci ne doivent être imprimés ou autrement reproduits sans son autorisation.
In compliance with the Canadian

Privacy Act some supporting forms may have been removed from this thesis.

While these forms may be included in the document page count, their removal does not represent any loss of content from the thesis.
Conformément à la loi canadienne sur la protection de la vie privée, quelques formulaires secondaires ont été enlevés de cette thèse.

Bien que ces formulaires aient inclus dans la pagination, il n'y aura aucun contenu manquant. 


\begin{abstract}
Using an information-based web site to seek target information depends largely on the usefulness of the site's information architecture (IA). Users must make guesses about the probability that a menu label will lead to target information. They are making judgments about the relevance or value of those labels and following what Pirolli (1997) refers to as an information scent.
\end{abstract}

This research explored the effects that different tasks and contexts have on information scent. The methodology used in this research proved to be a good tool for mapping the scent trails of an IA and the degree of agreement about a labels scent. The metric used for computing the probability that a menu label will be chosen also proved informative. Providing tools that allow researchers and developers to diagnose the usefulness of an IA and inform their design decisions is one of the main contributions of this research.

In addition, the results showed that providing users with multiple access points to the same target information increases the likelihood of a user finding that information. Results also showed that users identified a greater number of partially relevant menu labels when they were judged from a situational context rather than from a topical context. A final conclusions was that a menu label's information scent depends on the scenario driving the search. 
Mapping an Information Architecture's Scent

This thesis is dedicated to my son Chad Game whose inquisitive mind and philosophical view of the world is fertile ground for many great contributions.

May this thesis inspire you and motivate you to pursue your own path of higher learning. 


\section{Acknowledgments}

A few years ago, an ancient African proverb "It takes a village to raise a child" was popularized by the release of a book bearing the same title and written by former First Lady Hillary Rodham Clinton. When I began thinking about all the people who have helped, supported, influenced and contributed to my thesis in one way or another, I realized that it also takes a village to complete a thesis. The quality and richness of the experience is something that I can now take with me for the rest of my life and in large part, is due to the quality of people who made up this community of friends, family, colleagues, mentors, and professionals.

I am sure that many of these people are not even aware of their contributions, but I'd like to take this space to extend a very warm and heart felt thank you, and to let you all know that I feel very privileged to have had you as part of my village. Special thanks go to...

Christiane Séguin — My soul mate, my love, and the bedrock of my life. Thank you for always being there, for your continuous support and encouragement and your remarkable patience. You were like an $\mathrm{N}$ of 1000 , for it must have been a 1000 times that I would wake you up in the morning with the first words out of my mouth being... "...so what do you think about...", or "...pretend you are looking at.... And then this happens.......so how would you react...?". The countless times I used you as my sounding block, and my first point of contact to test out ideas, and sometimes just to hear myself try and articulate an idea. You supported me completely without ever once complaining or expressing signs of fatigue. Your quiet charm, grace and love was always there. In the 2004 movie "Shall We Dance", Susan Sarandon's character asks a male character, "So why do people get married?", the male character replied, "Well passion of course!". Susan's character responds, "No, its because we need a witness to our lives." She goes on to explain how by having someone witness our lives, our thoughts and 
emotions, it validates our lives and gives them meaning. Christiane, thank you so much for not only witnessing my life, but also for being such a willing participant.

Patricia Trbovich, Cathy Dudek and Kathryn "Kate" Oakley - My fog clearers and security blankets. In the same way that I felt unwavering support and willingness to commit time and energy from Christiane, I've been extremely fortunate to feel that same support and friendship from the three of you. From the first time I've met all three of you, you never hesitated to listen and challenge my ideas and would selflessly work through concepts and issues with me. What was particularly remarkable about your support was that these "discussions" would usually last for hours, were never planned, and you all had full lives of your own. Yet without hesitation you would drop whatever you were doing and engage yourselves with whatever I was grappling with at the moment. You all helped to clear the fog from my thinking on a number of occasions and gave me that secure feeling of knowing that my efforts were being supported.

Adrienne Game - My Mom, proof reader and Queen recruiter. Mom, thanks so much for your willingness to do whatever you could whenever you could. Your major recruiting efforts, proof reading and 47 years as an educator all provided me with avenues I could turn to 'at the drop of a hat' and new that I'd have someone I could rely on.

Andrew Aubrey, Jeff Schneider, Julaine and Peter Gray, Adam Bronsther, Stéphane Bernadel, Todd Game (my brother), Lianna Heitman, Felix Game (my father), The Hargreaves Family (Rick, Paul and Jeff), Rob Morrow, David \& Diana Ridgeway, Kavita Prakash, and all the guys and gals at the Ottawa Underwater Hockey Club and at Carleton's Human Oriented Technologies Lab (HOT Lab) — my Trojan army of recruiters, pilot subjects and supporters. Thank you all so much. 
Steve Dunik - My technical guru. Thanks for all the wonderful discussions, grappling and technical solutions that you came up with. This project sure had its challenges but you met them all. Its rare to have a technical person who is also interested in the usability of what he is building.

Craig Leth-Steensen - The Code Breaker. Early in the proposal part of this process, when Dick and I were stuck on an approach to analyzing this data, you cracked the code. Your adaptation of an existing formula was enormously helpful in calculating the probability of choosing target menu labels. It provided the analytical foundation around which this research centered, and as Dick said many times.... "it's a really neat measurement."

Lynn Giff, Etelle Bourassa, Kim Cook, and Nathalie Pressburger — My administrative stewards. Between you, you represent two different eras of administrative support. This rather unique journey certainly had its share of unusual administrative issues, but your constant smiling faces and willingness to always help and find a solution made the journey so much smoother. I really did feel supported.

Gitte Lindgaard, Avi Parush, Janice Singer - My committee members. Throughout this process your thoughtful questions and challenges and support both academically and administratively helped make this bumpy ride a worthwhile journey. It also helped to make the end product much better.

Timothy "Tim" Pychyl — My committee chairperson. Having you preside over my committee as chairperson was so fitting. It seems you have always been there at my most significant academic milestones - my first graduate course in 1981 (as an undergraduate), at my undergraduate degree ceremony and now my graduate thesis. Your presence made it special and so comfortable. Thank you also for lending an ear when I needed it. 
Jo Wood - A very special committee member. Jo you had the very unenviable task of trying to fill the large void left by Dick's death part way through this thesis process. As one of the founders of what is now the HOT lab your willingness to come out of retirement and help me was a testament to your caring and selfless commitment to helping students. For me, it provided an enormous sense of comfort and relief to have someone that I new and could trust with your stature and experience to help pick up the pieces and continue to move this process along. I felt that you had the most uncanny ability to understand when and where I was having problems, ask just the right questions and provide me with just enough of an answer to move me forward. Dick may have laid the foundation and helped frame this project, but Jo, you were the one to help make it shine. Thank you so much.

Richard F. Dillon - "Dick". You will always be missed, but in particular there are two things that I've missed most as I've completed this thesis... To hear what your response would have been when I would have told you “....after all these years, I'm finally done!.” What I've pictured is you sitting in the lab at your computer eating lunch out of your Tupperware and between bites saying simply "It's about time" or perhaps even "...mind boggling". The second thing I've missed has been your genuine excitement and reactions to the work I was doing. I really would have liked to know if this turned out in a way that you expected or would have liked.

If I were to consider my years of being a Carleton graduate student as a process of sculpting an academic mind, Dick was my sandpaper. Always smoothing and refining my thinking (though sometimes the paper may have been a little grittier than I would have liked). His tough exterior covered a truly good and sensitive heart, and his genuine interest in helping students came through loudly. My motivation to strive for excellence was partly motivated by his 
genuine excitement about this project, and the standards and no nonsense approach he took to commenting and critiquing my work. Perhaps the most important thing Dick taught me was to trust my committee, and to understand that the process really was one of mentoring rather than confrontation.

Dick died suddenly on July $26^{\text {th }}, 2004$ only a couple of hours, after he and I had been taking a first look at this experiment's data. We discussed an issue related to probabilities. I was later told by his daughter that the next day the family found a book in his room that was open to a chapter about probabilities. It was so typical of Dick to always be looking for the right or better answer to a question. Dick was a man who loved nothing more than to be helping a student and to be analyzing data. I feel very honoured to have shared some of the last moments of his life doing what he enjoyed the most, and to have shared that final handshake good-bye. He will be missed but his influence will always be felt.

Dick, thank you for not only helping me through this process but for shaping my thinking. As the last of your students to graduate, this thesis brings closure on many levels. 


\section{Table of Contents}

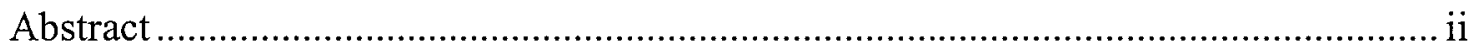

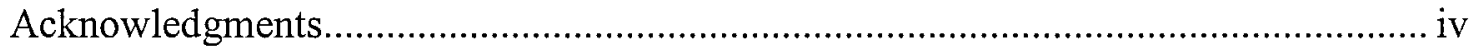

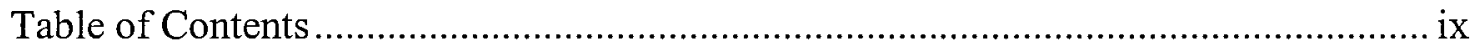

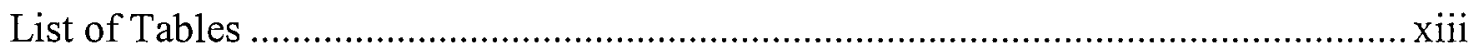

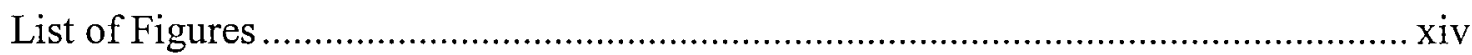

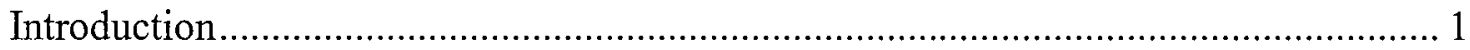

The Theory of Information Scent - A Theoretical Framework ............................ 3

Task Orientation - Classifying and Seeking................................................... 7

Context of Evaluation - Topical and Situational ............................................. 8

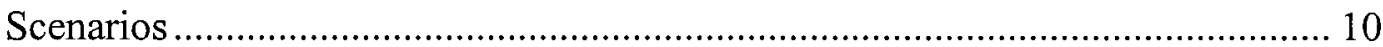

Regions of Relevance ............................................................................... 10

Using Magnitude Estimation to Measure Relevance.................................... 11

Research Questions and Hypotheses .............................................................. 13

Number of Menu Labels Judged Relevant............................................ 13

Number of Menu Labels Judged Partially Relevant ................................ 15

User Agreement About Most Relevant Menu Labels................................. 16

Probability of Choosing the Target Menu Label ..................................... 17

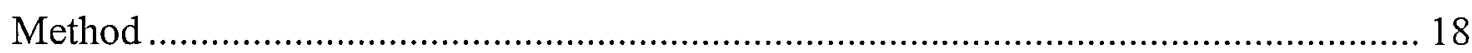

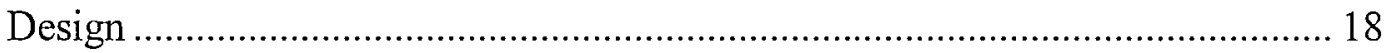

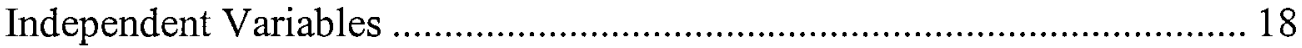

Dependent Variables .................................................................. 20

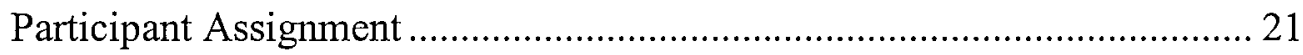


Experimental Control....................................................................... 21

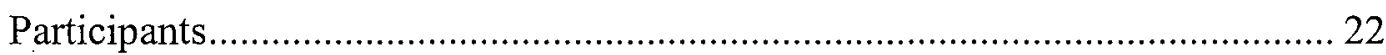

$\mathrm{N}$ and Power Analysis..................................................................... 22

Sampling Strategy \& Recruitment Procedures ........................................ 22

Setting, Materials and Apparatus ........................................................... 23

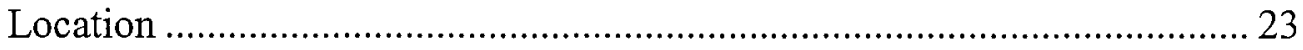

Technical Requirements and Controls ..................................................... 24

Web Site Structure and Functionality .................................................. 24

Validating Experimental Scenarios..................................................... 26

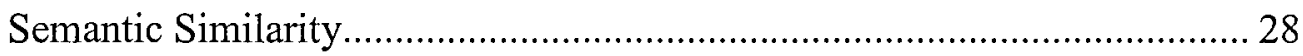

Regions of Relevance and Thresholds .............................................. 32

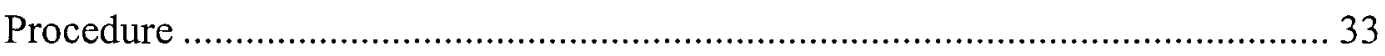

Initial Contact \& Informed Consent ................................................. 33

Participant Orientation \& Practice ............................................................. 34

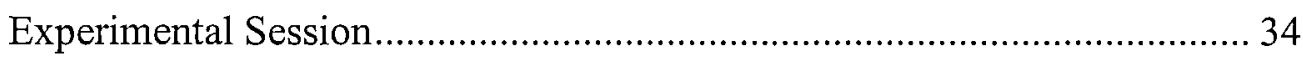

Closing Questions \& Debriefing Screen............................................. 35

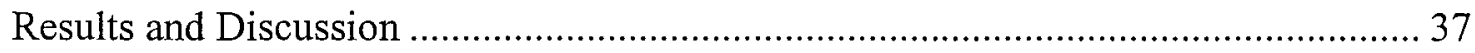

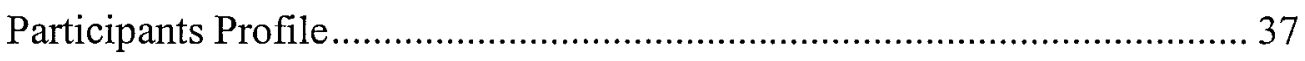

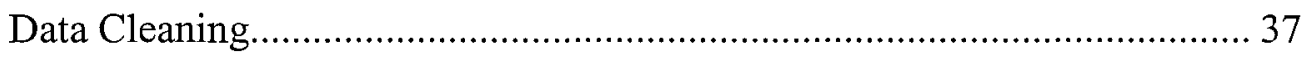

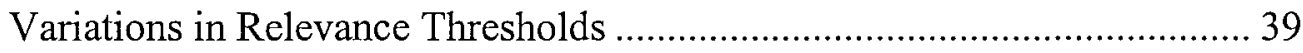

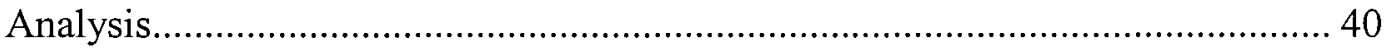

Mean Number of Relevant Menu Labels Per Scenario ............................. 41

Mean Number of Partially Relevant Menu Labels Per Scenario ................. 43 
Proportion of Agreement About Relevant Menu Labels ............................... 46

Probability of Choosing the Target Menu Label ........................................... 48

Participants Identify Mixed \& Competing Choices ....................................... 51

Comparing the Target Menu to Alternate Menu Label Choices..................... 52

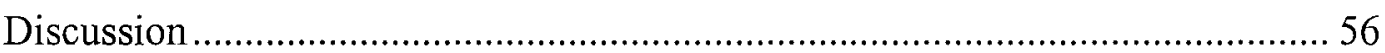

The Effects of Task and Context on Information Scent ................................56

Diagnosing Scent Trails and Informing Design Heuristics .......................... 57

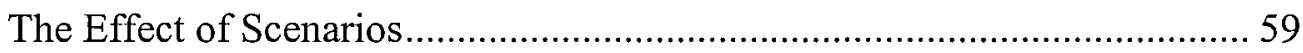

Relevance - The Construct, Thresholds \& Methodological Weaknesses ... 60

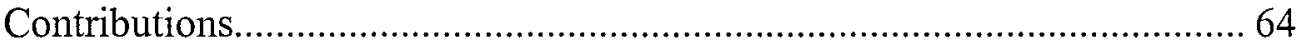

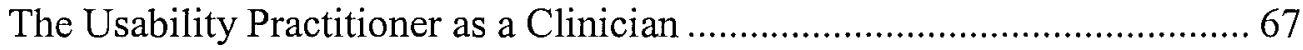

Appendix A - Experimental Information Architecture - Menu Labels .............. 68

Appendix B - Balanced Latin Square .............................................................. 73

Appendix C - Participant Profile ....................................................................... 74

Appendix D - Researcher's E-mail Recruiting Script.......................................... 75

Appendix E - Topic Validation Survey Showing Unclear Items ......................... 76

Appendix F - Experimental Site - Home Page …………................................. 86

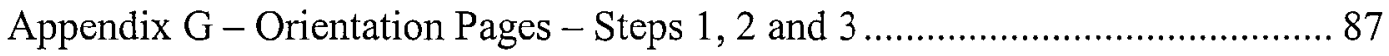

Appendix H - Practice Scenario 1 - All Four Experimental Conditions ............ 92

Appendix I - Final Question Page ..................................................................... 97

Appendix J - User Information Screen................................................................ 100

Appendix K - Text from Participant Debriefing Screen ..................................... 101

Appendix L - Face-to-Face Recruiting Scripts .................................................. 103 
Appendix M - Computing an IA's Usefulness.................................................... 104

Appendix N - Scenario Task \& Contexts Used During Experiment. ................. 107

Appendix O - Data Cleaning Details................................................................... 112

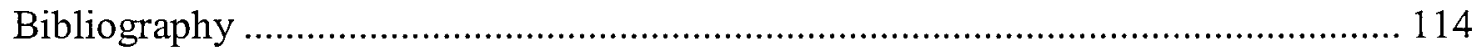


List of Tables

Table 1. Sample Scenario with Different Representations for each Experimental Condition 20

Table 2. Actual LSA Cosine Matrix Validating Context Descriptions in Table $1 \quad 30$

Table 3. Participant Sessions Removed from Dataset 38

Table 4. Regions of Relevance - Threshold Frequency Counts \& Summary Statistics $\quad 40$

Table 5. Mean Number of Menu Labels Judged Relevant per Scenario 41

Table 6. Mean Number of Menu Labels Judged Partially Relevant per Scenario 44

Table 7. Proportion of Participant Agreement About the Most Relevant Menu Label $\begin{array}{ll}\text { per Scenario } & 47\end{array}$

Table 8. Mean Probabilities of Selecting the Target Menu Label for Each Scenario 49

Table 9. Distribution of Participants with Weak, Clear and Multiple Option

Response Styles

Table 10. Comparing the Effects on Mean Probabilities of Adding an Alternate Label Choice 55

Table 11. Proportion of Age Groups having University Education 74

Table 12. Distributions of Population and Internet Users within the NCR 74

xiii 
List of Figures

Page

Figure 1. Components of a Three-Tier Information Architecture $(4 \times 3 \times 2)$

Figure 2. Navigational Path Required to Access Target Information 2

Figure 3. An Information Architecture with Competing Scent Trails 6

Figure 4. Hypothesis 1 - Mean Number of Relevant Menu Labels $\quad 14$

Figure 5. Hypothesis 2 - Mean Number of Partially-Relevant Menu Labels 15

Figure 6. Hypothesis 3 - Proportion of User Agreement About Most Relevant Menu Label 16

Figure 7. Hypothesis 4 - Probability of Users Selecting the Target Menu Label 17

Figure 8. Screen Capture of Slider Bars for Second-level Menu Labels 35

Figure 9. Effect of Scenario on Number of Relevant Ratings $\quad 42$

Figure 10. Scenario by Context Interaction for Relevant Ratings 43

Figure 11. Effects of Scenario on Partially Relevant Ratings $\quad 45$

Figure 12. Effect of Scenario on the Probability of Choosing the Target Menu Label 50

Figure 13. Scenario. x Context Interaction - Probability of Selecting Target Label 51

Figure 14. User Agreement of Relevance for Target Label v Alternate Labels 53

Figure 15. Comparing Probabilities - Target versus Target and Alternate 54 


\section{Mapping An Information Architecture's Scent: \\ Evaluating the Effects of Task and Context on Judgments of Relevance}

Today many users of the Internet are using information-based web sites in an attempt to satisfy a particular information need. However, even when a user identifies a relevant web site, its menu labels do not always lead the user to available information.

When an information seeker arrives at a web site they are usually confronted with a menu system - labels that allow the user to navigate further into the site. These menu labels generally group the site's content into a structure of hierarchical categories. The labels also suggest the type of content or information that might be linked to them. The structure and its corresponding menu labels form a site's Information Architecture (IA). The IA depicted in Figure 1 is threetiered, with menu labels at the first two levels, and content pages at the third level. In this example, a user is presented with a different number of navigational choices at each level of the IA - four at the first level, three at the second and two at the third $(4 \times 3 \times 2)$. Therefore, the IA of an information-based web sites, becomes an important interface between its users and the site's content.

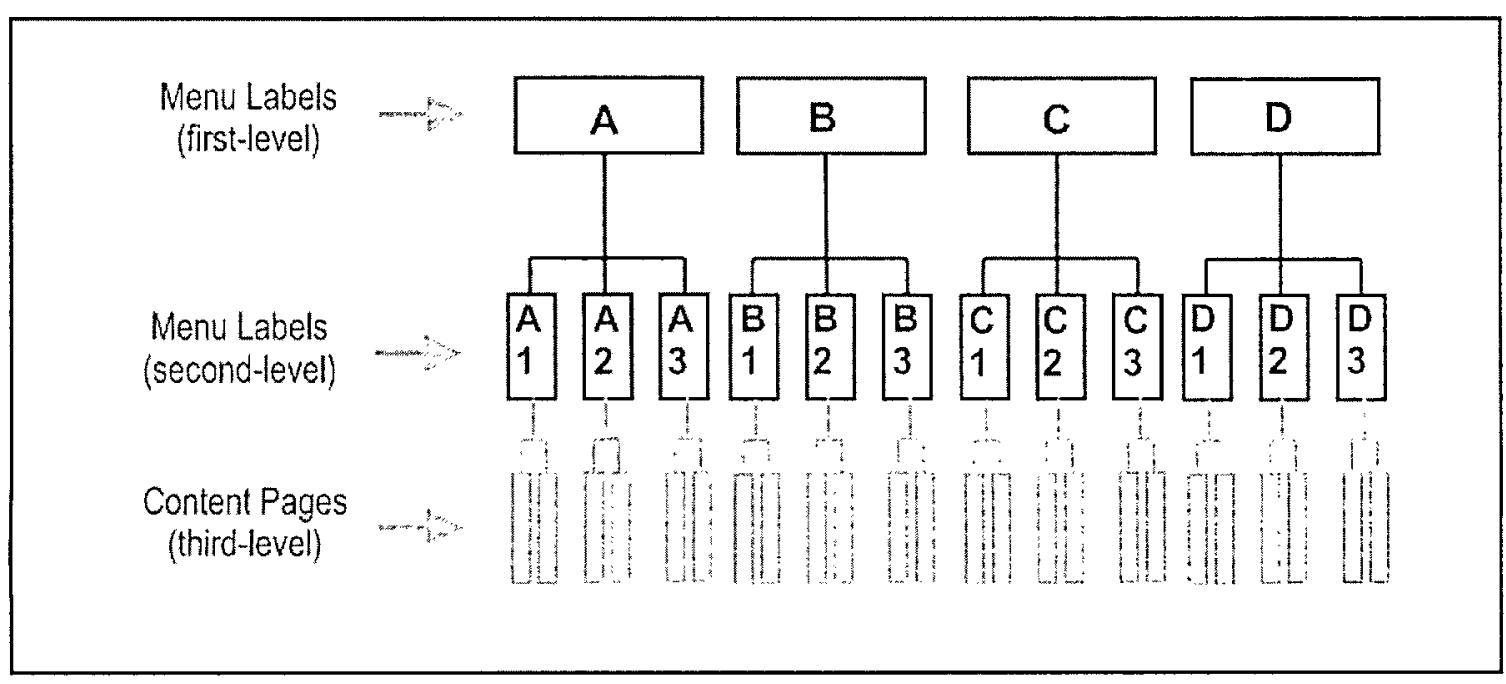

Figure 1. Components of a Three-Tier Information Architecture $(4 \times 3 \times 2)$ 
The usefulness of an information architecture depends on how well it guides users to relevant content - the target. Accessing content requires a user to first browse or scan the available menu labels. They are then required to make decisions about the potential relevance and utility of those labels to the information need at hand. In effect, users are making a guess at the likelihood that a given menu label will lead to relevant information - a probabilistic approach to navigating a web site. For a user to successfully access the target information in Figure 2, the user must correctly identify menu label $\mathrm{C}$ from the first-level labels, and then menu label C3 from the second-level labels.

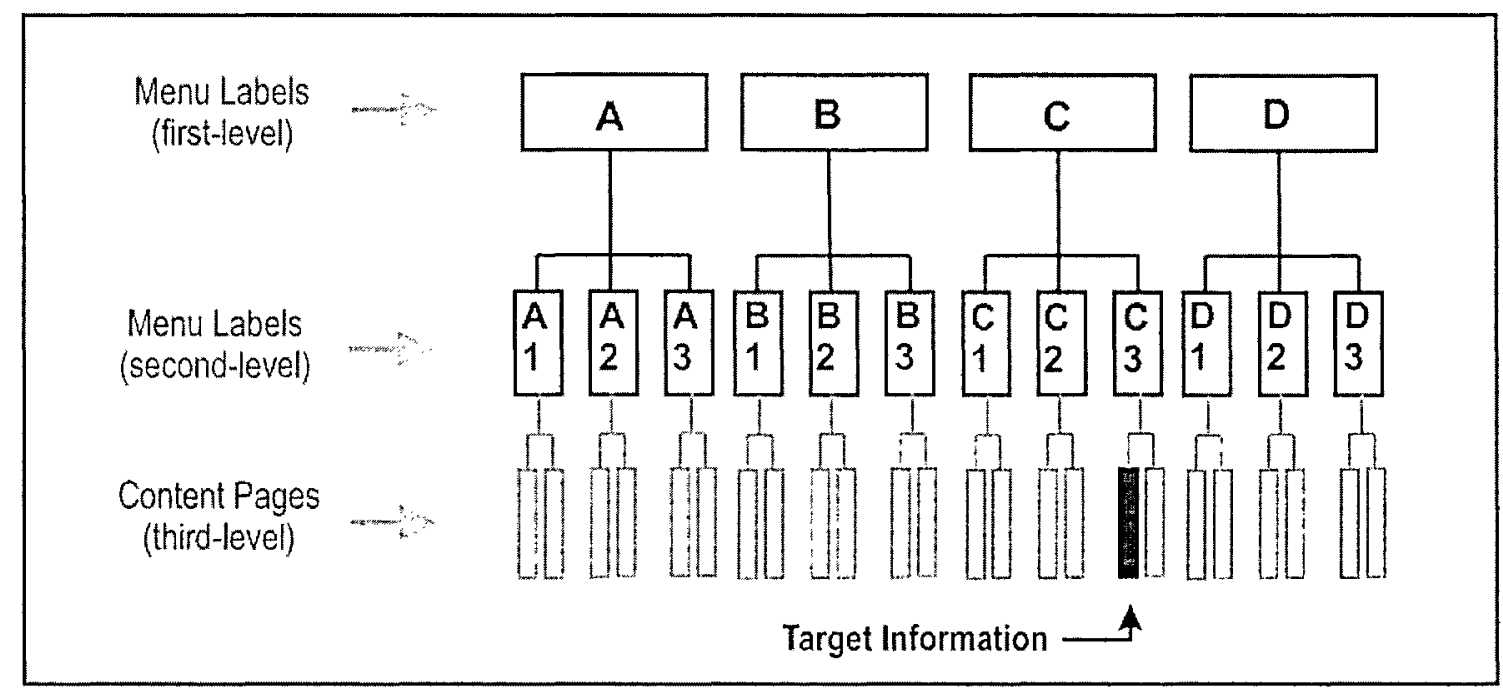

Figure 2. Navigational Path Required to Access Target Information

In contrast, the creators and maintainers of the information architecture (hereafter referred to as the designers) are responsible for organizing, clustering and classifying information within the site. Their decisions about which menu label(s) to link to specific content can be influenced by a number of factors. These include content knowledge and expertise, desired business or political outcomes, a directive from a colleague or supervisor or simply tradition and the constraints of legacy systems. However, their decisions are rarely informed by the information needs and browsing patterns of the site's users. 
Differences in task orientation and the contexts from which users and designers evaluate menu labels, may have an effect on their judgments of relevance. If so, then the menu label choices of information seekers may differ from those of the designers. Differences in the judgments of users and designers may ultimately reduce the usefulness of the information architecture, i.e. the ability to lead seekers to relevant information. It is the awareness of these potential dynamics that has motivated this research and shaped its objectives, which include:

1) exploring the effects that task and context may have on users' judgments of relevance;

2) introducing and evaluating a methodology for mapping the information scent of an information architecture (see next section for a discussion of information scent);

3) introducing an approach to evaluating an information architecture's usefulness;

The Theory of Information Scent - A Theoretical Framework

This research is exploratory in nature. As such, its goals are not intended to support or refute a particular theory but rather to gather data which may help explain why one information architecture might be more useful than another. In addition, another desired outcome is to present a tool that will assist web designers in evaluating the usefulness of their information architecture. The purpose of such a tool is to help inform designers and guide their decisions and heuristics. A theoretical framework is therefore required to situate the constructs, hypotheses and results that have been generated from this research.

The functional focus for this research is the idea that users are lead through an environment (the information architecture) during which probabilistic judgments (the likelihood of finding information) are being made about proximal cues (menu labels). Given this focus, a 
particularly appropriate theoretical framework is offered by the Theory of Information Scent (Pirolli, 2004).

Information scent is a derivative of Information Foraging Theory (Pirolli \& Card, 1995; Pirolli \& Card, 1999), which in turn was developed from a parallel theory within the fields of biology and anthropology known as Optimal Foraging Theory (Charnov, 1976; Stephens \& Krebs, 1986) - a theory of how animals search for food in the wild. Information foraging theory also borrows from the principles of Egon Brunswik's cognitive Lens Model of perception and judgment (Brunswik, 1952), a probabilistic view of how people use available cues to guess the value of something that cannot be immediately perceived.

Optimal foraging theory is based on the assumption that animals optimize their food foraging activities by making choices that maximize their food or energy intake. One challenge that animals face is that their attempts to maximize food intake usually takes place in environments where food is not evenly distributed. Animals are therefore using patchy environments which add to the costs of foraging for food. As Charnov (1976) explains:

"Food is found in clumps or patches. The predator encounters food items within a patch but spends time traveling between patches... ... The predator must make decisions as to which patch types it will visit and when it will leave the patch it is presently in." (p 129) The theory assumes that a predator makes decisions based on maximizing the net rate of food intake during each bout of foraging. In the context of this research, these patches are analogous to menu labels representing categories of information.

The cognitive lens model of perception and judgment introduced by Egon Brunswick (1952) is also an integral component of information foraging theory. In the lens model, a distal object or event (e.g. web content) is represented to the organism (the user) by proximal cues (e.g. 
menu labels). As the distal object cannot be seen, the organism must make an inference about its state. For example, a bird flies over a forest and sees berry bushes distributed throughout a clearing. Those patches of bush are proximal cues representing potential distal objects - the berries. A component of Brunswik's lens model is the probabilistic nature of the environment. On the basis of these proximal cues (the berry patches), a probabilistic judgment is made (a guess) of the expected value of the distal object (the fruitfulness of the berry patch). Information foraging theory (Pirolli et al., 1999) has transferred the metaphor of animals browsing for food and sustenance to humans browsing for information. In integrating the above theories, Pirolli and Card (1999) have provided a framework for examining how people adapt their information seeking behaviour to patchy, probabilistic information environments. Information foraging theory argues that information seekers modify their strategies to maximize the rate of gaining relevant or valuable information while minimizing costs (Katz \& Byrne, 2003) - a cost-benefit approach to foraging. The theory also explores how information environments can be designed or shaped to suit the needs of its users.

Information foraging theory is particularly well suited to the web environment. Web site users seeking information are required to navigate from web site to web site and from menu label to menu label (patch to patch) evaluating proximal cues (menu labels and links) making probabilistic judgments (guesses) about the value of distal content (web pages and documents) in order to optimize their rate of gaining relevant information while minimizing their costs (time and cognitive resources).

Embedded in information foraging theory is the theory of information scent. Scent refers to those cues that are judged as having value or utility as information foragers consider which path or alternative to pursue. The role of information scent is to guide users to the information 
they seek. Scent is a between-patch activity, and as such it assists users in judging the utility of alternative paths, and helps them to detect when they are off course (i.e. moving away from an area of topical relevance) (Pirolli, 2004).

Within this theoretical framework, a web site's information architecture functions as a network of scent trails. Therefore, the usefulness of an information architecture can be thought of as the degree to which it keeps information seekers on a relevant scent trail and minimizes missed opportunities for finding needed information. Figure 3 illustrates how label $\mathrm{A}$ and label $\mathrm{C}$ compete, with label A emitting stronger information scent than $\mathrm{C}$ and thereby leading the user away from the target information. Similarly, labels $\mathrm{C} 1$ and $\mathrm{C} 3$ also compete.

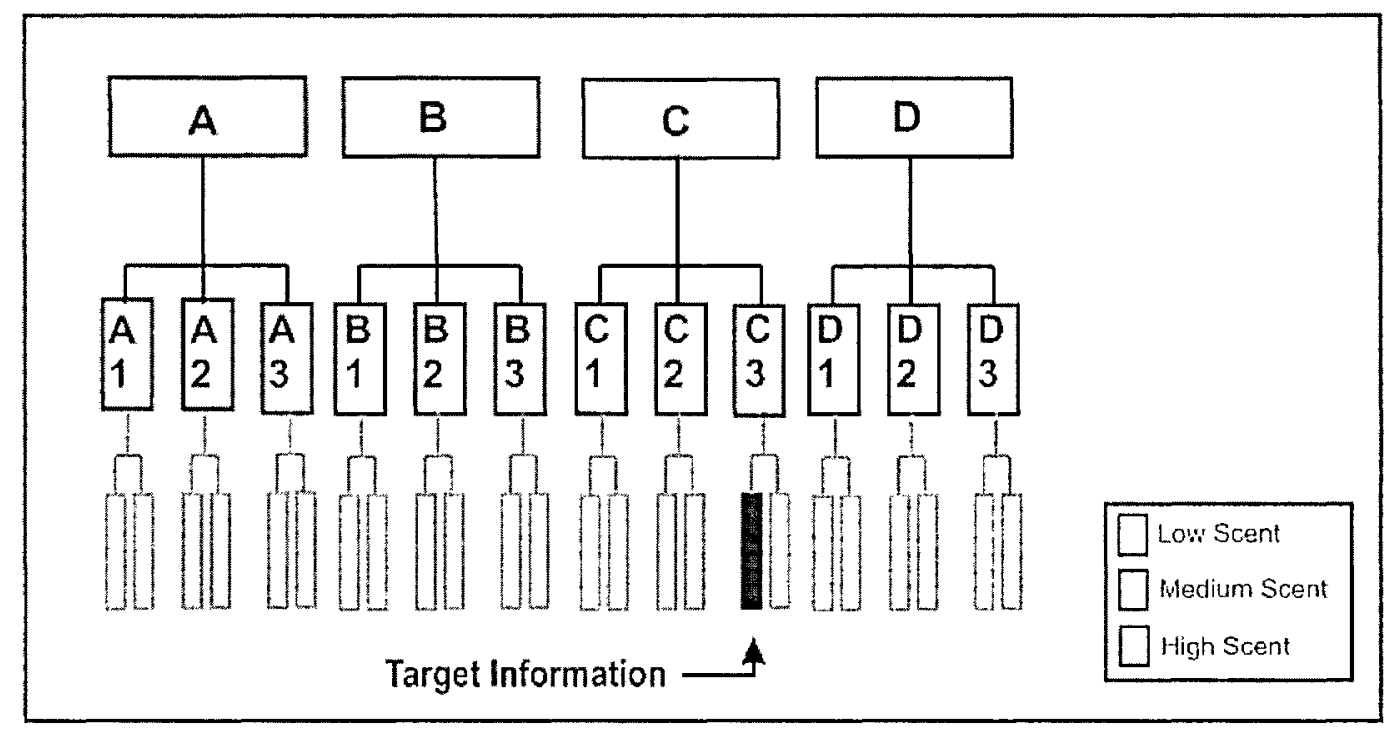

Figure 3. An Information Architecture with Competing Scent Trails

One of the prime foci of this research was to explore the effect(s) that different levels of task orientation and/or the context of menu label evaluation might have on information scent. In particular, whether these variables impact user's judgments of menu label relevance. 


\section{Task Orientation - Classifying and Seeking}

The menu labels of an information-based web site are used in two different ways, a) by searchers who browse or seek web content, and b) by developers who link or classify web content within a menu label category. The fundamental difference between these two uses is the orientation of the tasks - one is to seek, the other is to classify.

Information seekers and classifiers both make judgments about the relevance of menu labels to their given tasks. However, it is the classifiers who decide on which menu label(s) to link to what content. They are deciding which scent trail(s) will need to be followed to access the target information.

For example, assume a fictitious information architecture about food with three menu labels - Fruit, Vegetables and Dairy Products. As the person maintaining this web site you are given a document entitled The History of Tomatoes. Your task is to link The History of Tomatoes to one or more of the menu labels - a classification task.

Notice the classifier can choose one or more menu labels. As a classifier, you would probably link the History of Tomatoes to the Fruit category (provided you were aware that a tomato is a fruit). What about all those users who mistakenly think a tomato is a vegetable? Could the classifier also create a link to the target document from the Vegetables menu labelone that says Why a Tomato Is Not a Vegetable? The answer is yes. A classifier can consider linking multiple menu labels to any target information, thereby creating multiple points of access and multiple scent trails. The challenge for the classifier is to ensure that these multiple scent trails all lead to the same target information.

The methodology used in this research (see Methods section) provides a tool for mapping multiple scent trails and thereby informing the classification decisions of the web developers. In 
addition, the methodology was used to compare the effects of different task orientations on judgments of relevance.

\section{Context of Evaluation - Topical and Situational}

It is my assertion that users of information-based web sites evaluate the relevance of menu labels from one of two contexts - topical or situational. Context refers to the perspective users have of their information need. For example, there may be a need to acquire only topically relevant facts, e.g. "What can I find out about tomatoes?". This creates a topical context against which the menu labels are evaluated. In contrast, menu labels that are evaluated from a situational context must meet a more specific need or set of needs. For example, they may include time constraints, reading level of the content, a need to heighten or lower emotions, a need to receive direction or guidance, or perhaps a need to manage risks and identify decision alternatives. These specific needs influence the user's judgment of menu label relevance, and shift information scent. Therefore, if menu labels are being assessed from different contexts (topical or situational), their relevance may be perceived differently. In turn, these differences may result in a variety of scent trails.

When menu labels are being evaluated from a topical context, a seeker or classifier is trying to answer the question "What is this category of information about?". The user is focused on the topic or subject matter that the menu label represents. For example, earlier a user was given the task of classifying a document entitled The History of Tomatoes. The topic of the document was tomatoes. Within the information architecture was a menu item labeled Fruit. This menu label was judged as having topical relevance to the document in question. Therefore, 
it satisfied the classifiers need to link the document to topically appropriate menu label. The judgment was made from a topical context.

When the context of evaluation is situational, seekers and classifiers are trying to answer a different question, "Will the information contained in this category satisfy some specific needs or set of needs?" Therefore, a menu label that is being evaluated from a situational context must not only satisfy a need for topical relevance, but must also satisfy a set of additional needs. A menu label's ability to satisfy this collective set of needs is what generates its information scent. For example, your 10 year old child has been given a homework assignment (an event), to describe and illustrate (a need) why a tomato is not a vegetable (a topic). You want to help, so you scan a web site that uses the previously described labels. If the menu label Fruit is evaluated from this situational perspective, there is nothing in that label to suggest it can satisfy your child's need — to describe and illustrate (at a grade 5 reading level) why a tomato is not a vegetable. Therefore, an information seeker (you) may now judge this label as being less relevant than when it was evaluated in the earlier topical context. In other words, in this situational context the menu label Fruit has a weaker information scent.

One of the motivations for this research has been my observation that differences in the contextual perspectives of users (seekers and classifiers) may account for variations in the success with which seekers find targeted information. For example, if classifiers judge menu label relevance from a topical perspective and seekers judge relevance from a situational perspective, then each group would be drawn along different information scent trails. Therefore, differences in context may have a direct impact on the usefulness of an information architecture. 


\section{Scenarios}

To reliably evaluate an information architecture's usefulness, menu labels must be evaluated against scenarios that are representative of real or plausible circumstances in the user's environment.

A scenario is a description of a set of circumstances that combine the task elements (seeking or classifying) and the contextual perspective of the menu labels (topical or situational).

The variables of task (classifying or seeking) and context (topical and situational) will be manipulated in a $2 \times 2$ factorial design. Therefore, there are four different types of scenarios which must be considered: a) a seeker of information evaluating a menu label topically, b) a seeker of information evaluating a menu label situationally, c) a classifier of information evaluating a menu label topically, and d) a classifier of information evaluating a menu label situationally.

A challenge which will be discussed in the Method section, deals with making scenarios real and representative of a given web site's domain. This involves researching the most common types of information needs that occur amongst the users of the information architecture being evaluated.

\section{Regions of Relevance}

The definition and measurement of relevance is a complex topic that has been debated in the information science literature since the early 1950's (Eisenberg, 1986).

In the field of information science, relevance was initially viewed as a binary construct, that is, a document is either relevant or it is not relevant. This initial view gave way to an alternative construct — regions of relevance (Greisdorf, 2000). This alternative view suggested 
that there are degrees of relevance and that differences in degree can be measured. Typically, relevance was divided into three regions: 1) relevant, 2) partially-relevant, and 3) not relevant.

Another goal of this research was to determine if users who scan menu labels judge relevance along a continuum or as a binary construct. Specifically, do users judge some menu labels as being within a relevant region, others as partially relevant and still others as not relevant, or are their relevance judgments simply binary (relevant, not-relevant).

How to measure relevance or a region of relevance becomes an important question.

\section{Using Magnitude Estimation to Measure Relevance}

Methodologies for measuring relevance have varied throughout the information science literature. Some of the more central themes outlined by Griesdorf (2000) include category rating scales (Howard, 1994; Gluck, 1996), measures of semantic distance (Brooks, 1997) and magnitude estimation (Eisenberg, 1988). Eisenberg (1988) found magnitude estimation to be more robust than category rating scales and not influenced by contextual effects. For this reason magnitude estimation was chosen as the method for measuring relevance judgments during this research.

Magnitude estimation has its roots in the area of psychophysics - an area interested in measuring human perception of physical-sensory stimuli (e.g., loudness, brightness, taste, roughness). Eisenberg (1988) described magnitude estimation as “... requiring a subject to directly estimate, in numbers, the intensity of a given stimulus... The task is to assign a number... so that the number given matches the subject's impression of the strength of the stimulus." 
In this experiment, participants made estimates from 0-100 (a response), about the degree of relevance (their impression of the strength), of a particular menu label (a stimulus) and its relationship to a scenario (a description of a task and context).

Therefore, as the perceived relevance of a menu label increases (an increase in scent), there is a corresponding increase in the relevance estimate given to that menu label. This corresponds directly to what psychophysicists' refer to as the Power Law - an increase in a stimulus by a given proportion results in a corresponding proportional increase in response (Bruce, 1998).

While magnitude estimation was initially used for measuring physical-sensory stimuli, there have been successful attempts to adapt magnitude estimation methodologies to the measurement of social-psychological stimuli. Eisenberg $(1986 ; 1988)$ found that participants used magnitude estimation to judge the relevance of retrieved documents relative to their information queries in the same way that they judged physical stimuli such as line length. More recently, Bruce (1998) successfully used magnitude estimation to measure the perceived satisfaction of users searching the Internet for information.

Information scientists (Bruce, 1994; Eisenberg, 1986; Janes, 1991) have also successfully adapted techniques for establishing the validity and reliability of the magnitude estimation process (as cited in Bruce, 1998). Eisenberg (1986) used cross modality matching to establish validity. For example, participants would be asked to evaluate the length of several lines by providing a number for each (the higher the number the longer the line). The exercise would then be repeated with the same subjects only this time they would be asked to squeeze a hand dynamometer with a force equivalent to the line length (the more force the longer the line ). In this way the relationship between modalities could be compared and calibrated, and the validity 
of the estimation process could be established. Reliability or the stability of magnitude data was established by providing evidence that magnitude data is quantitative rather than a qualitative (Stevens, 1975; Eisenberg, 1988; Bruce, 1998). The premise for this assertion is that if participants can judge, quantify and articulate how much of a variable they are perceiving, then the variable is stable and reliable (Bruce, 1998).

\section{Research Questions and Hypotheses}

The general concept that motivated this research was that differences in a user's task and contextual perspective lead to different constraints on perceived information scent. - the perceived degree of relevance each menu label carries.

As this thesis is exploratory in nature, there were many research questions and hypotheses discussed in its planning, however four empirical questions were investigated:

Do differences in a user's task orientation and context of evaluation affect...

1) ... judgments of which menu labels are considered relevant?

2) ... judgments of which menu labels are considered partially relevant?

3) ... agreement about which menu labels are considered most relevant?

4) ... the probability of choosing the target content's menu label?

These questions assumed that there would be differences between scenarios, but that scenarios would not interact with context and task. Of primary interest were interactions between task and context. These general research questions lead to the following hypotheses:

1) Number of Menu Labels Judged Relevant. This hypothesis predicted that evaluating menu labels from a topical context would lead to a higher number of menu labels judged relevant 
(top line in figure 4) in contrast to menu labels that were evaluated from a situational perspective (bottom line in figure 4), but that this increase is dependent on the user's task orientation. In general, the classifying task would result in more labels considered relevant than the seeking task (left points higher than right points in Figure 4).

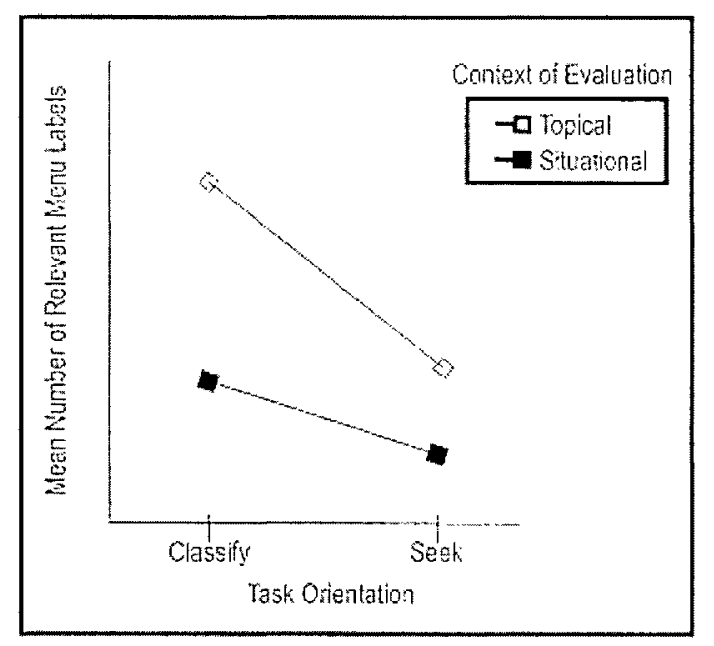

Figure 4. Hypothesis 1 - Mean Number of Relevant Menu Labels

The rationale for this prediction was that when viewing menu labels from a situational context, information scent would only be emitted by those labels specific to the needs of the situation - resulting in fewer scented labels. For example, a user looking for information related to the general topic of breast cancer would likely identify more scented labels than a user looking to satisfy information needs specific to the situation of "...my wife has been diagnosed with breast cancer and is scheduled for exploratory surgery, I need to reduce her anxiety...". Classifiers were considered to generate a greater number of scented menu labels because their task is to satisfy the needs of multiple users, and therefore likely that they would speculate on multiple menu labels emitting information scent for a given scenario. Support for this rationale came from comments during the pilot study. 
2) Number of Menu Labels Judged Partially Relevant. In contrast to the first hypothesis, this hypothesis predicted that menu labels evaluated topically would lead to a higher number of labels judged partially-relevant (top line in figure 5) when compared to labels judged from a situational perspective (bottom line in figure 5), and that this effect would also depend on the task orientation of the user. If users are seeking information, the number of menu labels judged partially-relevant will be higher than if they are classifying information (right points higher than left in Figure 5).

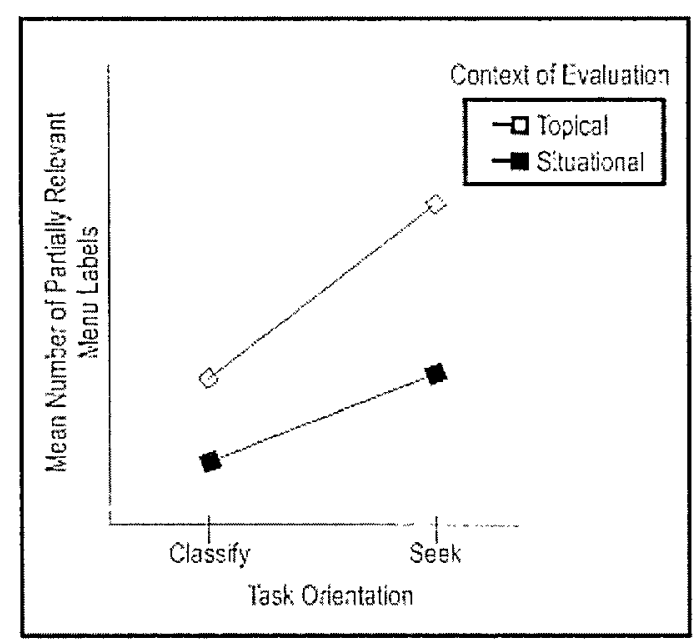

Figure 5. Hypothesis 2 - Mean Number of Partially-Relevant Menu Labels

The rationale for this prediction was that task orientation would create an inverse relationship between the number of strongly scented (relevant) and moderately scented (partially relevant) menu labels. Specifically, the more frequently a user identified strongly scented menu labels, the less likely moderately scented labels would be identified. However, it was predicted that this inverse relationship would not extend to context. Rather it was assumed that menu labels viewed from a situational context would continue to be easier to reject then those viewed 
from a topical context. If this rationale was supported, then there would be fewer partially relevant menu labels in the situational context.

3) User Agreement About Most Relevant Menu Labels. The previous hypotheses referred to the number of labels judged relevant. This hypothesis refers to the number of people who judge the same menu label as being the most relevant - the proportion of agreement.

This hypothesis predicted that evaluating menu labels from a situational context would lead to higher proportion of agreement among users (top line of figure 6) than if the menu labels were evaluated from a topical context (bottom line of figure 6), but that this relationship would depend on the users' task orientation. In general, the seeking task will result in a higher proportion of people agreeing to which menu label is the most relevant than the classifying task (right points higher than left in Figure 6).

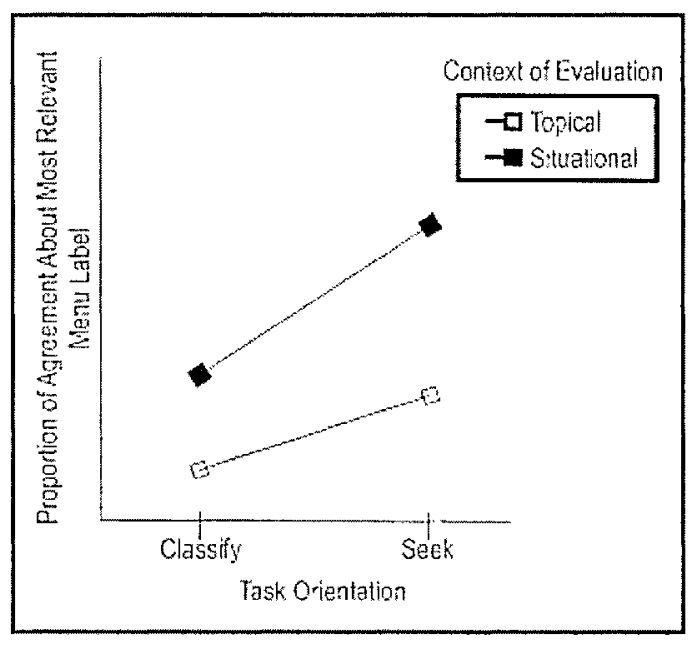

Figure 6. Hypothesis 3 - Proportion of User Agreement About Most Relevant Menu Labels

The rationale for this prediction was that if seekers of situational information do in fact identify fewer scented menu labels, there would be a higher level of agreement among users. 
4) Probability of Choosing the Target Menu Label. This hypothesis refers to the probability of the user choosing the target menu label, given all other relevant and partially relevant labels. For example, if menu label 7 leads to the target information but a user only considers menu labels 3,4 and 5 as being relevant, the probability of a user accessing the target information is zero. In addition, if the user identifies the target label as one of multiple labels being relevant (e.g. labels, 3,4,5 and 7), the probability of accessing the target content is not 1 but a value less than 1 due to the competition provided by the other relevant labels.

This hypothesis predicts that menu labels evaluated from a topical perspective would lead to a higher probability of selecting the target menu label (top line of figure 7) than if the menu labels were evaluated from a situational perspective (bottom line of figure 7 ). It also predicts that task orientation primarily affects judgments made from a topical context (left topical line points higher than right in Figure 7 whereas situation remains level).

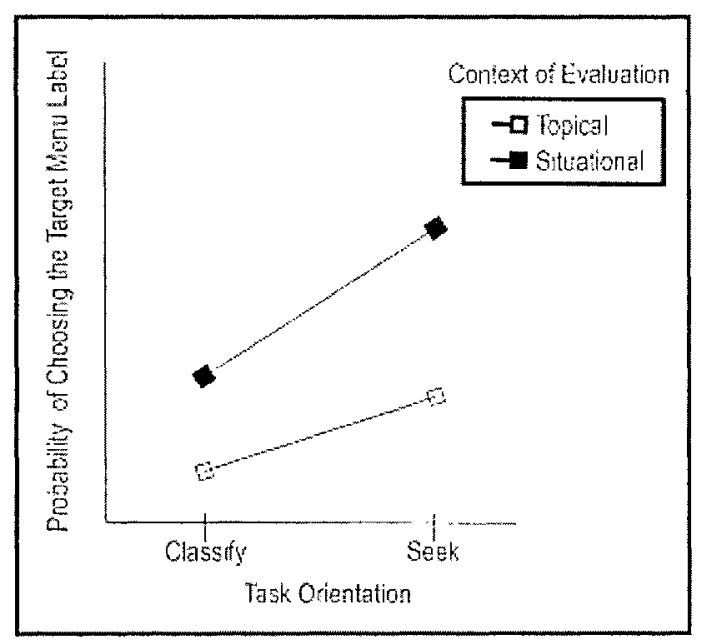

Figure 7. Hypothesis 4 - Probability of Users Selecting the Target Menu Label 


\section{Method}

Design

In this experiment, participants simulated the tasks of classifying and seeking information by judging the relevance of menu labels to a scenario. The topics of these menu labels were related to human health issues and drawn from a large existing web site. Health-related menu labels were presented in a two-level hierarchy or menu structure (see Appendix A). The organization of the menu labels, along with their various label choices, established the information architecture for the experimental web site. Participants were asked to estimate (on a scale of 0-100) the degree of relevance each menu label had towards a particular scenario.

Independent Variables. The design for this experiment was a mixed factorial design. There were three independent variables, two between-groups variables - Task and Context, and a single within-subjects variable - Scenario.

Scenarios concerned with human health were used to establish the task and context from which participants viewed menu labels. Scenarios described health issues from either a topical or situational perspective and assigned either a seeking or classification task (see Table 1). Scenarios were presented in a text format. Each participant was presented with 2 practice and 10 experimental scenarios. Therefore, as an independent variable, Scenario had 10 levels. As Scenario was a repeated-measures variable with possible order effects, the order of presenting scenarios was counterbalanced using a Balanced Latin Square (Appendix B).

Task, a between subjects independent variable, refers to the type of assignment each participant was given during the presentation of a scenario. There were two types of task assignments - Classifying and Seeking. Classification tasks required participants to make judgments about where to put or link information described in the scenario. In contrast, seeking 
tasks required participants to make judgments about where they expect to find scenario information within the same information architecture.

Context, the second between subjects independent variable, refers to the perspective from which each scenario was written. There were two levels of Context - Topical and Situational. A topical context referred to scenarios which only provided information about a topic or subject. Topical scenarios did not provide a description of an information need or goal, or a description of the event which created the information need. In contrast, situational contexts referred to scenarios containing all three descriptive components (i.e., the topic, the information need and the event that created the need).

Given these variables and the experimental design, each scenario required four different descriptive representations, one for each between subjects experimental condition (see Table 1). The four representations each had two sub-components, a context statement (representing either a topical or situational perspective) and a task statement (representing either a classification task or a seeking task). 
Table 1

Sample Scenario with Different Representations for each Experimental Condition

\section{Context of Evaluation}

Task

Topical

Situational

Orientation

(topic only)

(includes an event, topic, and need)

Context: "Potential radiation

effects of cellular phone usage."

Seeking

Classifying

Task: "Identify the menu labels where you would put or link information related to this topic."

Task: "Identify the menu labels where you would look for information related to this topic."

Context: "Potential Radiation

effects of cellular phone usage."
Context: " $A$ recently aired media broadcast has described potential radiation effects of cellular phone usage. You now feel you need more information about how to protect yourself from harmful effects." Task: "Identify the menu labels where you would look for information related to this situation." Context: "A recently aired media broadcast has described potential radiation effects of cellular phone usage. The public now feels they need more information about how to protect themselves from harmful effects." Task: "Identify the menu labels where you would put or link information related to this situation."

Dependent Variables. Borland (2003) describes relevance as a user's perception of the usefulness between an information object, such as a menu label, and a task oriented situation. In this experiment, relevance referred to a participant's subjective judgments about the value or 
usefulness of a menu label given a scenario's task and context. For example, if the participant's task is to classify information about the "potential radiation effects of cellular phone usage." (see Table 1), then the participant's relevance judgments are estimates of how well that topic fits each menu label.

The effects of independent variables were examined on a number of dependent measures. These include 1) the number of menu labels judged relevant, 2) the number of menu labels judged partially-relevant, 3) user agreement about strong relevant menu labels and 4) the probability of participants selecting the target menu label. These measures are more fully discussed in the Analysis section of Results and Discussion.

Participant Assignment. Participants were randomly assigned to one of the four experimental conditions outlined in Table 1. These include seeking topical information, seeking situational information, classifying topical information and classifying situational information. All participants were required to perform their tasks (classifying or seeking) using the same information architecture (Appendix A).

Experimental Control. The implementation and manipulation of this experiment was controlled through an interactive web site via the Internet (rather than by the experimenter). Data gathering was also system controlled. There was no direct contact between the researcher and the participants during the experiment, and subject data is only identified by subject numbers assigned at the beginning of the experiment (see Participants- in the next section). Therefore, the researcher was effectively blind to experimental manipulations and subjects' identities. 


\section{Participants}

$N$ and Power Analysis. It was determined prior to beginning recruitment that a minimum of 120 participants would be required for this experiment - 30 participants for each of the four experimental conditions. The number of participants $(\mathrm{N})$ was determined following a power analysis in which the significance criterion, alpha $(\alpha)$, was set to .05 , the population effect size (ES) was expected to be large (Cohen, 1992), the desired statistical power was set at .80 .

Sampling Strategy \& Recruitment Procedures. The sampling strategies employed for this research were aimed at identifying participants who represent a population of Internet users.

The prime strategy for recruiting was the use of a chain-letter e-mail. This involved sending an individually addressed e-mail (Appendix D) to 72 prospective participants assumed to use the Internet. These prospective participants were professional, personal, business and academic contacts known to the researcher. Each prospective participant was not only invited to complete the online experiment, but was also requested to pass the invitation along to others who use the Internet. In other words, participants could then become recruiters.

On occasion, the principal researcher approached potential participants directly (i.e., faceto-face or via the telephone ). On these occasions, the same recruiting script used in the chainletter e-mails was followed.

Initially there was a plan to offer participants a $\$ 10$ honorarium for their participation. However, the introduction of payment introduced several potential problems. Examples include a single individual accessing the experiment several times for the sole purpose of receiving $\$ 10$ for each session. This type of abuse would have contaminated the data and rendered it useless. In addition, the degree of additional administrative and programming overhead to control access, 
payment and anonymity made payment a significant problem. It was decided to recruit the first 40 participants without any payment. If successful recruiting would continue without payment or any form of remuneration. The number 40 was selected as it represented the first complete replicate of the Balanced Latin Square that was being used for counterbalancing. The 'chainletter' recruiting strategy (without payment) was indeed successful, and as a result, lead to the decision to recruit the remaining participants without payment. Therefore, throughout this experiment, no participant received any form of remuneration or inducement for their participation.

\section{Setting, Materials and Apparatus}

Location. Experiments were conducted remotely over the Internet using an experimental web site designed for this research. The precise physical location from which each participant completed the experiment is unknown. However, the requirement for participants to input their Canadian postal code at the end of the experiment allowed us to identify the participant's geographical region (city and province). When the experiment began, some requests to participate came from countries outside Canada. These included countries such as the United States, Germany, Britain and the Philippines. As the web site was only designed to accommodate Canadian postal codes, a unique postal code was used to identify international participants.

While the majority of participants represented Canada's National Capital Region, there was representation internationally as well as from other Canadian provinces. 
Technical Requirements and Controls. The web site was designed and developed specifically for this experiment. The technologies used for its development included hypertext markup language (HTML), JavaScript, active server pages (.asp) and images optimized in a Graphic Interchange Format (.gif).

Each participant required a computer with Internet Explorer 5.0+, JavaScript 1.2 enabled and access to the World Wide Web (WWW). At the time this experiment was launched, the choice of Internet Explorer 5.0+ represented 80.7\% of web users (W3Schools, 2004).

Once a prototype of the experimental web site was completed, a pilot test of the experiment was run. The pilot was conducted with five participants who were not part of the final sample of participants. Observations of how they interacted with the site and responded to its prompts and interface was evaluated. The result of this testing was to build additional practice screens and clarify some of the instructions.

Web Site Structure and Functionality. The web site developed for this experiment revolved around the use of its information architecture - the hierarchically organized system of menu labels representing categories of content. For this research, it will be referred to as the experimental information architecture.

To provide external validity to the experimental information architecture and to provide participants with tasks based on 'real-world' scenarios, the information space from which scenarios were created was human health. There were two factors influencing this choice. At the time this experiment was initially conceived, the third highest type of Internet use was seeking medical and health information. E-mailing was first, followed by general browsing (Statistics Canada, 2002). The second factor influencing this decision was my involvement with a public 
health organization which had recently spent 12 months developing an information architecture for a large web site (approximately 45,000 documents). The information architecture that resulted from this year-long process will be referred to as the original information architecture.

The development of the original information architecture was committee based. The committee involved content experts, stakeholders and external consultants who provided expertise in information and library science, and web development. One influence, notable by its absence during the development process, was the lack of consultation or testing with potential users of the web site. Therefore, this original information architecture is likely to have had an author-expert-owner bias towards its structure and menu labels.

In developing the experimental information architecture for this research, the original information architecture was edited and adapted. Labels that were descriptive of the organization or its owners (e.g., Branches, Regions and Agencies, or About Us) were eliminated. In addition, menu labels that required a parent label to provide context were eliminated. For example, the menu label Tracking and Prevention, on its own raises the question "The tracking and prevention of what?'. In this case, context was only provided by its parent label — Diseases and Conditions. All other menu labels remained identical to those created through the original committee process.

In addition to eliminating ambiguous or identifying menu labels, the structure of the original information architecture was also adjusted for this experiment. The original hierarchy contained three levels of menu labels (occasionally a fourth level existed). By its design, realworld users would find health information after clicking a third-level menu label. In this experiment, the scenarios were drawn from information contained in the third-level categories. For example, the scenario described in Table 1, (potential radiation effects of cellular phone 
usage) was drawn from the information contained in the third-level menu label titled Consumer Radiation. Its parent label (second-level) was Radiation, which in turn had a parent label of Environmental and Workplace Health. Only first and second-level categories were required for navigating to the third-level labels, thereby permitting the elimination of all third-level menu labels from the original information architecture.

The final design of the experimental information architecture consists of 10 first-level menu labels and 71 second-level labels (Appendix A). The second-level menu labels were not equally distributed among the first-level labels.

Functionality within the experimental information architecture was limited. Participants were permitted to navigate (click) through the hierarchy, to move a slider bar beside each second-level category label (to make relevance estimations), to click radio buttons and check boxes (to respond to questions) and to click a control button (Next Scenario, Previous Scenario or Quit).

Data collection was automatic and in a format allowing for easy importation into both Microsoft Excel 2003 and SPSS 10.

Validating Experimental Scenarios. This experiment required the writing of topical and situational descriptions for 12 different health-related scenarios. There were 218 third-level menu labels in the original information architecture from which the topics for these scenarios could have been drawn. The topic selection process for the original information architecture was without representation from its user community. Therefore, the comprehension or clarity of these third-level menu labels and their implied topics has never been validated amongst potential users. In this experiment, if the scenario topics are not clearly understood by participants, their 
understanding of a scenario's context and task could not be accurately evaluated. This could have invalidated the experiments results. Furthermore, if the choice of topics was not representative of real-world information needs, then the generalizability of the results could also have been threatened. As good scenario descriptions were essential for this experiment, it was necessary to validate the comprehension, clarity and choices of scenario topics.

A Topic Validation Survey (Appendix E) was created to meet two needs. The first, was to identify and eliminate menu labels that were either ambiguous or that lacked clarity. The second objective was to narrow topic choices to those which best reflect past and future health information needs.

The survey asked respondents to indicate topics where past information needs had existed, as well as topics where future information needs were likely to exist. Once topics had been identified which were considered clear and understandable, a final subset of topics was drawn from those showing the highest frequency of past or future needs. Any topic which was identified as unclear by a single survey respondent was eliminated as a potential choice for the final experiment.

Of the original 218 potential third-level menu labels, $69(31.7 \%)$ were identified as being unclear and were eliminated from consideration (Appendix E). Of the remaining menu labels, 68 $(31.2 \%)$ had high frequencies of respondents showing either past information needs or likely future needs for information relating to those topics. These topics were then grouped into related categories and then compared to the available web content. The final 12 scenarios were then drafted based on the available web content, and selection goals were then based on providing a varied selection of topics whose information was contained in a variety of locations within the experimental information architecture. 
Semantic Similarity. The semantic similarity of scenario descriptions was another consideration. Table 1 illustrates how each scenario's description required four slightly different versions - one for each experimental condition. As the experiment was designed to focus on differences in task description or contextual perspective, neglecting to measure semantic differences between the four corresponding statements could have resulted in overlooking effects due to semantic dissimilarity. Therefore, as part of the process of validating the final scenarios, semantic differences were measured and minimized.

One technique that was previously used to assess the semantic similarity between task descriptions and screen labels (Soto, 1998) was Latent Semantic Analysis (Deerwester, Dumais, Furnas, Landauer, \& Harshman, 1990; Landauer, Foltz, \& Laham, 1998). In this experiment, Latent Semantic Analysis (LSA) was used to establish (a priori) the semantic similarity between the four corresponding descriptions for each scenario. The software application that was used for indexing semantic similarity is available through the LSA web site which is affiliated with the University of Colorado at Boulder (http://sa.colorado.edu/)

LSA is described as both a theory and a method. It is a computational theory of knowledge acquisition and representation (Landauer \& Dumais, 1997). It is also described as a practical method for estimating the semantic similarity of words, sentences and documents in a multidimensional semantic space (Landauer et al., 1998; Soto, 1998). Estimates of semantic similarity are context-sensitive. They are calculated based on a term's pattern of occurrences across a large number of sentences, paragraphs and documents. For example, in a semantic space representing Human-Computer Interaction, the words human and user may never actually co-occur in the same documents. However, because they do occur in similar contexts having similar meaning, their semantic similarity is represented as being much higher. This would be an 
example of word-word association (Landauer et al., 1998). The fact that this experiment used scenarios to describe different contexts with similar meaning makes LSA an appropriate choice for measuring semantic similarity.

A semantic space is a mathematical representation of a large body of text. Some examples of semantic spaces used on the LSA web site include the literature space (English and American literature from the $18^{\text {th }}$ and $19^{\text {th }}$ centuries), the encyclopedia space (text from 30,473 articles) and the psychology space (text from university-level psychology text books). Within a semantic space, every word and word combination such as sentences, paragraphs and articles, are represented as a vector. When comparing terms (e.g., word-to-word, word-to-sentence, sentence-to-document), LSA is computing the cosine of the angle between the vectors that represent the terms - the smaller the angle the more similar the terms. Similar to values for correlations, cosine values range from 1 to -1 , where 1 represents a perfect semantic match (the same term), 0 represents no relationship between terms, and -1 represents terms of opposite meaning — which do not occur in natural languages (Soto, 1998; Landauer, 2002).

The LSA semantic space that was used for this experiment is TASAall. It is based on a variety of texts, novels and newspaper articles that represent the kind of reading material students are exposed to during their school years. The original body of material was compiled by Touchstone Applied Science Associates Inc. (TASA) when developing The Educator's Word Frequency Guide (Zeno, Ivenz, Millard, \& Duwuri, 1995). TASA provides the educational market with literacy and reading assessment tools. One of its products, the Degrees of Reading Power (DRP) scale, assigns a level of reading difficulty to samples of text. The text samples used in creating the TASAall semantic space were assessed as having reading levels ranging from grade three to college (university). There are a total of 37,651 text samples that make up 
the TASAall space and they cover a variety of academic areas including samples relating to health. The inclusion of health related topics, the overall reading level and methods used to develop the TASAall semantic space made it a suitable benchmark against which to validate this experiment's scenarios.

By completing a latent semantic analysis on each of this experiment's scenarios, The semantic similarity between each scenario's four contextual descriptions was established using latent semantic analysis. As an example, the similarity estimates (cosines) for the corresponding statements described in Table 1 are summarized in Table 2.

Table 2

Actual LSA Cosine Matrix Validating Context Descriptions in Table 1

\begin{tabular}{lcccc}
\hline & $\begin{array}{c}\text { Topical } \\
(\text { Seek })\end{array}$ & $\begin{array}{c}\text { Situational } \\
(\text { Seek })\end{array}$ & $\begin{array}{c}\text { Topical } \\
\text { (Classify) }\end{array}$ & $\begin{array}{c}\text { Situational } \\
\text { (Classify) }\end{array}$ \\
\hline Topical (Seek) & 1.00 & .62 & 1.00 & .66 \\
\hline Situational (Seek) & .62 & 1.00 & .62 & .94 \\
\hline Topical (Classify) & 1.00 & .62 & 1.00 & .66 \\
\hline Situational (Classify) & .66 & .94 & .66 & 1.00 \\
\hline
\end{tabular}

Perhaps the first question that must be addressed before evaluating the above date is "When can a cosine be considered high?" There are currently no LSA studies that have looked at this question (Quesada, 2003). However, some of the existing work can provide relative guidance. In a recent discussion of LSA, Landauer (2002) commented that in a typical LSA semantic space, $99.9 \%$ of the word-word associations had cosines below .40. Similarly, Soto 
(1998) completed a study where menu labels were created by using LSA to first identify the best word associations to a set of tasks, and then create two-word menu labels. The best associations between the two-word labels and the task descriptions had a mean cosine of .67 and a standard deviation of .17. Therefore, for this experiment, using Landauer's (2002) comments as a benchmark, a cosine of . 40 was used as the minimum acceptable estimate of semantic similarity.

Overall the estimates in Table 2 indicate a high semantic similarity between all conditions. When comparing statements within context and across task, the magnitudes of the estimates are extremely high and similar. For example, comparing the topical statement for seeking to the topical statement for classifying, the cosine is $1.00-$ a perfect semantic match. In fact, these statements are semantically identical. Also, when comparing the situational statements for seeking to the situational statements for classifying, the cosine of .94 is also extremely high. Comparing statements within task and across context, the magnitude of the estimates are less high, but still strong and similar. For example, comparing the topical statement for seeking to the situational statement for seeking, the cosine is . 62 - a strong estimate. Similarly, comparing the topical statement for classifying to the situational statement for classifying, the cosine is .66 - also a strong estimate. Therefore, the high semantic similarity between conditions can be viewed as validation of this scenario.

Prior to running the experiment, the corresponding statements within each of the 10 real scenarios and the 2 practice scenarios were compared. As there are four corresponding statements in each scenario there are 6 possible comparisons for each scenario. These include comparing seeking/topical to classifying/topical, seeking topical to seeking/situational, seeking/topical to classify/situational, classifying/topical to classifying/situational, classifying/topical to seeking/situational, and finally seeking/situational to classifying/situational. 
Any scenario having a comparison with an LSA cosine of less than .40 (i.e. semantically dissimilar) was rewritten, and then re-evaluated.

After comparing corresponding statements in all scenarios, all but two of the real scenarios showed LSA cosines of $>.40$ across all comparisons. The exceptions were scenarios 2 and 6 . In both these scenarios, the comparisons between like contexts (e.g. classifying/topic and seeking/topic) were above the .40 threshold, however comparisons between different contexts (e.g. classifying/topic and classifying/situation) were less than .40. A decision was made to keep these scenarios as drafted, however these semantic differences were considered during data analysis.

Regions of Relevance and Thresholds. When asking participants to rate relevance on a scale, there is an implied assumption that the same value of relevance represents the same judgment between two participants. While all participants used the same scale $(0-100)$, one participant's relevance estimate of 75 on that scale is not necessarily equivalent to another participant's estimate of 75 . For example, one participant may consider a rating of 75 as being relevant, whereas another participant may consider a rating of 75 as only partially relevant. To account for these differences in relevance thresholds (the beginning and end of each relevance region) some form of semantic standardization or transformation must be computed.

The assertion that participants have different thresholds to regions of relevance was supported by some early work by Eisenberg (1986). In an experiment where participants were required to make binary judgments (relevant, not-relevant), he asked participants where their break points were between the two constructs. The variability in their responses lead him to identify what he described as differences between a liberal approach to relevance estimates (e.g., 
"If it's a little relevant, then call it relevant") and a conservative approach (e.g., "It's got to be really relevant before I'll call it relevant'). Eisenberg's work did not consider thresholds for the partially-relevant region.

As part of the preparation for this experiment, the question of relevance thresholds was tested in an informal survey. Participants were asked to consider three regions of relevance (i.e., relevant, partially relevant, and not-relevant) and then indicate where within a scale of 0-100 they would place the threshold for each region of relevance (i.e., the not relevant /partially relevant threshold and the partially relevant/relevant threshold). In a small sample of 10 participants there was a fairly high degree of variability among their answers. Due to this variability in the test survey, the question of relevance thresholds was formalized in the experiment following the presentation of all scenarios (Appendix I).

\section{Procedure}

Initial Contact and Informed Consent. Initial participant contact was either from an original recruiting e-mail (Appendix D) or one that had been forwarded by a previous recipient.

A total of 72 recruiting e-mails were sent to professional, personal, business and academic contacts known to the researcher. Each prospective participant was not only invited to complete the online experiment, but was also encouraged to forward the invitation along to others who use the Internet. In other words, participants then became recruiters.

The home page of the experimental web site (Appendix F) contained both a description of the experiment, and a statement indicating that continuing implied informed consent.

The home page for the experiment also displayed contact information and the wordmark and logos for Carleton University and the Human-Oriented Technologies Lab. These graphic 
identity pieces were used to build trust and provide legitimacy to the experiment. It was assumed that trust might have been an important factor in encouraging participation as there was no human interaction throughout the experiment, there were no incentives to participate and nothing to lose by withdrawing.

Participant Orientation \& Practice Once participants began the experiment, they were presented with the first of three Orientation pages (Appendix G).

Step 1 introduced participants to the slider bar and the different options for interacting with the bar. Participants could click and drag the slider to a precise point on the bar, or simply click the bar and have the slider jump to that point. As the slider was moved, a number between zero and 100 appeared above the bar.

Step 2 provided participants with an opportunity to navigate the menu system, explore the labels and associate slider bars to second-level menu labels. It also enabled participants to orient themselves to the layout of the interface (i.e. menu labels on the left and instructions at the top).

Step 3 described participants' role and task during the experiment. Seekers were described as web surfers, and classifiers were described as web developers. Both were asked to identify and rate the relevance of menu labels to subsequent scenarios.

Experimental Session. Following the orientation screens, participants were presented with the first of 12 scenarios. Participants were not informed that the first two scenarios were for practice and calibration and would not be used in the final data analysis.

On each trial participants were presented with a scenario context and task in the upper portion of the browser window and the same first-level menu labels to the left of the screen 
(Appendix H). Participants were completely free to explore the menu label system in the order of their choosing. When a participant clicked a first-level menu label, a series of second-level menu labels appeared, to the right of which were slider bars used to rate these second-level menu labels. Figure 8 shows the Health of Canadians second-level menu label with a rating of 63.

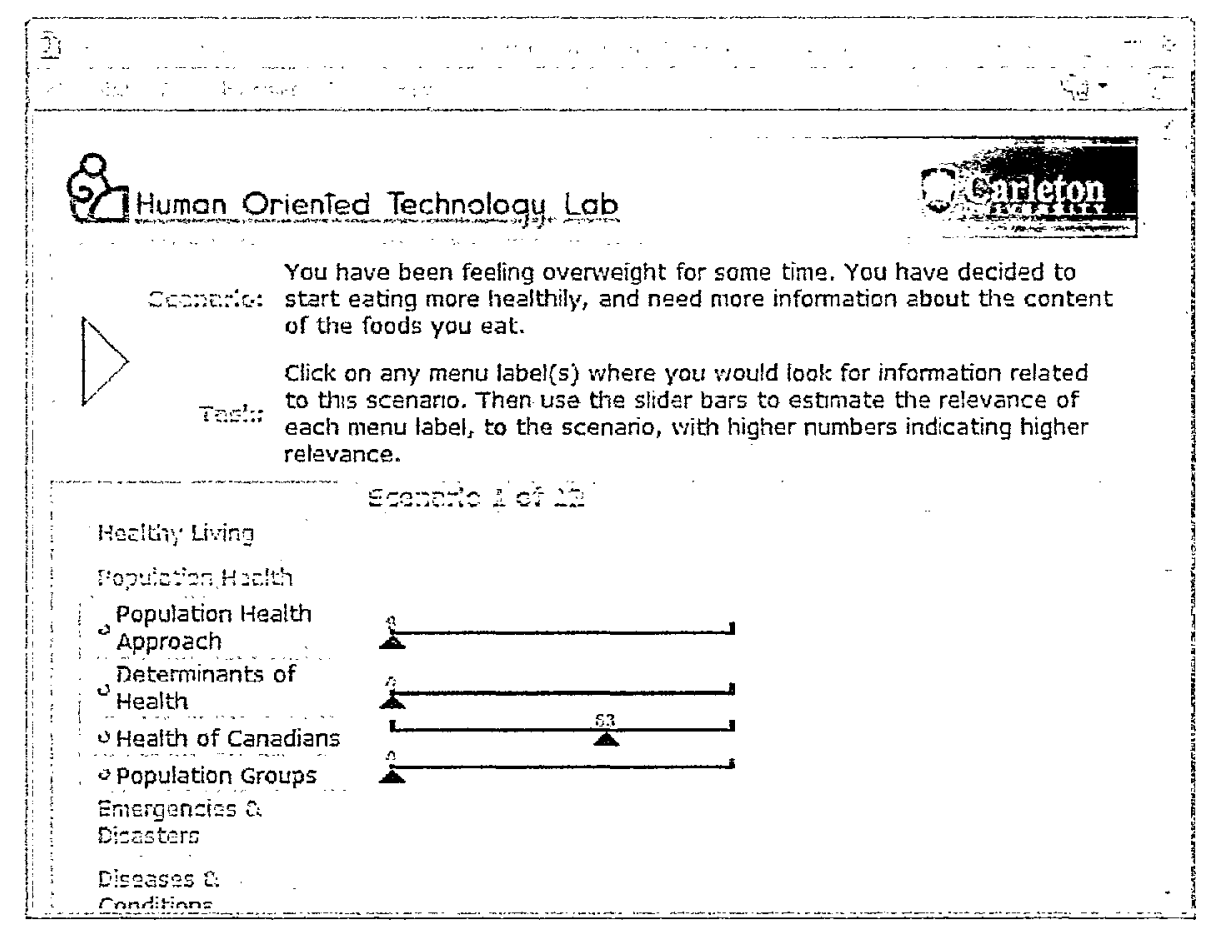

Figure 8. Screen Capture of Slider Bars for Second-level Menu Labels

There were no constraints as to time or the number of menu labels that a participant rate as having some degree of relevance to the scenario. Once a participant finished exploring the available menu labels, and rating relevant labels, they advanced to the next scenario. This cycle was repeated until the end of the twelfth scenario. The design of the interface allowed participants to revisit a previously rated scenario to examine or adjust a previous rating.

Closing Questions \& Debriefing Screen. The first set of closing questions (Appendix I) is aimed at understanding a participant's concept of relevance (i.e. binary versus regions of relevance) and the individual thresholds between each region of relevance. 
The first question asked if the participant considered any menu label partially-relevant. Those participants that responded with a "No" were considered to have a binary concept of relevance (i.e. menu labels were either relevant or not relevant). Those that answered "Yes" were considered to view relevance as having three regions - relevant, partially relevant and not relevant.

The second question asked where the participant would judge the threshold or limit to each region of relevance. In those cases where participants viewed relevance as a binary concept this would be the point that divided the not relevant region from the relevant region. In those cases were relevance was seen as also having a partially relevant region, there were two thresholds - the division between not relevant and partially relevant, and the division between partially relevant and relevant. These thresholds were later used as part of the protocol designed for assessing and aggregating data during the analysis phase of this experiment (see Standardizing Relevant and Partially-Relevant Responses in Results and Discussion).

The final set of questions was aimed at collecting demographic and usage information from participants (Appendix J). The questions captured participant's gender, geographic location, age, education, comfort level in reading English, family income, time spent on the web and frequency of searching for health information.

The experiment's final screen acted as the participant's debriefing screen (Appendix K). This page included an overview of the research and its purpose, a description of the participant's role in the research, and contact information for the principal researcher, the principal faculty advisor, the Chair of the Ethics Committee and the Chair of the Psychology Department. It also served as a page that could be printed out for future reference. 


\section{Results and Discussion}

Participants Profile. The total number of participants who completed the online experiment was 151. A balanced Latin square was used for counterbalancing the order of the 10 scenarios used for data analysis. As there were four experimental conditions, 40 participants were required for each replicate. Therefore, only the data from the first 120 participants (three replicates) who completed the experiment were used for the analysis.

Geographically, participants were predominately from Canada's National Capital Region (NCR). However, individuals from a number of other Canadian provinces as well as other countries participated in the experiment (participants from $\mathrm{NCR}=60 \%$, outside NCR but within Canada $=27 \%$, outside Canada $=13 \%$ ).

There were slightly more male participants than female (male $=54 \%$, female $=46 \%$, with the majority falling between the ages of 25 to $54(82 \%)$. As is typical of those using the Internet the majority of participants were university educated holding either a university diploma or degree $($ diploma $=11 \%$, degree $=58 \%)$. The remaining participants held college or high school diplomas $($ college $=19 \%$, post high school $=5 \%$, high school $=6 \%$ ).

Data Cleaning. There were four categories of data that were identified as needing to be eliminated from the database:

- incomplete sessions (i.e. did not complete the scenarios and/or the question requesting the identification of relevance thresholds)

- illogical relevance thresholds (e.g. the low threshold number being higher than the upper threshold number)

- sessions begun by the researcher or individuals associated with the experiment 
- $\quad$ suspiciously patterned responses (i.e. all menu options chosen at near maximum ratings)

Data cleaning of the first two categories was automated and handled directly by rules established in the database. The other two categories of data were removed by the researcher upon inspection. Table 3 illustrates the number of sessions started, completed and datasets removed for each of the above categories (see Appendix $O$ for further details).

\section{Table 3}

Participant Sessions Removed from Dataset

\begin{tabular}{lcc}
\hline \multicolumn{1}{c}{ Data Category } & Number of & Percentage of \\
& Sessions & Total \\
\hline Incomplete Sessions & 203 & $50.3 \%$ \\
\hline Illogical Relevance Threshold & 15 & $3.7 \%$ \\
\hline Suspicious Response Pattern & 2 & $0.5 \%$ \\
\hline Test Sessions & 32 & $7.9 \%$ \\
\hline Completed Sessions & 152 & $37.6 \%$ \\
\hline TOTALS & 404 & $100 \%$ \\
\hline
\end{tabular}

There was a total of 152 completed and valid sessions. There were three Balanced Latin Square replicates needed to complete the minimum dataset ( 3 replicates of 40 participants). Therefore, only 120 of the 152 sessions were used. As participants were randomly assigned, the first three completed replicates were used, leaving the remaining valid sessions in the active database. 
Variations in Relevance Thresholds. Participants were asked to identify the thresholds or limits of each region of relevance (e.g. the beginning or minimum rating for a menu label to be considered relevant) (Appendix I). There were two purposes for the questions relating to regions of relevance and their corresponding thresholds.

The first was to determine if a participant's construct of relevance was binary (i.e. relevant versus not relevant) or whether the participant saw relevance as a construct with three regions (i.e. relevant, partially relevant and not-relevant). Responses to these questions indicate that a strong majority of participants view the construct of relevance as having three different regions (construed as three regions $=96.7 \%$, construed as binary $=3.3 \%$ ).

The second purpose for the threshold questions was to semantically standardize judgments of relevance between participants. For example, if a participant's construct of relevance was not binary, and that participant identified the upper threshold of the not-relevant region as 20 , and the lower threshold of the relevant region as 55, that participant's regions of relevance were assumed to be:

$$
\begin{gathered}
0 \leq \text { NOT-RELEVANT } \leq 20 \\
21 \leq \text { PARTIALLY-RELEVANT } \leq 54 ; \\
55 \leq \text { RELEVANT } \leq 100 .
\end{gathered}
$$

Table 4 indicates that while the upper threshold for the not-relevant category centered around 25 and the lower threshold for the relevant category centered around 60 , there was a great deal of variability in participant's responses. This supports the earlier assertion that relevance ratings require semantic standardization prior to aggregation. 
Table 4

Regions of Relevance - Threshold Frequency Counts \& Summary Statistics

\begin{tabular}{|c|c|c|c|c|c|c|c|c|}
\hline \multirow{2}{*}{$\begin{array}{c}\text { Relevance } \\
\text { Region }\end{array}$} & \multicolumn{5}{|c|}{ Threshold Value (0-100) } & \multicolumn{3}{|c|}{ Summary Statistics } \\
\hline & $0-20$ & $20-39$ & $40-59$ & $60-79$ & $80-100$ & Mean & Median & Std. Dev \\
\hline $\begin{array}{l}\text { Not-Relevant } \\
\text { (upper limit) }\end{array}$ & 40 & 50 & 27 & 2 & 1 & 25.6 & 24.5 & 17.95 \\
\hline $\begin{array}{l}\text { Relevant } \\
\text { (lower limit) }\end{array}$ & 4 & 16 & 28 & 58 & 14 & 59.6 & 61.5 & 20.08 \\
\hline
\end{tabular}

Note: Actual range for the upper limit of the not-relevant region was 0 to 84 ; range for the lower limit of the relevant region was 4 to 100 .

Analysis

When analyzing the data for this experiment, there were four prime dependent variables of interest: 1) the number of menu labels judged relevant, 2) the number of menu labels judged partially-relevant, 3) user agreement about strong relevant menu labels and 4) the probability of participants selecting the target menu label. These data were available for each of the 10 scenarios. Therefore they were analysed using a mixed $2 \times 2 \times 10$ factorial design with two levels of task and two levels of context as between group variables, and 10 levels of scenario as the within subjects factor. Due to positive skewing and problems with homogeneity of variance, $\log$ transformations were applied. These improved, but did not eliminate problems with homogeneity of variance. The results of the analyses in terms of significance were identical. Consequently the following analyses are based on the original data. 
Mean Number of Relevant Menu Labels Per Scenario. The mean number of menu labels judged relevant per scenario, and the corresponding standard errors are shown in Table 5. The number of menu items judged relevant for each scenario varied from 3.38 for scenario 8 to 1.84 for scenario 3 .

Table 5

Mean Number of Menu Labels Judged Relevant per Scenario

\begin{tabular}{|c|c|c|c|c|c|}
\hline \multirow[t]{3}{*}{ Scenario \# } & \multicolumn{2}{|c|}{ Classify } & \multicolumn{2}{|c|}{ Seek } & \multirow{3}{*}{$\begin{array}{c}\text { Marginal } \\
\text { Means (SE) }\end{array}$} \\
\hline & Situation & Topic & Situation & Topic & \\
\hline & & $\mathrm{M}(\mathrm{SE})$ & $\mathrm{M}(\mathrm{SE})$ & $\mathrm{M}(\mathrm{SE})$ & \\
\hline 1 & $1.47(.33)$ & $2.53(.33)$ & $1.47(.33)$ & $2.17(.33)$ & $1.91(.16)$ \\
\hline 2 & $3.07(.54)$ & $2.63(.54)$ & $2.10(.54)$ & $1.77(.54)$ & $2.39(.27)$ \\
\hline 3 & $1.97(.54)$ & $2.00(.54)$ & $1.27(.54)$ & $2.13(.54)$ & $1.84(.27)$ \\
\hline 4 & $3.13(.80)$ & $4.57(.80)$ & $2.13(.80)$ & $3.50(.80)$ & $3.33(.40)$ \\
\hline 5 & $1.87(.42)$ & $2.50(.42)$ & $1.30(.42)$ & $2.17(.42)$ & $1.96(.21)$ \\
\hline 6 & $3.40(.56)$ & $2.47(.56)$ & $2.43(.56)$ & $2.47(.56)$ & $2.69(.28)$ \\
\hline 7 & $3.00(.82)$ & $3.87(.82)$ & $2.10(.82)$ & $3.20(.82)$ & $3.04(.41)$ \\
\hline 8 & $3.40(.79)$ & $4.33(.79)$ & $2.23(.79)$ & $3.53(.79)$ & $3.38(.40)$ \\
\hline 9 & $2.17(.46)$ & $2.70(.46)$ & $1.33(.46)$ & $2.10(.46)$ & $2.08(.23)$ \\
\hline 10 & $2.93(.57)$ & $3.07(.57)$ & $1.43(.57)$ & $2.47(.57)$ & $2.47(.28)$ \\
\hline Marginal & & & & & \\
\hline Means (SE) & $2.64(.5)$ & $3.07(.5)$ & $1.78(.5)$ & $2.55(.5)$ & $2.51(.25)$ \\
\hline
\end{tabular}

Note: $\mathrm{n}=30$ participants per group 
Box's test of the equality of the covariance matrices among the groups was statistically significant using the .01 level of significance $F(165,29172.4)=2.776, p<.01)$. Examination of Levene's tests of equality of error variances for each scenario shows that scenarios 4,9 and 10 were significant at the .01 level.

There were no statistically significant results for the between-group effects. (Task: $F(1,116)=1.865, p>.05, \eta^{2}=.016$, Context: $F(1,116)=1.409, p>.05, \eta^{2}=.012$ and Task $\mathrm{x}$ Context: $\left.F(1,116)=.116, p>.05, \eta^{2}=.001\right)$.

For tests involving effects of scenario, Mauchly's test of sphericity was statistically significant at the .01 level, $\chi^{2}(44)=316.29, p<.01$. Thus, to avoid positive bias, the Huynh-Feldt Epsilon correction to the degrees of freedom was applied $($ Epsilon $=.67)$.

There was a statistically significant effect of scenario $F(6.03,699.11)=10.97, p<.01$, $\eta^{2}=.086$

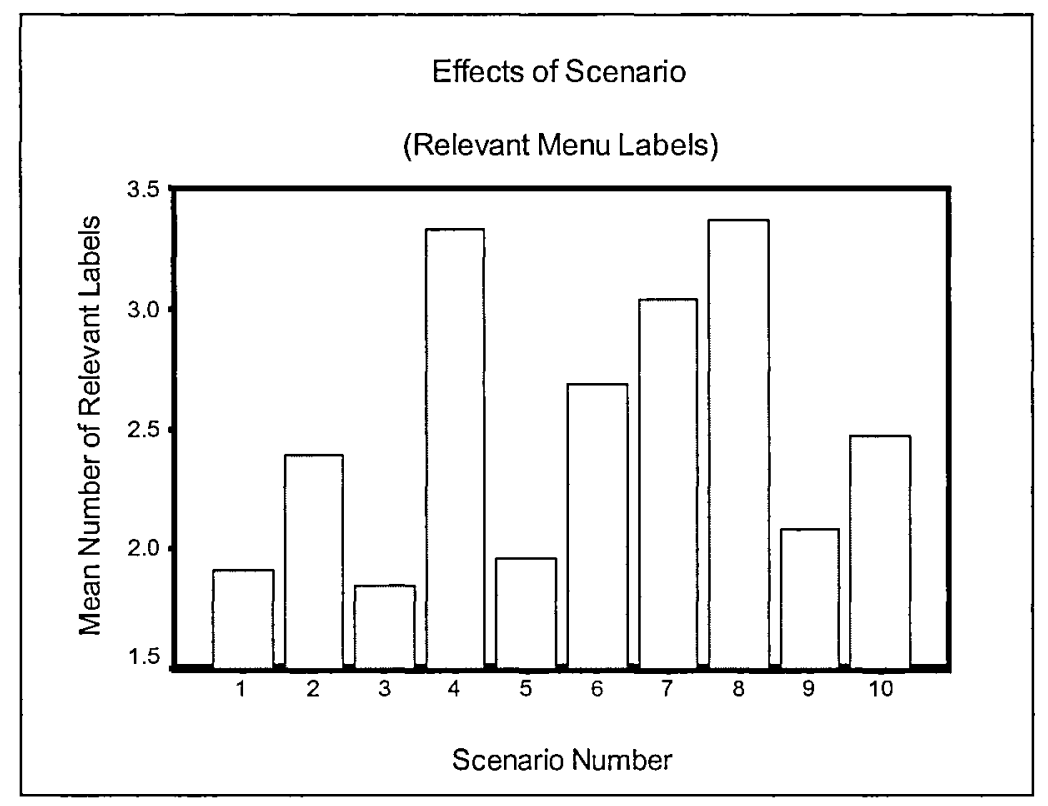

Figure 9. Effect of Scenario on Number of Relevant Ratings 
There was also a statistically significant scenario by context interaction $F(6.03,699.11)=$ $2.92, p<.01, \eta^{2}=.025$. With regard to the scenario by context interaction, simple main effects of context were computed at each level of scenario. The only significant difference was for scenario 1 in which there were more items judged relevant for topics than for situation.

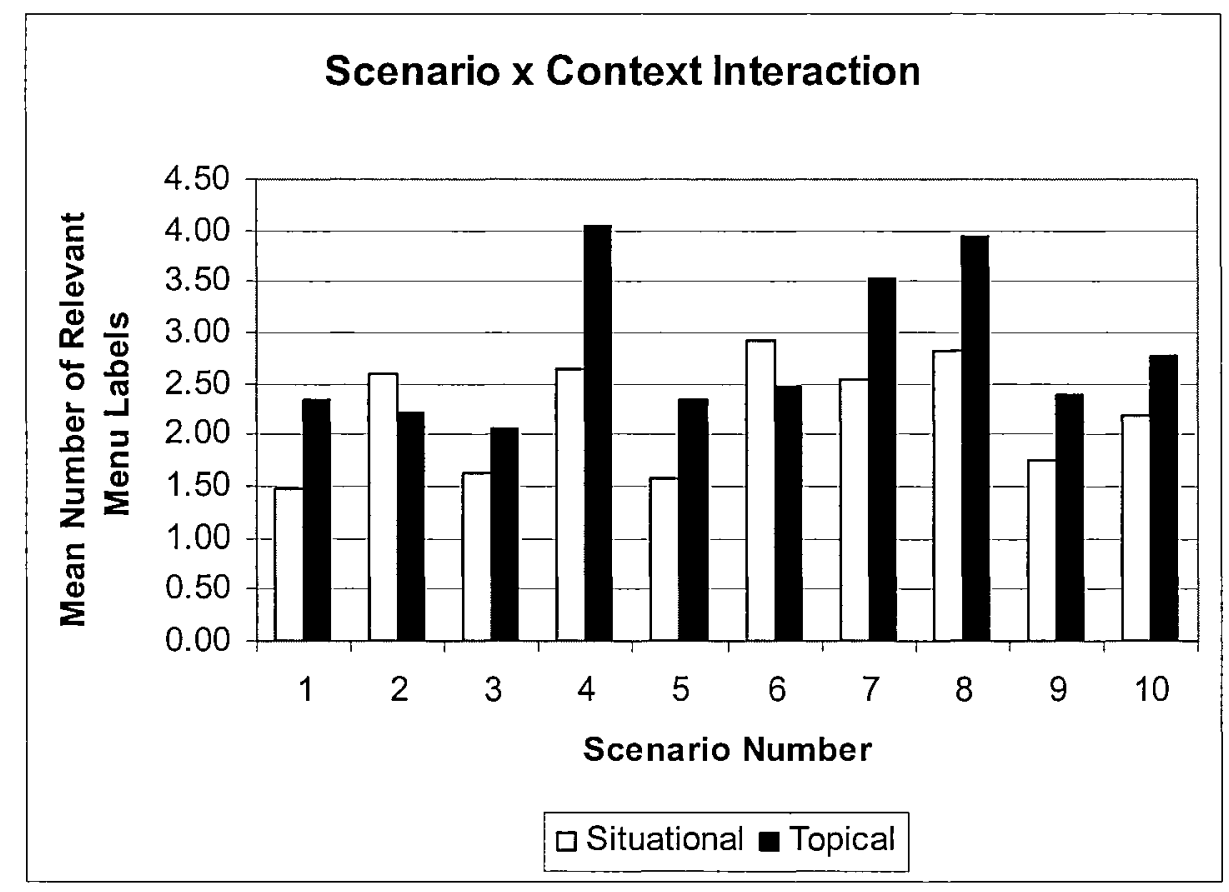

Figure 10. Scenario by Context Interaction for Relevant Ratings

Neither the scenario by task interaction nor the three-way interaction were statistically significant $-\left(\right.$ Scenario $\mathrm{x}$ Task: $F(6.03,699.106)=.822, p>.05, \eta^{2}=.007$ and Scenario $\mathrm{x}$ Task $\mathrm{x}$ Context: $\left.F(6.03,699.106)=.383, p>.05, \eta^{2}=.003\right)$.

Mean Number of Partially-Relevant Menu Labels Per Scenario. The mean number of menu labels judged partially relevant per scenario, and the corresponding standard errors are shown in Table 6. The number of menu items judged partially relevant for each scenario varied from 1.74 for Scenario 4 to .55 for scenario 1 . 
Table 6

Mean Number of Menu Labels Judged Partially Relevant per Scenario

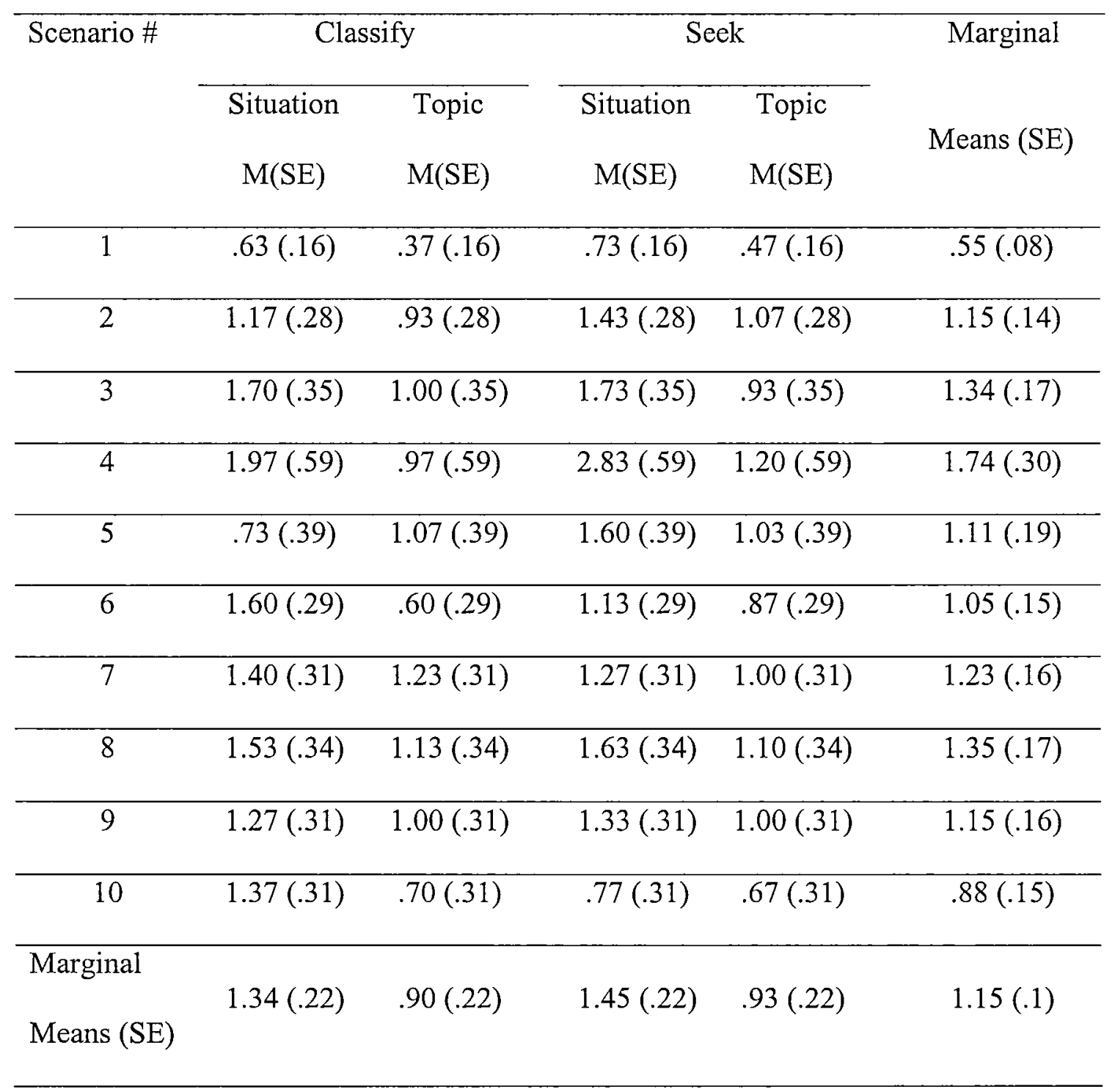

Note: $\mathrm{n}=30$ participants per group

Box's test of the equality of the covariance matrices among the groups was statistically significant using the .01 level of significance $(F(165,29172.4)=2.847, p<.01)$. Examination of Levene's tests of equality of error variances for each scenario shows that scenarios 4 and 6 were significant at the .01 level. 
There was a main effect of context $F(1,116)=4.654, p<.05, \eta^{2}=.039$ with the mean number of partially relevant menu items greater for the situational context $(M=1.392, S E=.156)$ than for the topical context $(\mathrm{M}=.917, \mathrm{SE}=.156)$. There were no other statistically significant results for the between-group effects. (Task: $F(1,116)=.106, p>.05, \eta^{2}=.001$; Task x Context Interaction: $\left.F(1,116)=.030, p>.05, \eta^{2}=.000\right)$.

For tests involving effects of scenario, Mauchly's test of sphericity was statistically significant at the .01 level, $\chi^{2}(44)=326.69, p<.01$. Thus, to avoid positive bias, the Huynh-Feldt Epsilon correction to the degrees of freedom was applied $($ Epsilon $=.53)$.

There was a statistically significant effect of scenario $\left(F(4.81,557.45)=4.85, p<.01, \eta^{2}\right.$ $=.040$. There were no statistically significant interactions with Scenario (Scenario $\mathrm{x}$ Task: $F(4.81,557.45)=.856, p>.05, \eta^{2}=.007 ;$ Scenario $\mathrm{x}$ Context: $F(4.81,557.45)=1.54, p>.05, \eta^{2}$ $=.013$; Scenario $\mathrm{x}$ Task $\mathrm{x}$ Context: $\left.F(4.81,557.45)=.714, p>.05, \eta^{2}=.006\right)$.

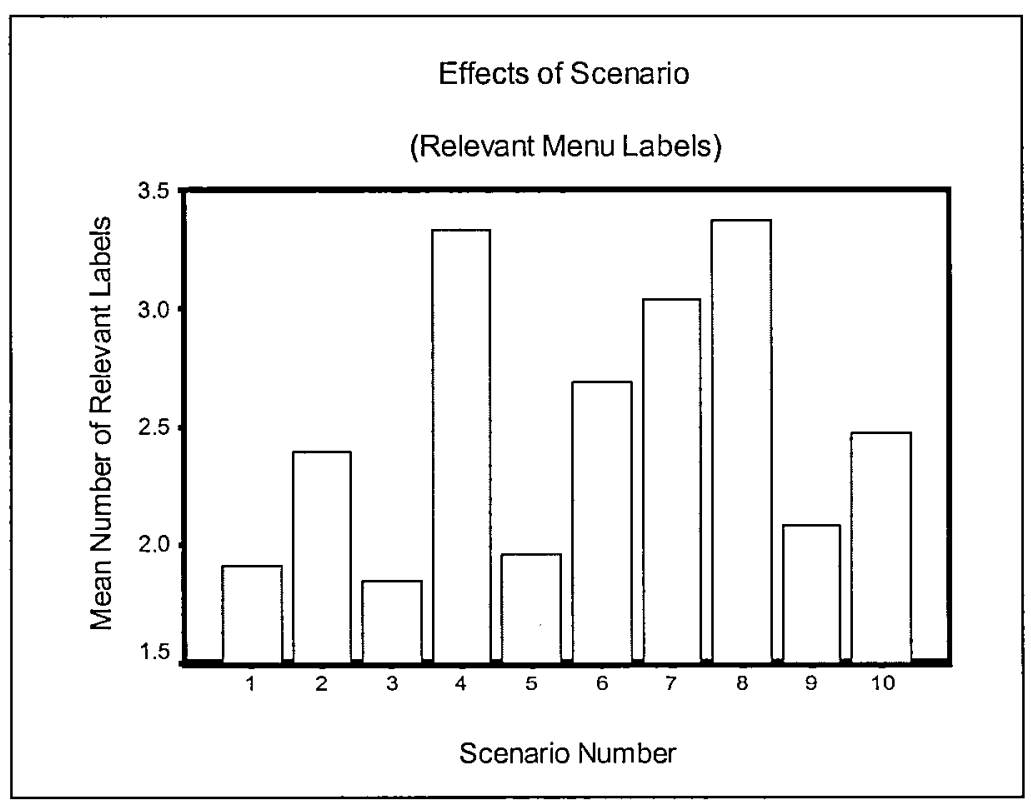

Figure 11. Effects of Scenario on Partially Relevant Ratings 
Proportion of Agreement About Relevant Menu Labels. The previous hypotheses referred to the number of labels judged either relevant or partially relevant within each scenario. This hypothesis refers to the proportion of participants who judged the same menu label as being the most relevant (i.e. the highest rated above the relevant threshold).

The proportions of agreement among participants, regarding which menu label is the most relevant menu is shown in Table 7. The mean proportion of agreement for each scenario varied from .82 for scenario 1 to .28 for scenario 3 . To examine whether differences among the groups could be found, a $2 \times 2$ univariate analysis of variance was conducted with Task and Context as the factors and the 10 scenarios as the "subjects". Homogeneity of variance was tested using Levene's Test of Equality and a violation of this assumption was not found using the .01 level of significance $(F(3,36)=.318, p>.01)$.

There were no statistically significant results for the between-groups effects (Task: $F(1,36)=.693, p>.05, \eta^{2}=.019 ;$ Context: $F(1,36)=.028, p>.05, \eta^{2}=.001 ;$ Task $\mathrm{x}$ Context: $\left.F(1,36)=.001, p>.05, \eta^{2}=.000\right)$. 
Table 7

Proportion of Participant Agreement About the Most Relevant Label per Scenario

\begin{tabular}{|c|c|c|c|c|c|}
\hline \multirow[t]{2}{*}{ Scenario \# } & \multicolumn{2}{|c|}{ Classify } & \multicolumn{2}{|c|}{ Seek } & \multirow{2}{*}{$\begin{array}{l}\text { Margina } \\
\text { Means }\end{array}$} \\
\hline & Situation & Topic & Situation & Topic & \\
\hline 1 & .80 & .83 & .77 & .87 & .82 \\
\hline 2 & .60 & .43 & .40 & .43 & .47 \\
\hline 3 & .43 & .20 & .27 & .23 & .28 \\
\hline 4 & .53 & .67 & .50 & .43 & .53 \\
\hline 5 & .70 & .53 & .43 & .63 & .58 \\
\hline 6 & .57 & .40 & .60 & .53 & .53 \\
\hline 7 & .43 & .53 & .40 & .47 & .46 \\
\hline 8 & .67 & .63 & .47 & .70 & .62 \\
\hline 9 & .53 & .57 & .57 & .57 & .56 \\
\hline 10 & .70 & .73 & .73 & .70 & .72 \\
\hline Marginal & & & & & \\
\hline Means & .60 & .55 & .51 & .57 & .56 \\
\hline
\end{tabular}

Note: $\mathrm{n}=30$ participants per group 
Probability of Choosing the Target Menu Label. This hypothesis refers to the probability of the user choosing the target menu label, given all other relevant and partially relevant labels.

The metric used to estimate the probability of choosing the target menu label was adapted by Leth-Steensen (2003) based on work reported by Nosofsky (1984) which in turn is based on Luce's (1963) choice theory. It is a ratio of the user's judgment of the target menu's relevance to the relevance of all other menu labels. Therefore, to achieve a perfect probability (1.00) of choosing the target menu label, a participant must judge the target label to be $100 \%$ relevant $\mathrm{AND}$ all other menu labels must be judged as having $0 \%$ relevance. For a complete description of how probabilities were computed, see Appendix M.

The probabilities of a user choosing the target label for each scenario, and their corresponding standard errors are shown in Table 8. The mean probabilities of a user choosing the target label varied from .59 for scenario 1 to effectively .00 for scenarios 2 and 8 . 
Table 8

Mean Probabilities of Selecting the Target Menu Label for Each Scenario

\begin{tabular}{|c|c|c|c|c|c|}
\hline \multirow[t]{2}{*}{ Scenario \# } & \multicolumn{2}{|c|}{ Classify } & \multicolumn{2}{|c|}{ Seek } & \multirow{2}{*}{$\begin{array}{l}\text { Marginal } \\
\text { Means (SE) }\end{array}$} \\
\hline & $\begin{array}{l}\text { Situation } \\
\text { (SE) }\end{array}$ & $\begin{array}{l}\text { Topic } \\
\text { (SE) }\end{array}$ & $\begin{array}{l}\text { Situation } \\
\text { (SE) }\end{array}$ & $\begin{array}{l}\text { Topic } \\
\text { (SE) }\end{array}$ & \\
\hline 1 & $.64(.06)$ & $.47(.06)$ & $.64(.06)$ & $.60(.06)$ & $.59(.03)$ \\
\hline 2 & $.01(.03)$ & $.09(.03)$ & $.08(.03)$ & $.04(.03)$ & $.06(.01)$ \\
\hline 3 & $.29(.07)$ & $.31(.07)$ & $.26(.07)$ & $.26(.07)$ & $.28(.03)$ \\
\hline 4 & $.24(.06)$ & $.38(.06)$ & $.32(.06)$ & $.28(.06)$ & $.31(.03)$ \\
\hline 5 & $.45(.06)$ & $.33(.06)$ & $.36(.06)$ & $.39(.06)$ & $.38(.03)$ \\
\hline 6 & $.22(.04)$ & $.17(.04)$ & $.26(.04)$ & $.15(.04)$ & $.20(.02)$ \\
\hline 7 & $.18(.06)$ & $.25(.06)$ & $.26(.06)$ & $.24(.06)$ & $.23(.03)$ \\
\hline 8 & $.10(.02)$ & $.06(.02)$ & $.03(.02)$ & $.04(.02)$ & $.06(.01)$ \\
\hline 9 & $.28(.06)$ & $.27(.06)$ & $.35(.06)$ & $.37(.06)$ & $.32(.03)$ \\
\hline 10 & $.34(.07)$ & $.37(.07)$ & $.52(.07)$ & $.45(.07)$ & $.42(.03)$ \\
\hline $\begin{array}{l}\text { Marginal } \\
\text { Means (SE) }\end{array}$ & $.28(.03)$ & $.27(.03)$ & $.31(.03)$ & $.28(.03)$ & $.28(.01)$ \\
\hline
\end{tabular}

Note: $\mathrm{n}=30$ participants per group

Box's test of the equality of the covariance matrices among the groups was statistically significant using the .01 level of significance $(F(165,29172.4)=1.468, p<.01)$. Examination of Levene's tests of equality of error variances for each scenario shows that scenario 2 was significant at the .01 level. 
There were no statistically significant results for the between-group effects (Task:

$F(1,116)=.677, p>.05, \eta^{2}=.006 ;$ Context: $F(1,116)=.361, p>.05, \eta^{2}=.003$; Task x Context: $\left.F(1,166)=.169, p>.05, \eta^{2}=.001\right)$

For tests involving effects of scenario, Mauchly's test of sphericity was statistically significant at the .01 level, $\chi^{2}(44)=189.270, p<.01$. Thus, to avoid positive bias, the HuynhFeldt Epsilon correction to the degrees of freedom was applied $($ Epsilon $=.86)$.

There was a statistically significant effect of scenario $F(7.760,900.182)=40.580, p<.01$, $\eta^{2}=.259$

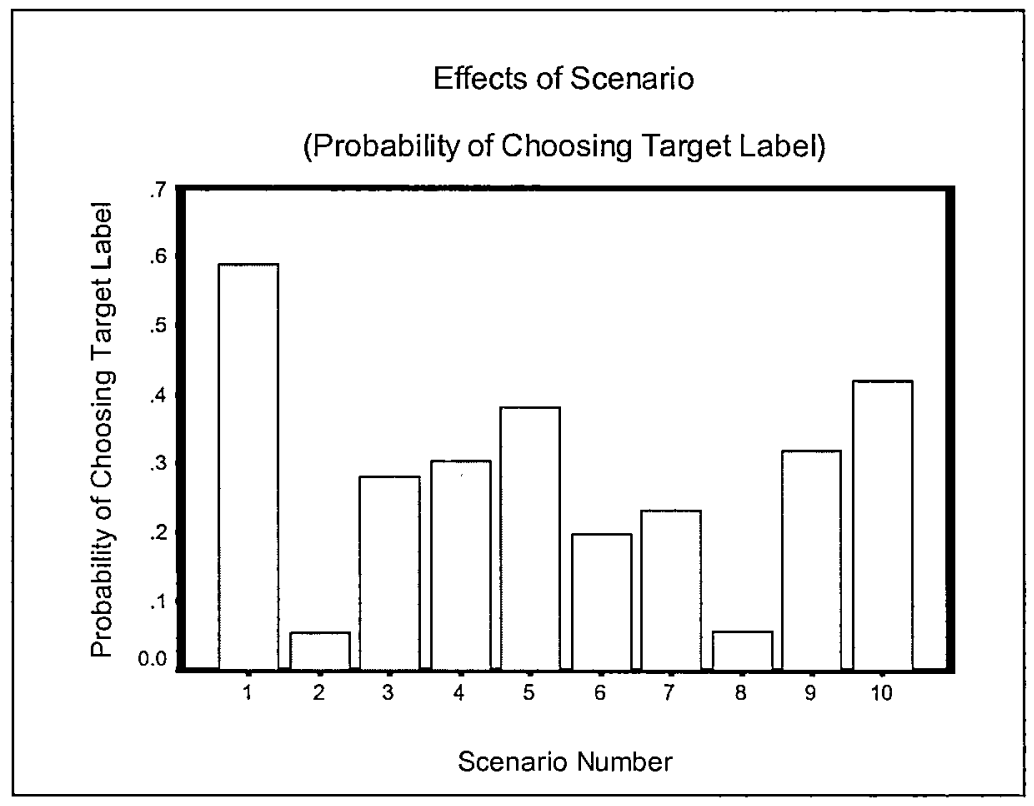

Figure 12. Effect of Scenario on the Probability of Choosing the Target Menu Label

There was also a statistically significant scenario by context interaction $F(6.03,699.11)=$ $2.92, p<.01, \eta^{2}=.025$. With regard to the scenario by context interaction, simple main effects of context were computed at each level of scenario. The only significant difference was for scenario 6 in which the probability of choosing the target menu label was higher in the situational context than in the topical context. 


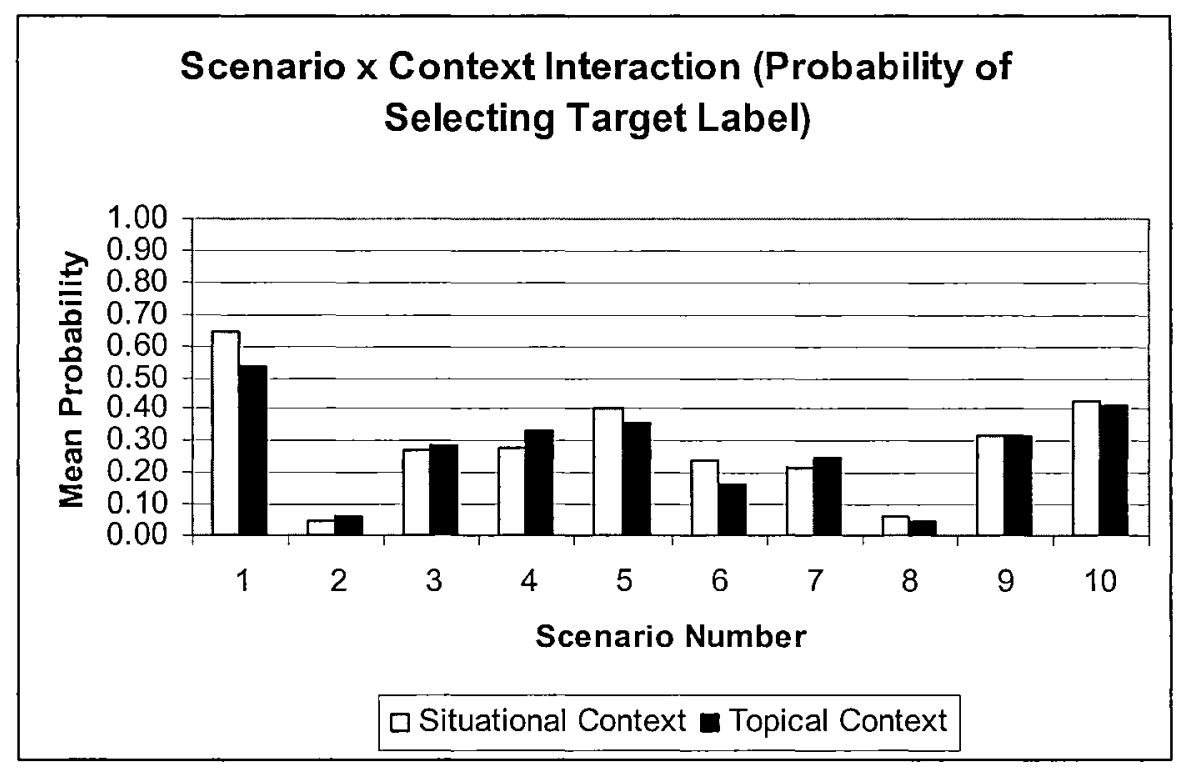

Figure 13. Scenario x Context Interaction - Probability of Selecting Target Label

There were no other statistically significant interactions (Scenario x Task: $F(7.760$, $900.182)=1.287, p>.05, \eta^{2}=.011 ;$ Scenario $\mathrm{x}$ Context: $F(7.760,900.182)=.941, p>.05, \eta^{2}$ $=.008$; Scenario $\mathrm{x}$ Task $\mathrm{x}$ Context: $\left.F(7.760,900.182)=1.117, p>.05, \eta^{2}=.010\right)$.

Participants Identify Mixed and Competing Choices. In this experiment, each time a participant was presented with a scenario, the information architecture offered a total of 71 second-level menu labels (i.e. 71 choices from which to choose the potential target menu label). Among those menu label choices, some participants identified multiple relevant labels (multiple choices), some participants only identified one label as relevant (a clear choice), and still others did not identify any potential choice as being relevant. These patterns of choices tended to be a response style specific to individual participants and relatively consistent across scenarios and groups. Table 9 illustrates that across scenarios, the largest proportion of participants (48.7\%) viewed the information architecture as having multiple choices for any given scenario. 
Table 9

Distribution of Participants with Weak, Clear and Multiple Option Response Styles

No Choices Identified One Choice Identified Multiple Choices Identified (weak option)

(clear option)

(multiple options)

\begin{tabular}{lccc}
\hline Mean & $19.3 \%$ & $32.1 \%$ & $48.7 \%$ \\
\hline Std. Deviation & 8.0 & 8.5 & 9.1
\end{tabular}

Note: $\mathrm{n}=120$ (Across groups)

Comparing the Target Menu to Alternate Menu Label Choices. Two final analyses were completed on this dataset: 1) a comparison of the proportion of agreement about the relevance of the target menu label and the proportion of agreement about the relevance of the alternate menu label (the most relevant label other than the target label); and 2) a comparison of the probability of choosing the target and the probability of choosing the alternate menu label.

The comparison of the proportions of agreement of the target menu label to the proportions of agreement to the alternate menu label is shown in Figure 14. Scenarios 2 and 8 show that there was a substantially higher proportion of agreement among users for an alternate menu label over the target menu. In addition, scenarios 3, 4, 5, 6, 7 and 9 all show relatively strong proportion of agreement for an alternate menu label as well as the target menu. 


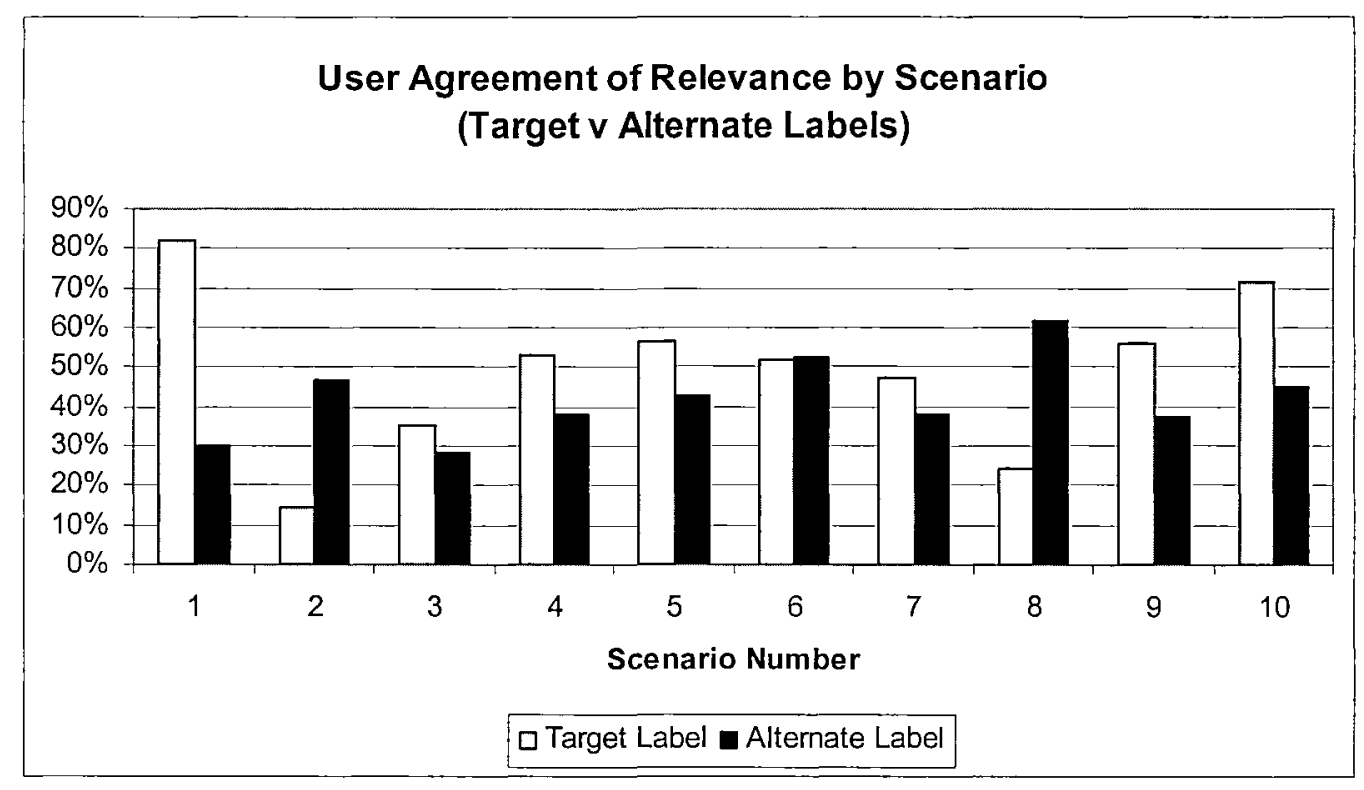

Figure 14. User Agreement of Relevance for Target Label v Alternate Labels

Earlier, the probabilities of choosing each scenarios' target menu label were identified.

The metrics and methodology used in this experiment allows for the exploration of the effects of adding an alternate menu label as an additional access point to the target information. One important question remains unanswered" "Would there be an increase in the probability of accessing target information if both the target and the alternate labels were designed as points of access?"

As shown in Figure 15, the probability of selecting a menu label providing access to target information would have increased in all 10 scenarios with the addition of an alternate label. The most substantial increases would have been in scenarios 2 and 8 . 


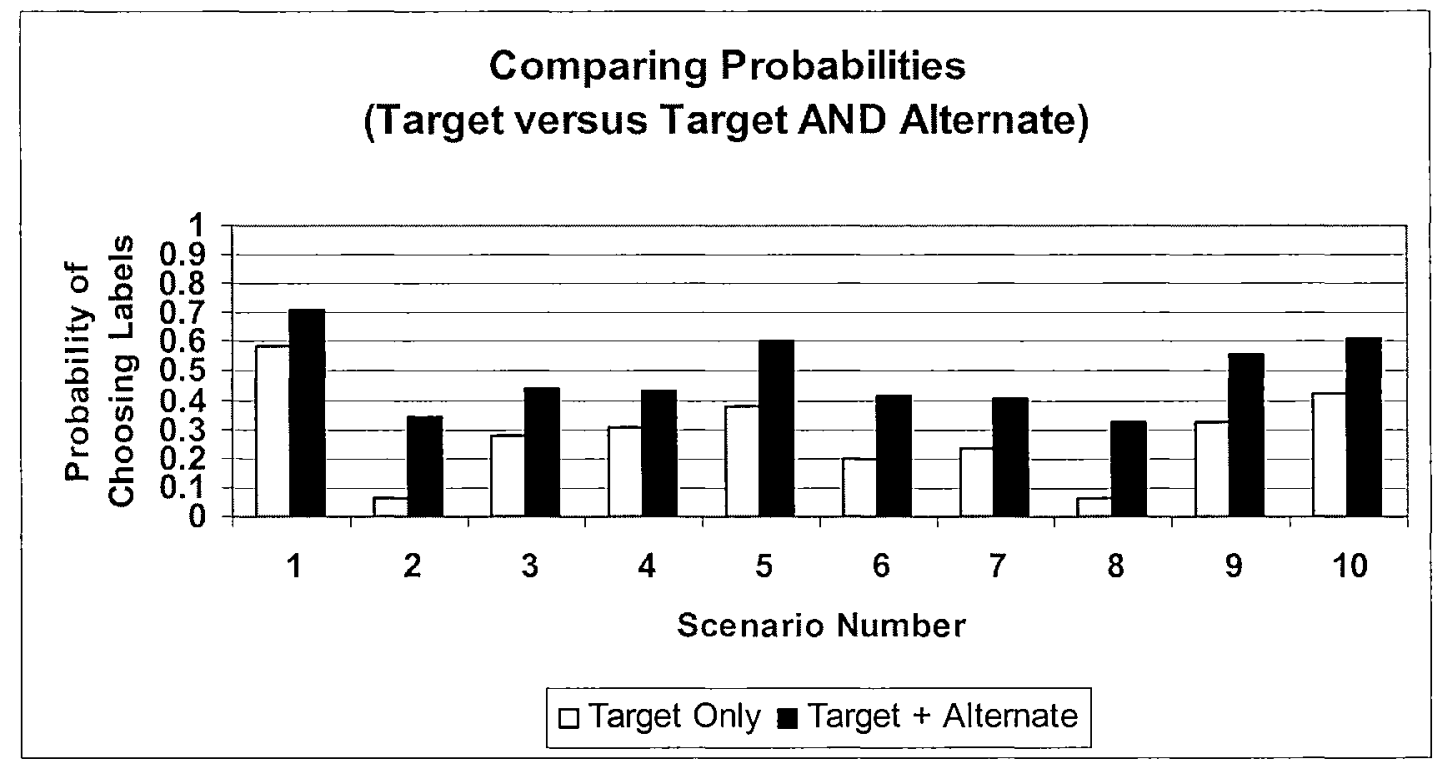

Figure 15. Comparing Probabilities - Target versus Target and Alternate

Furthermore, as shown in Table 10, the results suggest that there would have been an average increase of .20 if both the user's target and alternate labels had been used to provide access to the target information. 


\section{Table 10}

Comparing the Effects on Mean Probabilities of Adding an Alternate Label Choice

\begin{tabular}{cccc}
\hline Scenario \# & Target Label & Target or Alternate & Probability Increase \\
\hline 1 & .54 & .71 & .12 \\
\hline 2 & .06 & .35 & .29 \\
\hline 3 & .28 & .44 & .16 \\
\hline 4 & .31 & .44 & .22 \\
\hline 5 & .38 & .61 & .22 \\
\hline 6 & .20 & .42 & .17 \\
\hline 7 & .23 & .40 & .27 \\
\hline 8 & .06 & .33 & .24 \\
\hline 9 & .32 & .56 & .19 \\
\hline 10 & .42 & .62 & .20 \\
\hline Means & .29 & & \\
\hline
\end{tabular}

Note: $\mathrm{n}=120$ 


\section{Discussion}

The Effects of Task and Context on Information Scent. One of the objectives of this research was to explore the effects that a user's task orientation and context of evaluation have on their judgments of a menu label's information scent. Of particular interest was the effects that these variables may have had on the number of strongly scented menu labels (relevant), and moderately scented labels (partially relevant).

The results show that the number of strongly and moderately scented menu labels is dependent on the scenario. However, there was no evidence to support the hypothesis that a greater number of strongly scented menu labels would be identified by classifiers in a topical context, than would be identified by seekers in a situational context. Similarly, there was no evidence to support the hypothesis that a greater number of moderately scented menu labels would be identified by seekers of topical content than would be classifiers of situational content.

However, there is evidence to show that regardless of task orientation, users who evaluate menu labels from a situational context identify a greater number of moderately scented (partially relevant) menu labels than those who evaluate the same menu labels from a topical context. It is assumed that judgments of partial relevance are indicators of uncertainty. Therefore, while the magnitude of the effect of context was weak (accounting for 3.9\% of the variance) it provides some evidence that label evaluations made from situational contexts may increase the amount of uncertainty or indecisiveness surrounding a user's information foraging activity.

An increase in uncertainty and the number of potential scent trails is likely to increase the costs associated with finding information. These costs can result from an increase in the cognitive resources required to process the information and make a decision, the time costs required to navigate through additional options, and the costs associated with making incorrect 
choices. A potential increase in foraging costs may cause users to leave the site prematurely and thereby reducing the IA's overall usefulness - regardless of the value of the information it contains.

While these points are speculative and require further research, it continues to highlight the need for methodologies which can map an IA's information scent trails.

Diagnosing Scent Trails and Informing Design Heuristics. The two metrics used in this experiment (proportion of agreement and probability of choosing a target menu) both serve as diagnostic tools for the usability practitioner and inform design heuristics. While neither method lead to the predicted results with respect to task and context, their utility for improving menu design is clear.

The hypothesis that there would be a higher proportion of agreement among seekers given a situational scenario than there would be among classifiers, given a topical scenario was not supported. There were no significant effects of task and context on the proportion of agreement and no significant dependency between task and context for any of the scenarios.

Generally, among the 71 second-level menu labels presented in each scenario, there were two to three labels reflecting the most agreement (averaging $38 \%$ to $56 \%$ per label), followed by two to five additional labels reflecting moderate agreement (averaging $10 \%$ to $23 \%$ per label). This provides some evidence that as a group users tended to identify and follow the same scent trails. Even in cases where the wrong scent trails were being followed (see scenarios 2 and 8 in Figure 14) agreement among users remained high (47\% and $62 \%$ respectively). Therefore, a designer can improve the user's likelihood of finding target information by testing user's label 
choices, and confirming that the scent trails that they are following do in fact lead to target information.

The hypothesis that there would be a higher probability of choosing a target menu label among seekers given a situational scenario than there would be among classifiers, given a topical scenario was also not supported. There were no significant effects of task and context on the probability of choosing a target menu label. However, the probability of selecting a target menu label was dependent on the scenario being presented.

The probability of selecting a target menu label is different from agreement in that agreement is analogous to a simple vote - the number of users who judged that menu label as being their top choice. In contrast, the probability of choosing a target label uses a formula that takes into account all the user's relevance judgments about all 71 menu labels. Therefore, as information scent increases and is distributed among the other menu labels, the probability of choosing the target menu label decreases. These concepts (target and agreement) go hand-inhand in diagnosing scent trails and informing design heuristics.

If we review the probabilities of choosing the target menu labels for scenarios 2 and 8 we see that they were close to zero (Table 8), yet both target labels obtained moderate levels of agreement about their relevance (.14 and .24 respectively - Figure 14). These low probabilities can be accounted for by the fact that in general users selected additional menu labels as being relevant. In both scenarios users' top choices were not the target menu labels but alternate labels. The proportions of agreement for these alternate labels rose to .47 and .62 respectively (Table 7).

This capacity of being able to identify the existence of an alternate menu label with high information scent is important in being able to diagnose an IA's usefulness. It allows designers' 
decisions to be informed by empirical evidence of user behaviour. In particular, it affords designers the opportunity to structure multiple access points within the IA that all lead to the target information. Previously, the challenge was in finding a methodology which could assist usability practitioners in determining which menu labels should be selected as access points.

Using scenarios 2 and 8 as an example, we can now compute the increase in probability of adding the alternate menu labels as additional access points to target information. Adding the alternate label choices in scenarios 2 and 8 , increased the probability of choosing one of these labels (target or alternate) to .35 and .33 respectively (Table 10 ). This represents an average increase of $30 \%$ in the likelihood that the user will be provided access to the target information. As shown in Table 10, the average increase in adding alternate labels across scenarios was .21.

This metric has the added benefit of providing the designer with an index against which to compare iterative IA designs and evaluate the effects of new designs on information scent.

A question that could not be answered from this research and is fertile ground for future research is "What variables are producing the observed fluctuations in agreement between menu labels?". Is it the strength of the scent of competing or confusing labels? Is it the user's experience or knowledge about the subject matter? Is it the semantic similarities or differences between a scenario and the IA's menu labels? Recent work in Cognitive Walkthroughs for the Web (Blackmon, Polson, Kitajima, \& Lewis, 2002) suggest that semantic differences may play a key role. Specifically, their research uses Latent Semantic Analysis (see the Methods section) to objectively estimate the degree of similarity between goal statements and menu labels.

The Effect of Scenarios. In analyzing the data for each hypothesis, one thing remained constant - there was always a significant within-subject effect of scenario. If these results 
consistently depend on scenario, then it is important for designers to understand the prototypical information needs of their users. A recommendation resulting from this analysis, is therefore made that as part of assessing the usefulness of an IA, designers complete a User Information Needs Assessment (UINA). The focus of this assessment would be to identify the most prototypical scenarios surrounding the conditions in which users seek information from a specific web site in order to generate a representative profile of likely target information needs. From this profile, scenarios can then be created to asses and map the IAs information scent trails using the proportion of agreement and probability of selection metrics.

Relevance - The Construct, Threshold \& Methodological Weaknesses. In this experiment little evidence was found to support the hypotheses regarding task and context. Does this lead to the conclusion that the concepts of task and context were not useful or that the methodology of the experiment could be improved? One potential weakness of the study may have been the method of measuring relevance.

The experimental protocol and methodology for data analysis were attempting to meet two conflicting needs. The first was the need for continuous data to compute probabilities of selecting target menu labels. The second was the need to have categorical data to semantically standardize responses.

Magnitude estimation was chosen as a method for estimating relevance judgments because it had been found to be more robust and did not suffer from contextual effects (Eisenberg, 1988). The short-coming of magnitude estimates is that they do not inherently standardize the semantic value that participants place on a given score. For example, one user's score of 75 may mean relevant to one user and only partially relevant to another. For this reason 
the methodological and computational overhead of standardizing these continuous scores into categorical data was incurred.

A potential weakness of the methodology was the final question which asked participants to identify their relevance thresholds. Anecdotal reports from a small group of participants following the experiment indicated that some participants found the question of thresholds confusing, i.e. they did not understand the intent of the question. This anecdotal evidence is also supported by the fact that data from $3.7 \%$ (Table 3 ) of the online sessions were eliminated due to illogical threshold designations, e.g. the lower threshold had a higher value than the upper threshold. In an effort to determine if this may have changed the texture of the data and its final results, the data was re-analysed using the raw scores, and the mean and median threshold levels. The results from this second analysis were consistent with the standardized categorical data.

As described in the Results section, $96.7 \%$ of users identified relevance as having three regions. The remaining 3.3\% construed relevance as a binary construct. This finding supports the literature (Eisenberg, 1988; Greisdorf, 2000) which suggests that relevance is not a binary construct. The fact that a small proportion of participants reported viewing relevance as a binary construct was not a problem during data analysis. The process of semantically standardizing responses into one of three categories accounted for these different perspectives (see Methods section).

The variability regarding users thresholds between regions of relevance was noteworthy. As Table 4 indicates the lower threshold (between not relevant and partially relevant) centered around 25 with a standard deviation of 17.95. Similarly, the upper threshold (between partially relevant and relevant) centered around 60 with a standard deviation of 20.08 . These findings suggest that the original concern about semantically standardizing judgments of relevance was 
well founded. However, the method of standardizing these judgments may not have been the most appropriate.

In retrospect, a potentially more appropriate and less confusing approach may have been a double report process, whereby the user was first asked to make a categorical judgment, and then asked to attribute a value to that judgment. For example, the interface would present the participant with three radio buttons (not relevant, partially relevant, relevant). The participant would then be asked to select one of the three categories. Once a category had been selected, a slider bar would be presented and the participant would be asked to assign a value to that judgment (between 0 and 100).

This approach would not only provide both semantically standardized categorical data, but the required continuous data needed to calculate probabilities of selecting target labels. In addition, it would provide a method of tracking changes to the participants relative scale over the course of the experiment. For example, in the current research there was an implied assumption that participant's scores were stable across all trials, i.e. that an assigned value of 75 in scenario 1 carried the same semantic value as a score of 75 in scenario 12. If participants refined their judgments or shifted their internal scales during the experiment, the current methodology did not account for this. A double report approach would not only account for this but allow shifts in internal scales to be monitored.

A final benefit of the double report approach would be the additional costs of time and cognitive resources as well as potential test fatigue. This is seen as a benefit as it would more likely approximate the costs to real world searching and perhaps minimize the likelihood of participants selecting 10 to 20 "relevant" menu labels, as was done by a few of the participants. 
Another weakness of the methodology may have been the freedom or lack of constraints on how users were asked to respond. Users were not asked to limit their responses to say the top two or three menu items, or the first label noticed. Users were completely free to rate as many or as few labels as they wished. This was a planned feature of the experimental protocol. Its purpose was to try and replicate lack of real-world constraints or direction when a user interacts with a web site - they can browse as many or as few menu labels as they choose. However, the results suggest that by constraining users responses and providing more direction (e.g. rate the menu labels in the order that you would choose them up to a maximum of three), I may have reduced the error variance for analysis. The error variance seems to have been generated by differences in users' response styles.

As indicated in Table 9, users tended to adopt one of three response styles - weak choice, clear choice and multiple choice. A user adopting a weak choice response style (19.3\% of users) was characterized by a participant who for every scenario tended to rate menu labels as partially relevant, seldom identifying a label as being relevant. Similarly, a user adopting a clear choice response style (32.1\% of users) was characterized by users who typically identified one single menu label as being relevant. There may have been additional labels considered partially relevant, but only one relevant label. Finally, the users adopting a multiple choice response style ( $48.7 \%$ of users) generally found more than one relevant label per scenario. A small number of multiple choice responders would typically identify 10 to 25 relevant menu labels per scenario. It is these extremes in response style that is the suspected source of the error variance.

With respect to the generalizability of the results, the measurement and mapping of information scent is specific to a single information architecture and a set of scenarios, and therefore can not be generalized to all web sites. Therefore, the results of this experiment are 
specific to this IA and the scenarios selected for testing. However, the scenarios were carefully selected to be representative and the use of a single information architecture is sensible for developing new procedures. In fact, some methodological modifications of the experiment using the current architecture would be recommended to see if the independent variables have an impact before generalizing the results to other domains.

What has been shown by this research is that by systematically diagnosing the most agreed upon information scents within an information architecture and then providing multiple scent trails to specific target information results in a large increase in the probability of finding information.

Contributions. Perhaps the real contribution of this research is a practical one - the framework for a methodology to evaluate the usefulness of an information architecture and map its information scent trails.

There may also be one final contribution. This was my first and only experience with conducting an experiment online. The choice of the Internet as a medium for conducting this research was an obvious one given that the effects I was exploring was part of the Internet's ecology. Therefore, the final contribution of this research is to share what went right and what went wrong

I had envisioned and ultimately realized several benefits to conducting research online. There was fast and efficient data capture, ready for uploading into the statistical or spreadsheet packages of my choosing (well almost). There were no geographic boundaries, and perhaps more importantly no time of day or time zone constraints. There was no administrative burden of scheduling participants nor the frustrations of having those same participants not show up. 
The time savings from that aspect alone proved to be immense, and the "chain letter" method of recruiting via e-mail proved to be particularly successful. It was relatively easy to prototype experimental interfaces, test and iterate designs. And finally, I had complete and unvaried control over my manipulations while still remaining blind to the participants.

In its simplest form, the methodological process for this experiment was to recruit participants from a distance and encourage them to go to the web site. Once on the web site, they would be qualified (demographically) and then their access would be controlled (in order to pay them and prevent them from contaminating the dataset).

The first lesson learned revolved around paying participants. In order to pay participants, you would have had to have a way of identifying them. This means capturing personal information which introduces several issues around rights to privacy and ethics. Paying them also means administrative and technical overhead in making sure that they are only paid once, that the right person was paid and that there were no opportunities for abuse (i.e. somebody deciding to go through the experiment several times to earn multiples of $\$ 10.00$ and thereby contaminating the data in the process). It became apparent that the problems all seemed to revolve around money. If we took money out of the equation, we would take away the motivation for abuse and the need for administrative and technical controls. So the decision was taken to not pay participants. The assumption was that, since participants were not being paid, no one would invest the time to go through the entire experiment unless they were genuinely interested in completing it in good faith.

The next lesson learned related to the live monitoring of participant responses. An administrative screen was built which allowed me to monitor a participants progress as they were navigating the experimental web site. On the first day I noticed several participants stopping 
with no further progress. Assuming that they had quit because of lack of interest I deleted their database records to make room for the next randomly assigned participant, and later discovered through discussions with participants that some had in fact returned to the site to complete the experiment. Therefore, while the experiment may have only taken 30 to 60 minutes to complete, in real time for some participants this took as long as 7.5 hours. Therefore, as part of the experiments protocol, a system for allowing interruptions was needed. In the case of this experiment, participant's records were allowed to be inactive for 24 hours before the record was moved to an area of the database we referred to as "the parking lot" — an area of the database that was only accessible to myself and the database developer.

This experience of interrupted sessions lead to another lesson. If a user left their browser window open, returning later to complete the experiment, and I had in fact deleted their record. Their responses were being captured into an new database record with the first half of the scenarios showing missing values. These records were later identified and eliminated. During the data cleaning process.

A final shortcoming of online experimentation is the inability to observe and interact with the participants completing the experiment. Therefore, some potentially rich qualitative information may be lost.

A positive lesson was the original decision to use a database structure for capturing user behaviours. This allowed me to quickly respond to control issues during development and during the experiment (e.g. building the "parking lot"). In addition, when it came time to analyse the data, strategically querying the database for particular types of information was very useful. 
The Usability Practitioner as a Clinician. Hassenzahl (1999) uses a metaphor comparing usability practitioners to clinicians. In the paper he describes how the usability practitioner, like the clinician is cast in a role of diagnosing problems and planning solutions. He makes the point that an improved diagnosis results in better solutions, and therefore as usability practitioners we need to develop methodologies and instruments that generate data which have diagnostic value (in terms of information).

The introduction of this thesis contained research objectives, two of which were to:

a) introduce and evaluate a methodology for mapping an IA's information scent;

b) introduce an approach to evaluating an information architecture's usefulness.

In mapping an information architecture's scent using the methodology outlined in this research a usability practitioner can generate data which has diagnostic value. Specifically, the usability practitioner will be able to identify scent trails that lead both towards and away from target information. The metric used in this research for evaluating the probability of users selecting a target menu label adds to a usability practitioners diagnostic capability. Together the introduction of this methodology and its associated metric achieve those final research objectives.

What remains is to extend this research and test the reliability and validity of these capabilities through further research. 
Appendixes

Appendix A - Experimental Information Architecture - Menu Labels

Italicized headings reflect level-one categories. Below each are the respective level-two categories.

Healthy Living

Alcohol

Healthy Children \& Adolescents

Healthy Eating

Healthy Pregnancy \& Babies

Safe Environments \& Injury Preventions

Sexual and Reproductive Health

Substance Use \& Abuse

Tobacco

Travel Health

Violence \& Abuse

Population Health

Population Health Approach

Determinants of Health

Health of Canadians

Population Groups 
Emergencies \& Disasters

Bio \& Lab Safety

Chemical, Biological, Radiological, Nuclear \& Explosive (CBRNE) Events

Electronic Information Sharing \& IT Security

Emergency Planning, Training \& Exercises

Global Health Security Initiatives

Medical Intelligence \& Counter-Terrorism

Natural Disasters

Diseases \& Conditions

Arthritis

Asthma

Cancer

Depression

Diabetes

Heart \& Stroke

Hepatitis

HIV \& AIDS

Sexually Transmitted Diseases (STDs) 
Food \& Nutrition

Food Inspection

Food Safety

Genetically Modified Foods \& Other Novel Foods

Nutrition

Environmental \& Workplace Health

Air Quality

Climate Change \& Health

Environmental Contaminants

Noise

Occupational Health \& Safety

Pest Control \& Management

Radiation

Soil Quality

Water Quality 
Consumer Products

Children's Products

Household Products

Personal Products

Recreational and Sports Products

Health Care System

Canada's Health Care System (Medicare)

eHealth

Health Human Resources

Home and Community Care

Hospital Care

Long Term Care

Palliative / End-of-Life Care

Pharmaceuticals

Primary Health Care 
Science \& Research
About Science and Research
Investing in Science \& Research
Speaking of Science

Drugs \& Health Products

Adverse Reaction Information

Biologics \& Genetic Therapies

Biotechnology

Complementary \& Alternative Medicine

Compliance \& Enforcement

Cosmetic Products

Drug Products

Drug Resistance

Immunization \& Vaccines

Medical Devices

Natural Health Products

Veterinary Drugs 


\section{Appendix B-Balanced Latin Square}

A row represents the order of scenario presentation for a single participant. For example, the participant receiving the second row order was presented first with scenario two, then three, then 1 , then 4 , etc.

Given that there are 30 participants for each experimental condition, and 10 scenarios, the order of scenario presentation was repeated three times for each experimental condition

\begin{tabular}{|c|c|c|c|c|c|c|c|c|c|c|}
\hline Participant & \multicolumn{10}{|c|}{ Scenario Presentation Sequence } \\
\hline 1 & 1 & 2 & 10 & 3 & 9 & 4 & 8 & 5 & 7 & 6 \\
\hline 2 & 2 & 3 & 1 & 4 & 10 & 5 & 9 & 6 & 8 & 7 \\
\hline 3 & 3 & 4 & 2 & 5 & 1 & 6 & 10 & 7 & 9 & 8 \\
\hline 4 & 4 & 5 & 3 & 6 & 2 & 7 & 1 & 8 & 10 & 9 \\
\hline 5 & 5 & 6 & 4 & 7 & 3 & 8 & 2 & 9 & 1 & 10 \\
\hline 6 & 6 & 7 & 5 & 8 & 4 & 9 & 3 & 10 & 2 & 1 \\
\hline 7 & 7 & 8 & 6 & 9 & 5 & 10 & 4 & 1 & 3 & 2 \\
\hline 8 & 8 & 9 & 7 & 10 & 6 & 1 & 5 & 2 & 4 & 3 \\
\hline 9 & 9 & 10 & 8 & 1 & 7 & 2 & 6 & 3 & 5 & 4 \\
\hline 10 & 10 & 1 & g & 2 & 8 & 3 & 7 & 4 & 6 & 5 \\
\hline 11 & 1 & 2 & 10 & 3 & 9 & 4 & 8 & 5 & 7 & 6 \\
\hline 12 & 2 & 3 & 1 & 4 & 10 & 5 & 9 & 6 & 8 & 7 \\
\hline 13 & 3 & 4 & 2 & 5 & 1 & 6 & 10 & 7 & 9 & 8 \\
\hline 14 & 4 & 5 & 3 & 6 & 2 & 7 & 1 & 8 & 10 & 9 \\
\hline 15 & 5 & 6 & 4 & 7 & 3 & 8 & 2 & 9 & 1 & 10 \\
\hline 16 & 6 & 7 & 5 & 8 & 4 & 9 & 3 & 10 & 2 & 1 \\
\hline 17 & 7 & 8 & 6 & 9 & 5 & 10 & 4 & 1 & 3 & 2 \\
\hline 18 & 8 & 9 & 7 & 10 & 6 & 1 & 5 & 2 & 4 & 3 \\
\hline 19 & 9 & 10 & 8 & 1 & 7 & 2 & 6 & 3 & 5 & 4 \\
\hline 20 & 10 & 1 & 9 & 2 & 8 & 3 & 7 & 4 & 6 & 5 \\
\hline 21 & 1 & 2 & 10 & 3 & 9 & 4 & 8 & 5 & 7 & 6 \\
\hline 22 & 2 & 3 & 1 & 4 & 10 & 5 & 9 & 6 & 8 & 7 \\
\hline 23 & 3 & 4 & 2 & 5 & 1 & 6 & 10 & 7 & 9 & 8 \\
\hline 24 & 4 & 5 & 3 & 6 & 2 & 7 & 1 & 8 & 10 & 9 \\
\hline 25 & 5 & 6 & 4 & 7 & 3 & 8 & 2 & 9 & 1 & 10 \\
\hline 26 & 6 & 7 & 5 & 8 & 4 & 9 & 3 & 10 & 2 & 1 \\
\hline 27 & 7 & 8 & 6 & 9 & 5 & 10 & 4 & 1 & 3 & 2 \\
\hline 28 & 8 & 9 & 7 & 10 & 6 & 1 & 5 & 2 & 4 & 3 \\
\hline 29 & 9 & 10 & 8 & 1 & 7 & 2 & 6 & 3 & 5 & 4 \\
\hline 30 & 10 & 1 & 9 & 2 & 8 & 3 & 7 & 4 & 6 & 5 \\
\hline
\end{tabular}

Note: $\mathrm{N}=30$ and Scenarios $=10$ 
Appendix C-Participant Profile

Table 11

Proportion of Age Groups having University Education

\begin{tabular}{lccccc}
\hline & \multicolumn{5}{c}{ University Education } \\
& \multicolumn{5}{c}{ (\% of each Age Group) } \\
\cline { 2 - 6 } & $20-24$ & $25-34$ & $35-44$ & $45-54$ & $55-64$ \\
\hline Canada & $13.4 \%$ & $27.6 \%$ & $21.9 \%$ & $22.1 \%$ & $20.3 \%$ \\
\hline National Capital Region & $18.1 \%$ & $40.5 \%$ & $33.8 \%$ & $33.6 \%$ & $31.8 \%$ \\
\hline Sample Participants & $42.9 \%$ & $72.22 \%$ & $56.7 \%$ & $50.0 \%$ & $40.0 \%$ \\
\hline Note. Percentages were calculated using Statistics Canada's 2001 Census data.
\end{tabular}

Table 12

Distributions of Population and Internet Users within the NCR

\begin{tabular}{lccccc}
\hline & \multicolumn{5}{c}{ Age Group } \\
\cline { 2 - 6 } & $20-24$ & $25-34$ & $35-44$ & $45-54$ & $55-64$ \\
\hline Expected number of & 19 & 32 & 37 & 26 & 6 \\
Participants (N=120) & & & & & \\
\hline Actual number of & 7 & 36 & 30 & 30 & 10 \\
Participants (N=113) & & & & &
\end{tabular}

Note. Actual number of participants $(\mathrm{N}=113)$ does not include 4 participants who chose not to provide their age group, and 3 participants whose age was in the $65-74$ category. 


\section{Appendix D-Researcher's E-mail Recruiting Script}

Hello:

I'm writing because I'm doing research for a Masters thesis at Carleton University. The web site to run the experiment is now developed. So now I'm asking everyone I know for two favours....

1) Would you consider being a participant? It will take about 30 minutes, but the good news is all you have to do is access the Internet from wherever you like, at whatever time of the day you like. The web address is www.menutest.com and the site explains and guides you along everything you have to do. Essentially, you are going to be asked to read 12 scenarios ( 3 to 6 lines each) and judge the relevance of the menu labels to each of the scenarios. It is totally anonymous and voluntary. If you are going to do this I would need you to complete it within the next couple of days.

Requirements: Can only be done with Internet Explorer v. 5.0 or higher

2) The second favour I need to ask, is if you could spread the word to anyone (friends, family, business or school associates) who might be willing to take half an hour to complete this experiment for me. I need 120 participants to complete this by the middle of next week. Any recruiting help you could give me would help greatly.

IMPORTANT: If anyone you recruit is not a Canadian resident, they will need a Canadian postal code at the end of the experiment. Please ask them to use J9H 2E3

\section{Thanks a bunch.}

Mark Game

PS If you or anyone you recruit has any comments afterwards, l'd love to hear them, just send them to me at markgame@menutest. 
Appendix E - Topic Validation Survey Showing Unclear Items

\section{TOPIC VALIDATION SURVEY}

This survey is trying to better understand the types of Health Information needs people are likely to have in the FUTURE, and those they have had in the PAST. We would also like to know if any of the Health information topics listed below are UNCLEAR or not well understood.

The health information need could be for you, a friend or family member, or perhaps part of a professional or educational project.

For each topic listed below, please indicate

1. How likely you are to need information in the FUTURE

2. If you have ever needed information on this topic in the PAST

3. If this topic is NOT CLEAR

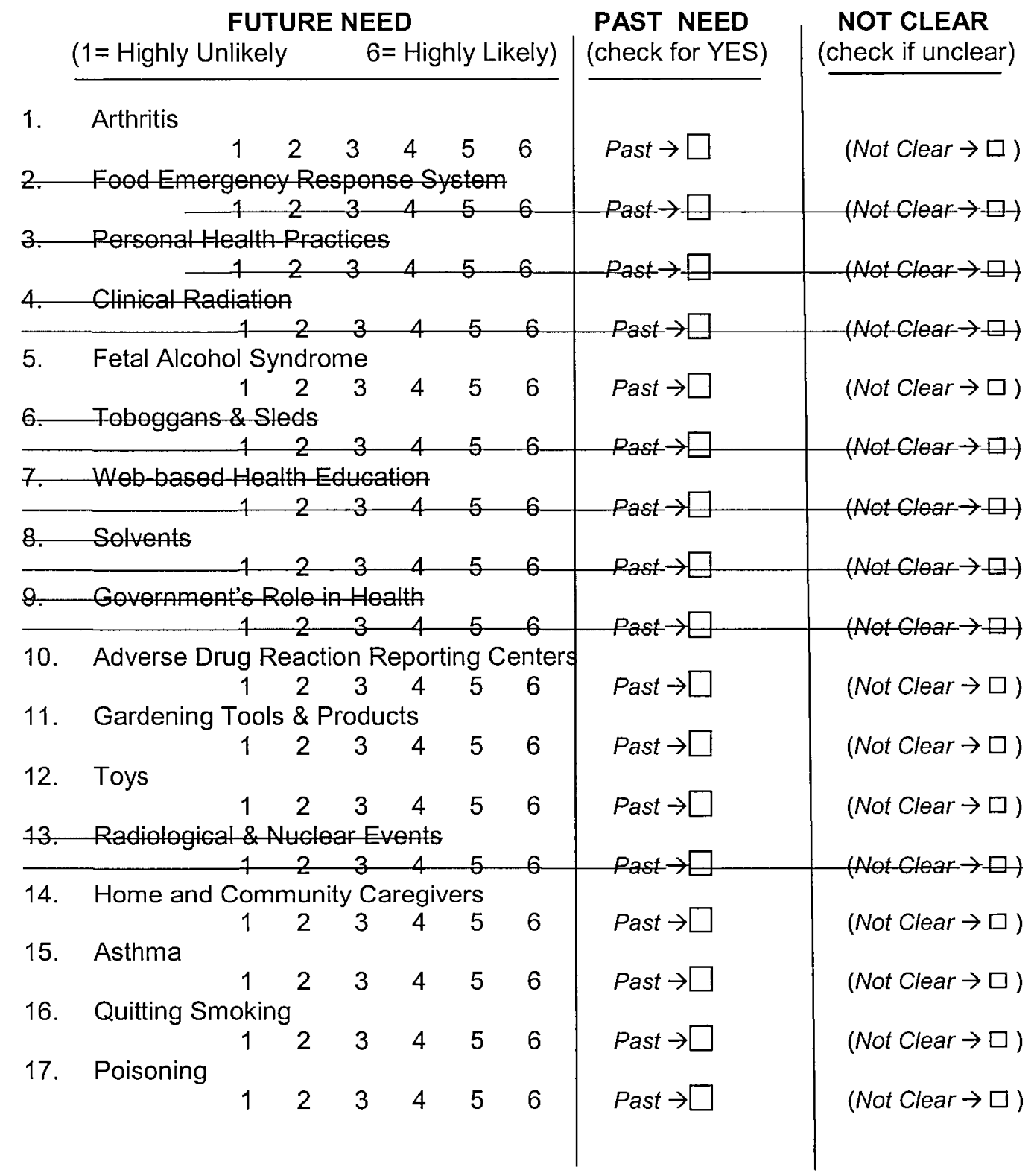




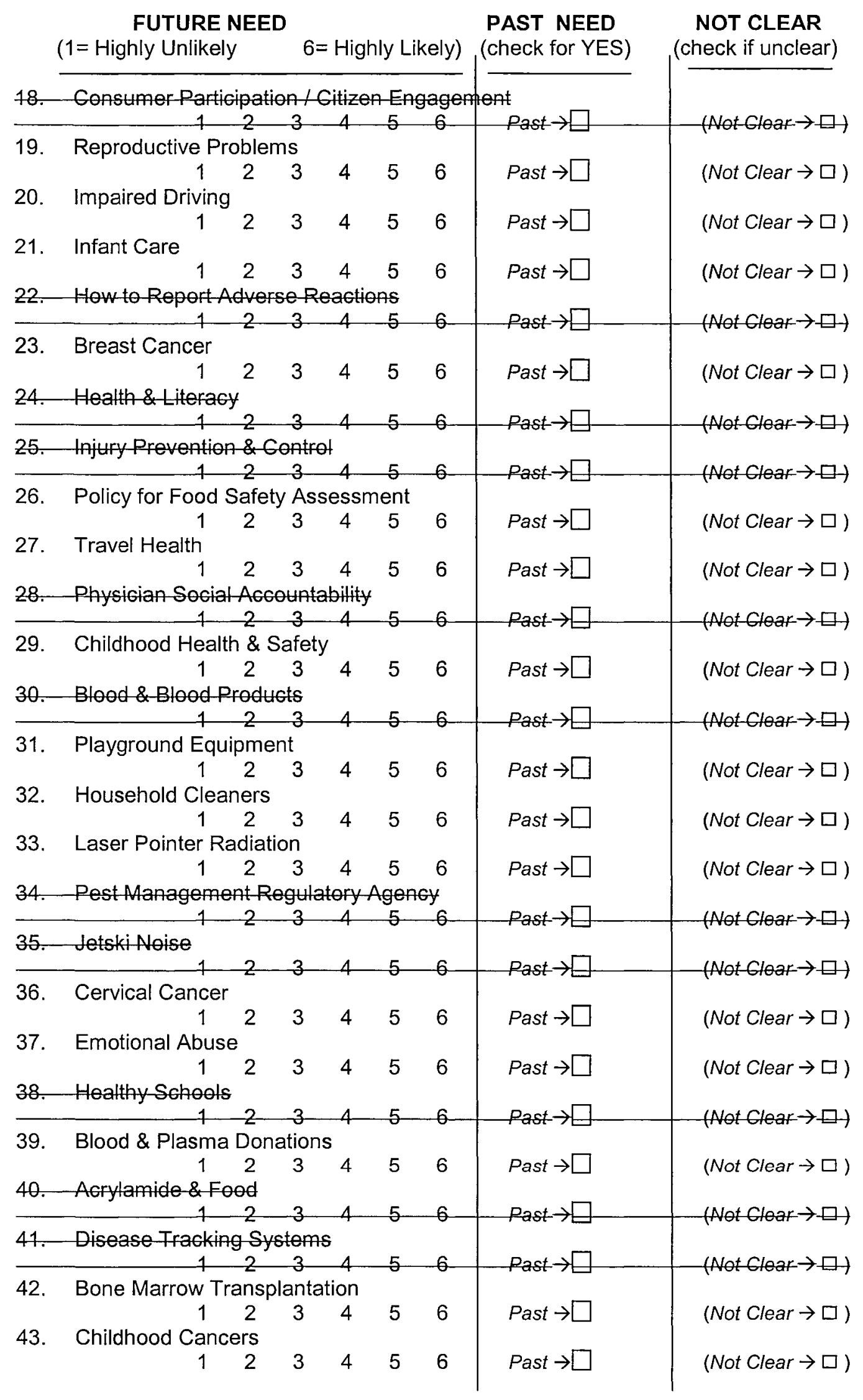




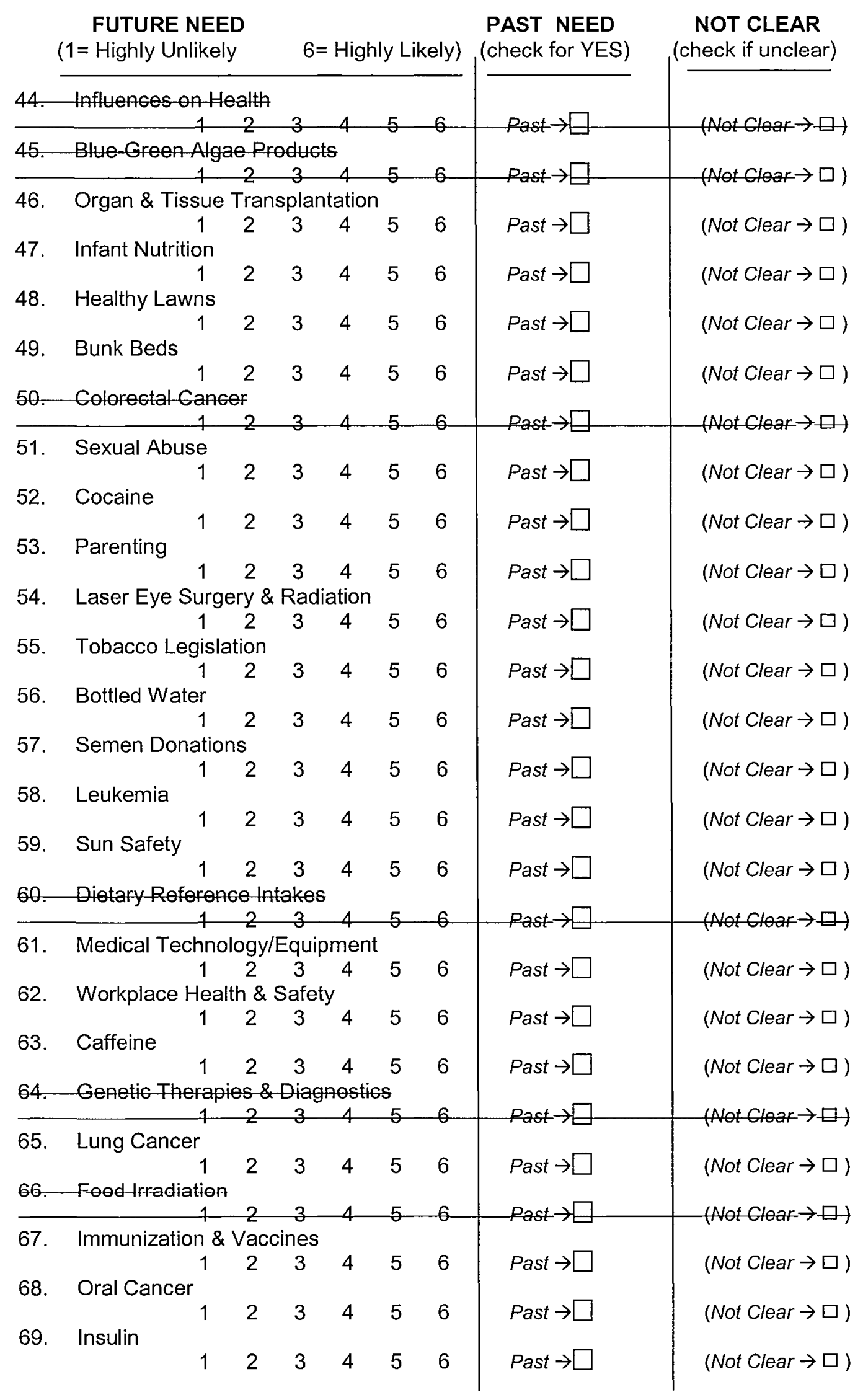




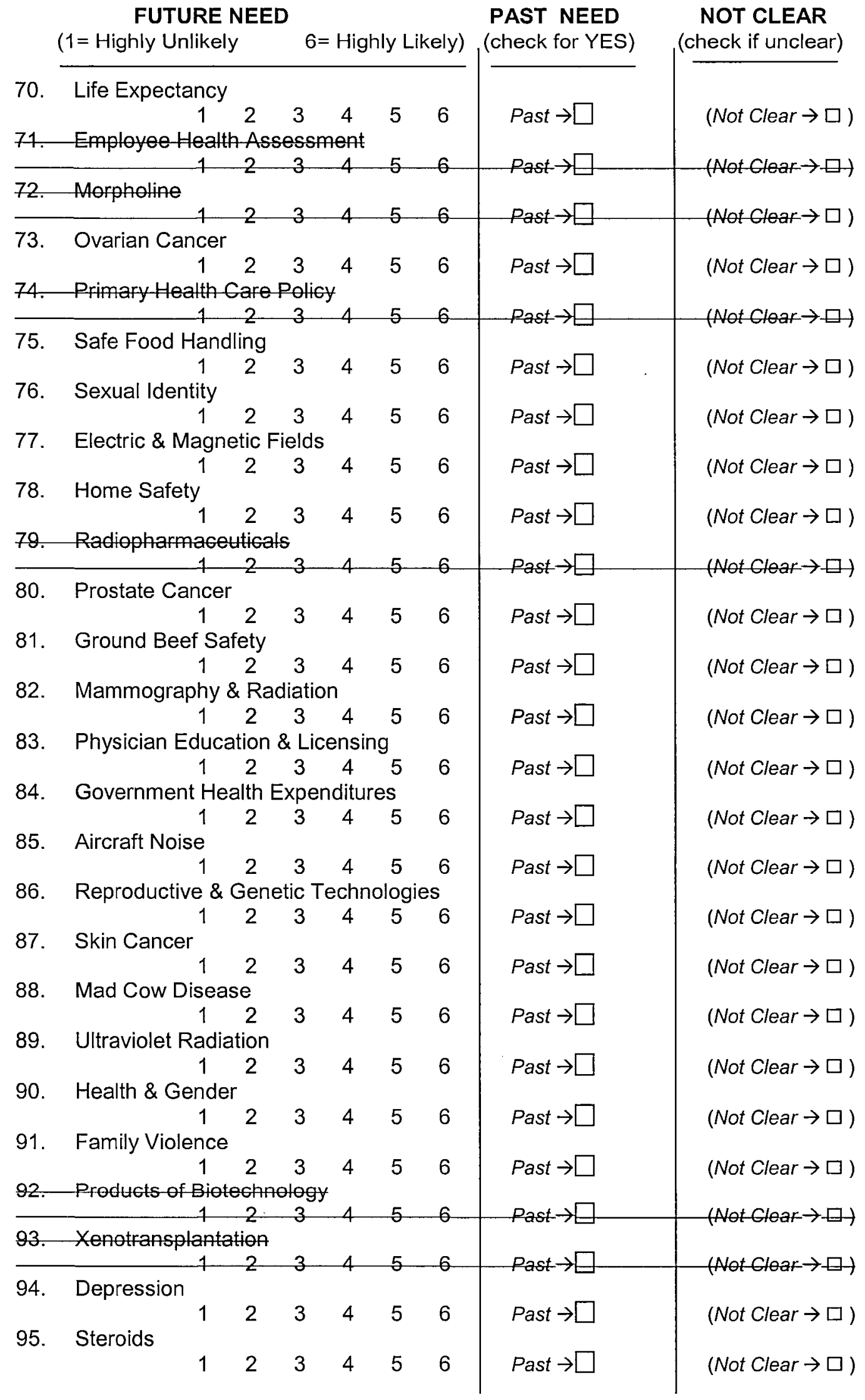




\section{FUTURE NEED}

(1 = Highly Unlikely
6= Highly Likely) (check for YES)
PAST NEED

NOT CLEAR

(check if unclear)

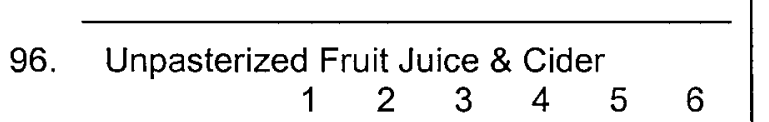

97. Pesticides

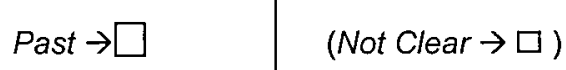

Past $\rightarrow \square \quad$ (Not Clear $\rightarrow \square)$

98. Patient Safety

99. Aboriginal Medicine

100. Ganadian Diabetes Strategy

101. Health by Population Group

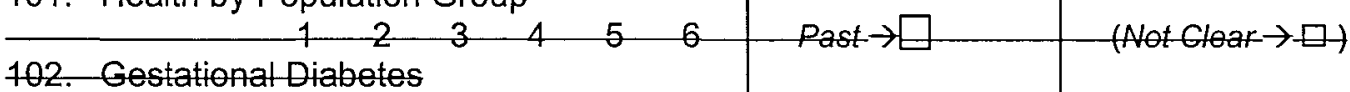

103. PGBs $\quad \begin{array}{llllll}1 & 2 & 3 & 4 & 5 & 6\end{array}$

104. Birth Control

$\begin{array}{llllll}1 & 2 & 3 & 4 & 5 & 6\end{array}$

105. Genetically Modified Foods

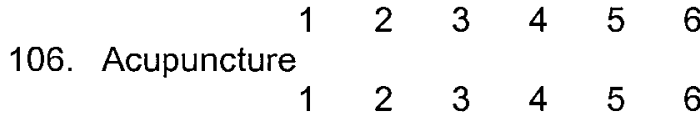

107. Type 1 Diabetes

$\begin{array}{lllllll} & 1 & 2 & 3 & 4 & 5 & 6\end{array}$

108. Electronic Health Records

$\begin{array}{llllll}1 & 2 & 3 & 4 & 5 & 6\end{array}$

109. Management of Hazardous Substances

$$
\begin{array}{llllll}
1 & 2 & 3 & 4 & 5 & 6
\end{array}
$$

110. Novel Foods \& Ingredients

111. Chiropractic Therapy

$\begin{array}{rllllll} & 1 & 2 & 3 & 4 & 5 & 6\end{array}$

112. Type 2 Diabetes

$\begin{array}{cccccc}1 & 2 & 3 & 4 & 5 & 6 \\ \text { 113. Explosive Events } & & & & & \\ 1 & 2 & 3 & 4 & 5 & 6\end{array}$

114. X-Rays

115. Lead

$\begin{array}{llllll}1 & 2 & 3 & 4 & 5 & 6\end{array}$

\begin{tabular}{l|l} 
Past $\rightarrow \square$ & $\quad($ Not Glear $\rightarrow \square)$ \\
Past $\rightarrow \square$ & (Not Clear $\rightarrow \square)$
\end{tabular}

\begin{tabular}{l|l} 
Past $\rightarrow \square$ & (Not Clear $\rightarrow \square)$ \\
Past $\rightarrow \square$ & (Not Clear $\rightarrow \square)$
\end{tabular}

Past $\rightarrow \square$ (NotGlear $\rightarrow$ 口)

\begin{tabular}{l|l} 
Past $\rightarrow \square$ & (Not Clear $\rightarrow \square$ )
\end{tabular}

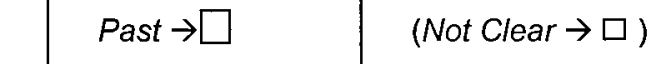

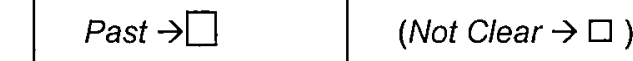

Past $\rightarrow \square \quad($ Not Clear $\rightarrow \square)$

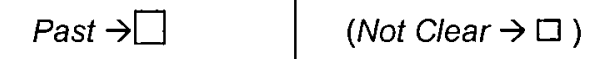

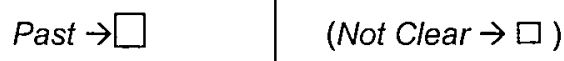

Past $\rightarrow \square \quad($ Not Clear $\rightarrow \square)$

\begin{tabular}{l|l} 
Past $\rightarrow \square$ & (Not-Gloar $\rightarrow \square$ )
\end{tabular}

Past $\rightarrow \square \quad($ Not Clear $\rightarrow \square)$

Past $\rightarrow \square \quad($ Not Clear $\rightarrow \square)$

$\begin{array}{llllll}1 & 2 & 3 & 4 & 5 & 6\end{array}$

116. An Historic View of Science \& Research

117. Cribs

$\begin{array}{llllll}1 & 2 & 3 & 4 & 5 & 6\end{array}$

$\begin{array}{lllllll}1 & 2 & 3 & 4 & 5 & 6\end{array}$

118. Maternal Health

$\begin{array}{llllll}1 & 2 & 3 & 4 & 5 & 6\end{array}$

119. Regulation of Food Biotechnology

120. Blood Pressure (Hypertension)

121. Vitamins \& Minerals

$$
\begin{array}{llllll}
1 & 2 & 3 & 4 & 5 & 6
\end{array}
$$

$\begin{array}{llllll}1 & 2 & 3 & 4 & 5 & 6\end{array}$

Past $\rightarrow \square$

Past $\rightarrow \square$

Past $\rightarrow \square$

Past $\rightarrow \square$

Past $\rightarrow$

Past $\rightarrow \square$
(Not Glear $\rightarrow$ 마)

$($ Not Clear $\rightarrow \square)$

(Not-Glear $\rightarrow$ 마)

$($ Not Clear $\rightarrow \square)$

$($ Not Clear $\rightarrow \square)$

$($ Not Clear $\rightarrow \square)$

(Notelear $\rightarrow$ 마)

$($ Not Clear $\rightarrow \square)$

(Not Clear $\rightarrow \square$ ) 
FUTURE NEED

(1= Highly Unlikely $\quad 6=$ Highly Likely)

122. Microwave Oven Radiation

123. Resouces-on Quality in Health

124. Dioxins \& Furans

125. Ear Gandling

126. Cardiovascular Disease

$\begin{array}{lllllll}1 & 2 & 3 & 4 & 5 & 6\end{array}$

127. Marijuana

128. Chlorinated Disinfection By-Products

129. Food Guide to Healthy Eating

$\begin{array}{lllllll} & 2 & 3 & 4 & 5 & 6\end{array}$

130. Massage Therapy

$\begin{array}{llllll}1 & 2 & 3 & 4 & 5 & 6\end{array}$

131. Swimming Pools $\begin{array}{cccccc}1 & 2 & 3 & 4 & 5 & 6\end{array}$

132. Fire Safety

133. Drug Benefit Programs

$\begin{array}{llllll}1 & 2 & 3 & 4 & 5 & 6\end{array}$

134. Commercial Chemicals

$\begin{array}{llllll}1 & 2 & 3 & 4 & 5 & 6\end{array}$

135. Sexual Health Promotion

$$
\begin{array}{llllll}
1 & 2 & 3 & 4 & 5 & 6
\end{array}
$$

136. Heart Disease \& Stroke

$\begin{array}{cccccc}1 & 2 & 3 & 4 & 5 & 6 \\ \text { 137. Canadian Nutrient File } & & & & \\ 1 & 2 & 3 & 4 & 5 & 6\end{array}$

138. Breast Implants

$\begin{array}{llllll}1 & 2 & 3 & 4 & 5 & 6\end{array}$

$\begin{array}{lllllll}1 & 2 & 3 & 4 & 5 & 6\end{array}$

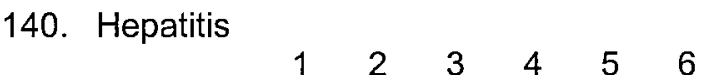

141. Newborn Care

$\begin{array}{llllll}1 & 2 & 3 & 4 & 5 & 6\end{array}$

142. Nursing Advisory Committee

143. Garage Sales $\begin{array}{rrrrrr}1 & 2 & 3 & 4 & 5 & 6\end{array}$

$\begin{array}{rrrrrr}1 & 2 & 3 & 4 & 5 & 6\end{array}$

144. Dietary Reference Intakes

145. BOTOX

146. Outdoor $\begin{array}{lllllll}1 & 2 & 3 & 4 & 5 & 6\end{array}$

PAST NEED NOT CLEAR

(check for YES)

(check if unclear)

$($ Not Clear $\rightarrow \square)$

(Not Clear $\rightarrow$ Q

(Notgloar $\rightarrow$ 曰日)

(NotCloar $\rightarrow \square$ )

(Not Clear $\rightarrow \square$ )

$($ Not Clear $\rightarrow \square)$

(Not Cloar $\rightarrow$ 口)

$($ Not Clear $\rightarrow \square)$

(Not Clear $\rightarrow \square$ )

$($ Not Clear $\rightarrow \square$ )

$($ Not Clear $\rightarrow \square$ )

$($ Not Clear $\rightarrow \square$ )

(Not Clear $\rightarrow \square$ )

$($ Not Clear $\rightarrow \square$ )

(Not Clear $\rightarrow \square$ )

(NotGlear $\rightarrow$ 마)

$($ Not Clear $\rightarrow \square)$

$($ Not Clear $\rightarrow \square$ )

$($ Not Clear $\rightarrow \square$ )

$($ Not Clear $\rightarrow \square$ )

$($ Not Clear $\rightarrow \square)$

$($ Not Clear $\rightarrow \square)$

(Not Glear $\rightarrow \square$ )

(Not Clear $\rightarrow \square$ )

Past $\rightarrow \square$

$($ Not Clear $\rightarrow \square$ )

(Not Cloax $\rightarrow \square$ ) 
FUTURE NEED

(1= Highly Unlikely $6=$ Highly Likely)

148. HIV \& AIDS

149. $\begin{array}{rlllll}1 & 2 & 3 & 4 & 5 & 6\end{array}$

149. Food \& Nutrition $\begin{array}{cccccc}1 & 2 & 3 & 4 & 5 & 6\end{array}$

150. Drug Product Database

151. $\begin{array}{llllll}1 & 2 & 3 & 4 & 5 & 6\end{array}$

152. Air Pollutants \& Smog

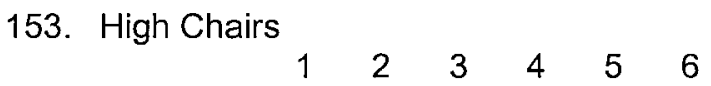

154. Ghancroid $\begin{array}{lllllll}1 & 2 & 3 & 4 & 5 & 6 \\ 1 & 2 & 3 & 4 & 5 & 6\end{array}$

155. Cosmetics

$\begin{array}{llllll}1 & 2 & 3 & 4 & 5 & 6\end{array}$

$\begin{array}{llllll}1 & 2 & 3 & 4 & 5 & 6\end{array}$

157. Cellular Phone Radiation

158. Drug Submission Performance-Reports

159. Climate Change \& Health

$\begin{array}{rrrrrr}1 & 2 & 3 & 4 & 5 & 6 \\ \text { 160. Sudden Infant Death Syndrome } & \text { (SIDS) } \\ 1 & 2 & 3 & 4 & 5 & 6\end{array}$

161. Chlamydia $\begin{array}{llllll}1 & 2 & 3 & 4 & 5 & 6\end{array}$

162. TeleHealth

163. Healthy Weights

164. Second-Hand Smoke

$\begin{array}{lllllll} & 1 & 2 & 3 & 4 & 5 & 6\end{array}$

165. Soil Contamination

$\begin{array}{llllll}166 \text { - Drug-Export-Gertificate-Fees } & \\ \text { 167. Radon } & 1 & 2 & 3 & 4 & 5 \\ & 1 & 2 & 3 & 4 & 5\end{array}$

168. Genital Warts

169. Danger Symbols $2 \quad 3 \quad 4$

$\begin{array}{lllll}- & 2 & 3 & -4 & 5\end{array}$

170. Nutrient-Content-Claims

171. Physical Activity

172. Drug Legislation $\&$ Guidelines

173. Indoor Air $\begin{array}{lllllll} & 1 & 2 & 3 & 4 & 5 & 6\end{array}$
PAST NEED

NOT CLEAR

(check for YES)

(check if unclear)

$($ Not Clear $\rightarrow \square)$

(Not Clear $\rightarrow \square$ )

$($ Not Clear $\rightarrow \square)$

$($ Not Clear $\rightarrow \square)$

(Not Clear $\rightarrow \square$ )

$($ Not Clear $\rightarrow \square)$

(Not Cloar $\rightarrow$ 마)

$($ Not Clear $\rightarrow \square$ )

$($ Not Clear $\rightarrow \square$ )

(Not Clear $\rightarrow \square$ )

Past $\rightarrow$

(NotClear $\rightarrow \square$ )

$($ Not Clear $\rightarrow \square$ )

Past $\rightarrow \square$

$($ Not Clear $\rightarrow \square$ )

Past $\rightarrow$

(Not Clear $\rightarrow \square$ )

(Not-Clear $\rightarrow \square$ )

(Not Clear $\rightarrow$ ㅁ)

(Not Clear $\rightarrow \square$ )

Past $\rightarrow \square$

$($ Not Clear $\rightarrow \square)$

Past $\rightarrow$

(Not Clear $\rightarrow$ ㅁ)

past $\rightarrow$

Past $\rightarrow$

(Not-Cloar $\rightarrow \square$ )

$($ Not Clear $\rightarrow \square)$

Past $\rightarrow \square$

(Not Clear $\rightarrow$ ㅁ)

$($ Not Clear $\rightarrow \square$ )

Past $\rightarrow$

Past $\rightarrow \square$

$($ Not Clear $\rightarrow \square$ )

Past $\rightarrow \square$

(Not Clear $\rightarrow \square$ )

Past $\rightarrow \square$

(Not Clear $\rightarrow \square$ ) 


\section{FUTURE NEED}

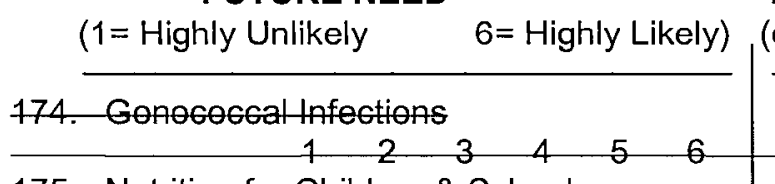

175. Nutrition for Children \& Schools 176. Gollaborative-Gare

177. Antibiotic Resistance $\begin{array}{llllll}1 & 2 & 3 & 4 & 5 & 6\end{array}$

178. Adverse Veterinary Drug Reactions

\section{Gonorrhea}

$\begin{array}{llllll}1 & 2 & 3 & 4 & 5 & 6\end{array}$

$\begin{array}{lllll}1 & 2 & 3 & 4 & 5\end{array}$

180. Nutrition for Pregnancy

$\begin{array}{lllllll} & 1 & 2 & 3 & 4 & 5 & 6\end{array}$

181. Flu Shots

182. Heroin

183. Vitamin \& Mineral Supplements

184. Herpes

$$
\begin{array}{llllll}
1 & 2 & 3 & 4 & 5 & 6
\end{array}
$$

$\begin{array}{lllllll}1 & 2 & 3 & 4 & 5 & 6\end{array}$

185. Nutrition Labelling

$\begin{array}{lllllll} & 2 & 2 & 3 & 4 & 5 & 6\end{array}$

186. Computer Monitors

$\begin{array}{cccccc}1 & 2 & 3 & 4 & 5 & 6 \\ \text { 187. Human Papillema virus } & & & \\ 1 & 2 & 3 & 4 & 5 & 6\end{array}$

188. Nutrition Research \& Policy Reports

$\begin{array}{lllllll}1 & 2 & 3 & 4 & 5 & 6\end{array}$

189. Physical Abuse

190. $\begin{array}{llllll} & 2 & 3 & 4 & 5 & 6\end{array}$

190. Infant \& Child Vaccines $\begin{array}{llllll}1 & 2 & 3 & 4 & 5 & 6\end{array}$

191. Primary Health Gare Transition Fund

192. Leaf Blower Noise

193. Farm Safety

$$
\begin{array}{lllllll} 
& 1 & 2 & 3 & 4 & 5 & 6
\end{array}
$$

184. Nutraceuticals \& Functional Foods

195. Syphilis

$\begin{array}{cccccc}1 & 2 & 3 & 4 & 5 & 6 \\ 1 & 2 & 3 & 4 & 5 & 6\end{array}$

197. Population Health History

198. Research on Healthy Eating

199. Bicycles

$\begin{array}{llllll}1 & 2 & 3 & 4 & 5 & 6 \\ 1 & 2 & 3 & 4 & 5 & 6\end{array}$

PAST NEED

NOT CLEAR

(check for YES)

(check if unclear)

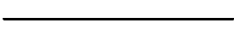

Past $\rightarrow$

Past $\rightarrow \square$

$($ Not Clear $\rightarrow \square$ )

(Not Clear $\rightarrow \square$ )

$($ Not Clear $\rightarrow \square$ )

Past $\rightarrow \square$

(Not Clear $\rightarrow \square$ )

Past $\rightarrow \square$

$($ Not Clear $\rightarrow \square$ )

Past $\rightarrow \square$

(Not Clear $\rightarrow \square$ )

Past $\rightarrow \square$

(Not Clear $\rightarrow \square$ )

Past $\rightarrow \square$

(Not Clear $\rightarrow \square$ )

Past $\rightarrow \square$

$($ Not Clear $\rightarrow \square$ )

Past $\rightarrow \square$

(Not Clear $\rightarrow \square$ )

Past $\rightarrow \square$

$($ Not Clear $\rightarrow \square)$

Past $\rightarrow \square$

$($ Not Clear $\rightarrow \square$ )

Past $\rightarrow \square$

$($ Not-Clear $\rightarrow \square)$

Past $\rightarrow$

Past $\rightarrow \square$

(Not Clear $\rightarrow \square$ )

Past $\rightarrow \square$

(Not Clear $\rightarrow \square$ )

Past $\rightarrow \square$

$($ Not Clear $\rightarrow \square$ )

Past $\rightarrow$

(Not-Glear $\rightarrow$ 므)

(Not-Glear $\rightarrow \square$ )

Past $\rightarrow \square$

Past $\rightarrow \square$

(Not Clear $\rightarrow \square$ )

(NotGlear $\rightarrow \square$ )

Past $\rightarrow$

Past $\rightarrow \square$

$($ Not Clear $\rightarrow \square$ )

Past $\rightarrow \square$

$($ Not Clear $\rightarrow \square$ )

Past $\rightarrow \square$

(Not Clear $\rightarrow \square$ )

Past $\rightarrow \square$

$($ Not Clear $\rightarrow \square$ )

Past $\rightarrow \square$

(Not Clear $\rightarrow \square$ ) 


\section{FUTURE NEED}

(1 = Highly Unlikely
PAST NEED

$6=$ Highly Likely) (check for YES)

\section{NOT CLEAR}

(check if unclear)

200. International Travel Immunizations

201. $\begin{array}{llllll}1 & 2 & 3 & 4 & 5 & 6\end{array}$

(check for

$\begin{array}{rrrrrr}1 & 2 & 3 & 4 & 5 & 6\end{array}$

202. Palliative/End-of-Life Care

Past $\rightarrow \square$

$($ Not Clear $\rightarrow \square)$

Past $\rightarrow \square$

$($ Not Clear $\rightarrow \square$ )

Past $\rightarrow \square$

(Not Clear $\rightarrow \square$ )

Past $\rightarrow$

$($ Not Clear $\rightarrow \square)$

204. Prenatal Nutrition

205. Health Gare AscessAWaiting Times

206. West Nile Virus

207. Pacifiers

$\begin{array}{llllll}1 & 2 & 3 & 4 & 5 & 6 \\ 1 & 2 & 3 & 4 & 5 & 6\end{array}$

208. Bacterial \& Viral Vaccines

$\begin{array}{lllllll} & 1 & 2 & 3 & 4 & 5 & 6\end{array}$

209. Vitality

210. Health \& Age

$\begin{array}{rllllll} & 1 & 2 & 3 & 4 & 5 & 6\end{array}$

211. Quitting Drugs

$\begin{array}{llll}1 & 2 & 3 & 4 \\ 212 . \text { Biologieat Events } & & & \\ 1 & 2 & 3 & 4 \\ \text { 213. Homeopathic Preparations } & 1 & 2 & 3\end{array}$

214. Arts \& Craft Materials

$\begin{array}{lllllll} & & 2 & 3 & 4 & 5 & 6\end{array}$

215. Investing in Science \& Research

216. In-Line Skates

$\begin{array}{cccccc}1 & 2 & 3 & 4 & 5 & 6\end{array}$

217. Folic Acid

$\begin{array}{llllll}1 & 2 & 3 & 4 & 5 & 6\end{array}$

$\begin{array}{rllllll}1 & 2 & 3 & 4 & 5 & 6\end{array}$

Past $\rightarrow \square$

$($ Not Clear $\rightarrow \square$ )

(Not Cloar $\rightarrow$ ㅁ)

$($ Not Clear $\rightarrow \square)$

Past $\rightarrow \square$

(Not Clear $\rightarrow \square$ )

$($ Not Clear $\rightarrow \square)$

(Not Glear $\rightarrow \square$ )

Past $\rightarrow$

$($ Not Clear $\rightarrow \square)$

Past $\rightarrow$

$($ Not Clear $\rightarrow \square)$

Past $\rightarrow \square$

(Not Clear $\rightarrow \square$ )

(Not Clear $\rightarrow$ 口)

$($ Not Clear $\rightarrow \square)$

Past $\rightarrow \square$

$($ Not Clear $\rightarrow \square)$

Past $\rightarrow \square$

$($ Not Clear $\rightarrow \square)$

Past $\rightarrow \square$

$($ Not Clear $\rightarrow \square)$

Past $\rightarrow \square$

$($ Not Clear $\rightarrow \square)$

In order that we can compare health information needs to different groups of individuals, it would be appreciated if you would complete the following information. None of this information identifies you personally, it cannot be cross-referenced to you directly. Only those directly involved with this research experiment will have access to these questionnaires.

Please check $(\checkmark)$ the descriptions that best apply....

1. Your Gender: $\square$ Male $\square$ Female

2. Your Postal Code: 
3. Your age group:<smiles>[Z10][R6]1CCC1</smiles>

$\square 25-34$

$\square 35-44$

45-54

$55-64$

4. What is your level of education?

(Highest Earned Diploma, Degree or Certificate)

Less than a High School Graduation Diploma

High School Graduation Diploma

Post High School Diploma or Certificate:

1 or 2-year program

More than 2-years

Professional or Trade Certification or Training:

1 or 2-year program

More than 2-years

University Education:

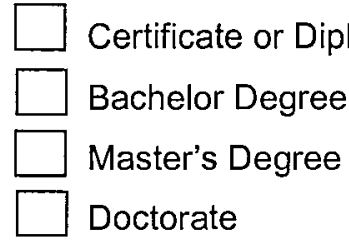

5. What language are you most comfortable reading?

(If you are equally comfortable in more than one language check bot and specify)

$\square$ English

$\square$ Other (please specify)

6. What is your annual family income?

$\square$ \$0 - \$19,999 $\square \$ 20,000$ - \$39,999 $\square \$ 40,000$ - $\$ 74,999 \square \$ 75,000+$

7. How many hours per week do spend searching for information in a Web environment?

(Note: Web environment includes Intranets and Corporate sites)

$\square$ less than $2 \mathrm{hrs} / \mathrm{wk} \quad \square$ up to $7 \mathrm{hrs} / \mathrm{wk} \quad \square$ up to $14 \mathrm{hrs} / \mathrm{wk}$
$\square$ up to $28 \mathrm{hrs} / \mathrm{wk}$
$\square$ never


Appendix F- Experimental Site - Home Page

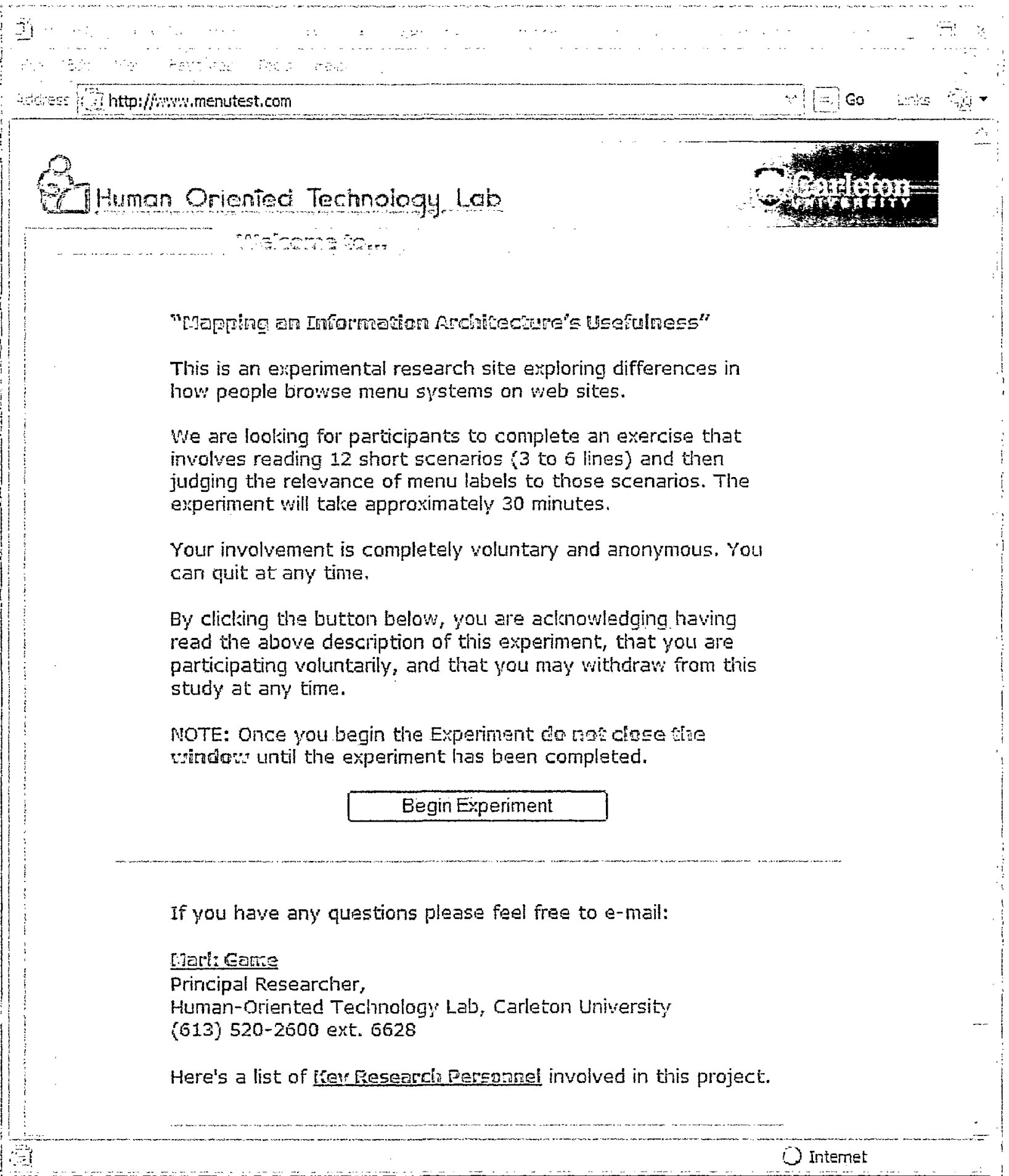


Appendix G-Orientation Pages - Steps 1, 2 and 3

Step 1 - Practicing using the slider bar:

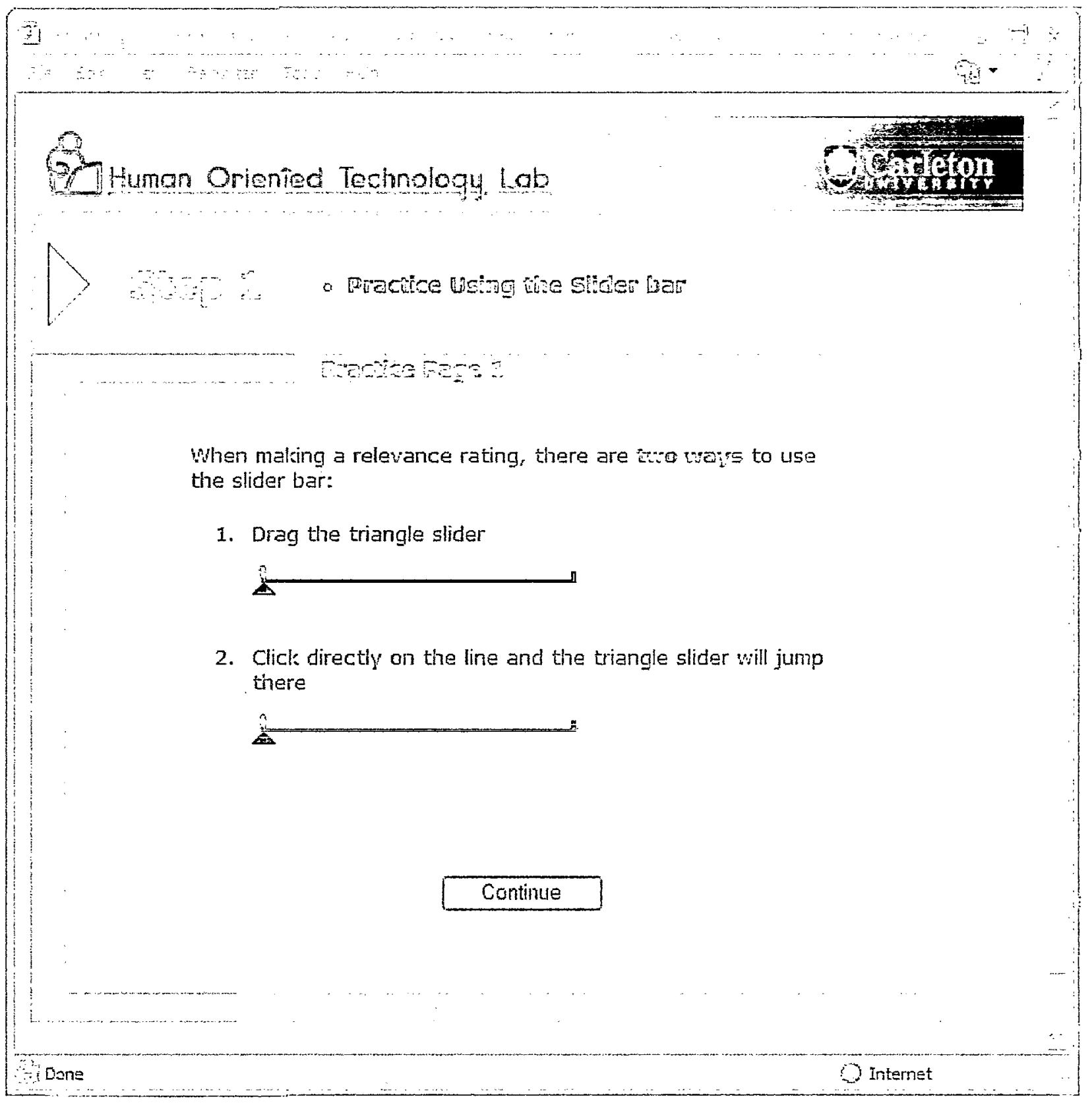


Step 2 - Practice Opening \& Closing Menu Labels

Closed Menu Iabels

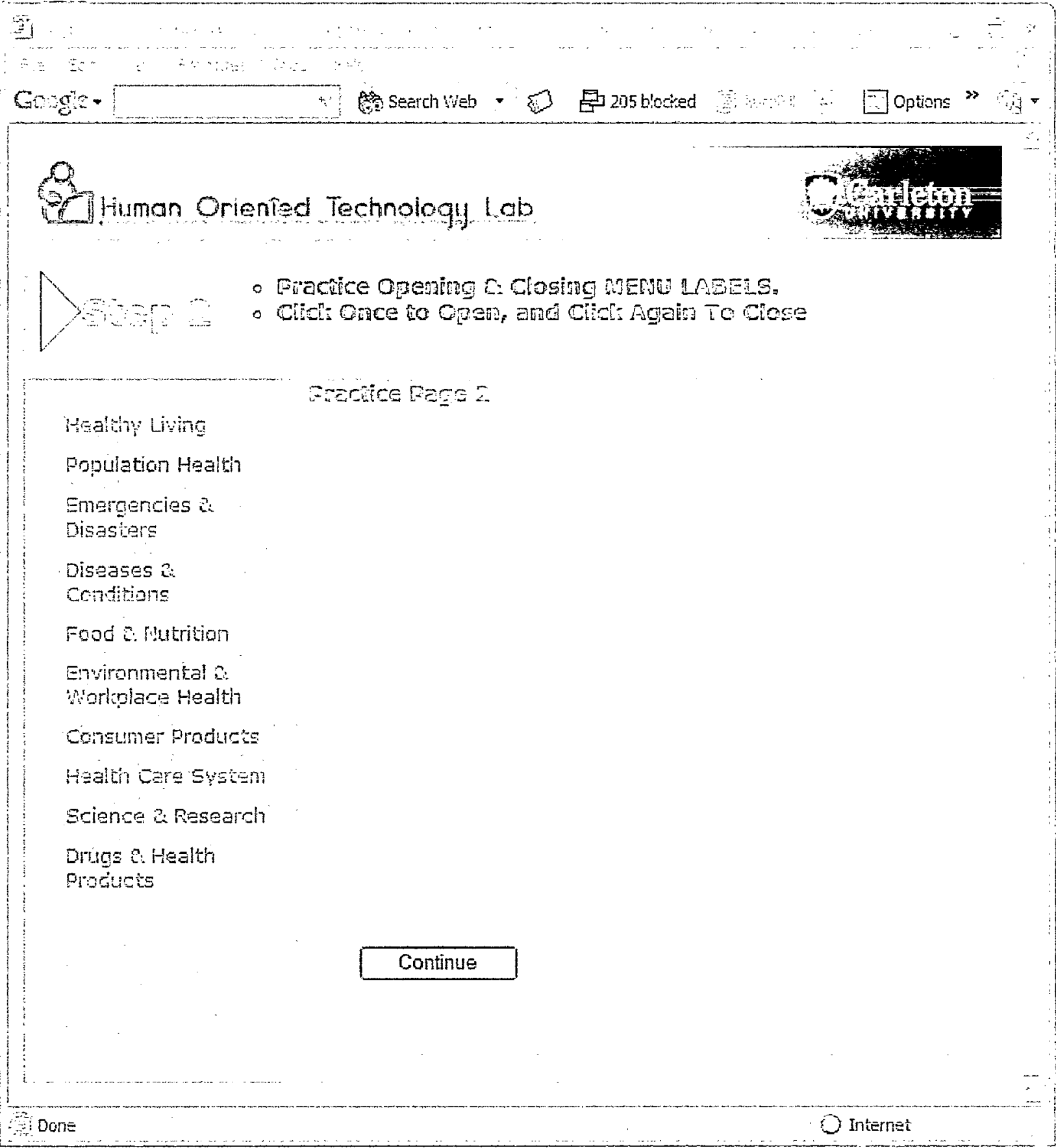


Step 2 - Practice Opening \& Closing Menu Labels

An Open Menu Label with Relevance Ratings

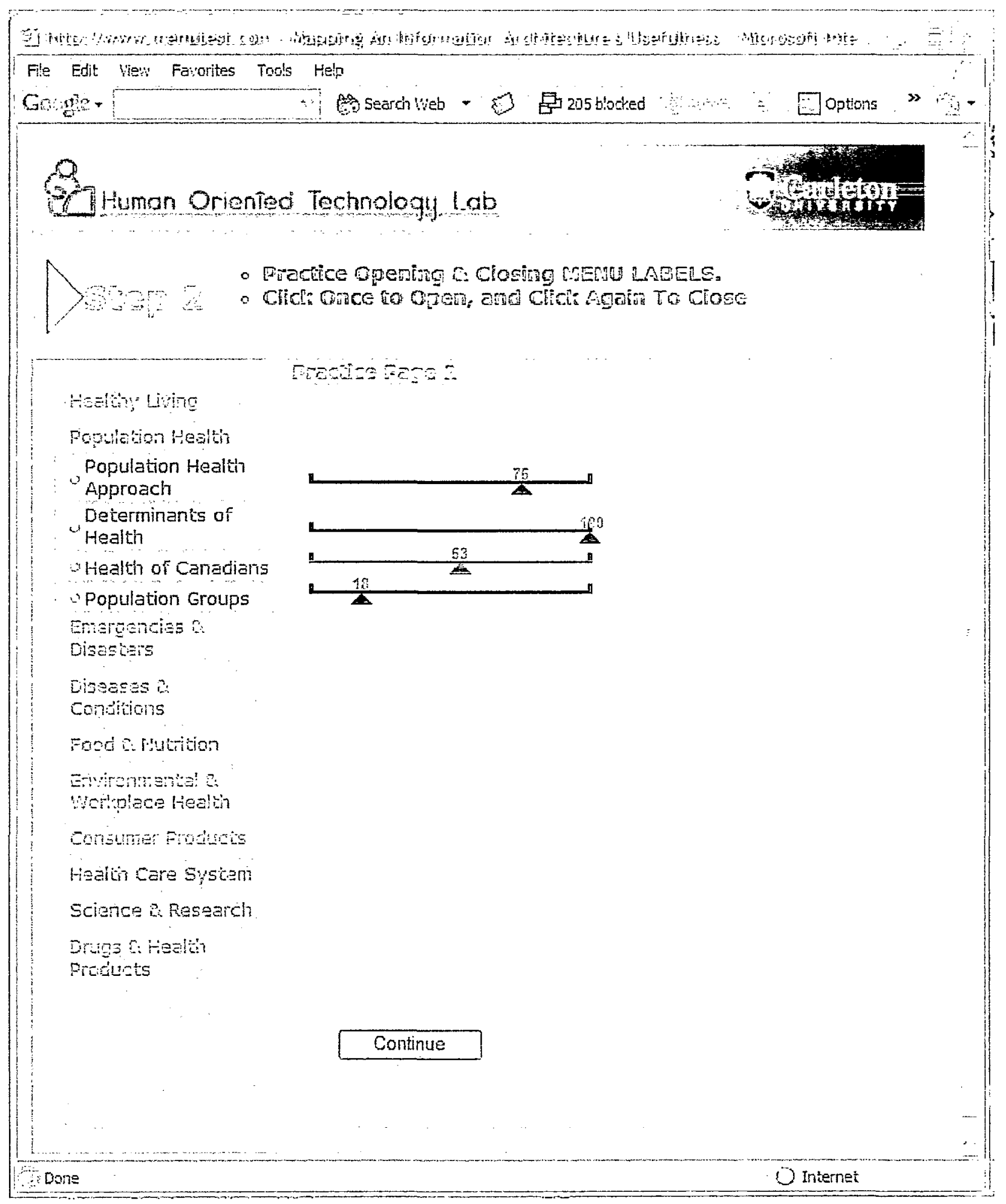


Step 3 - Reading YOUR Role

Seeker's Role and Instructions

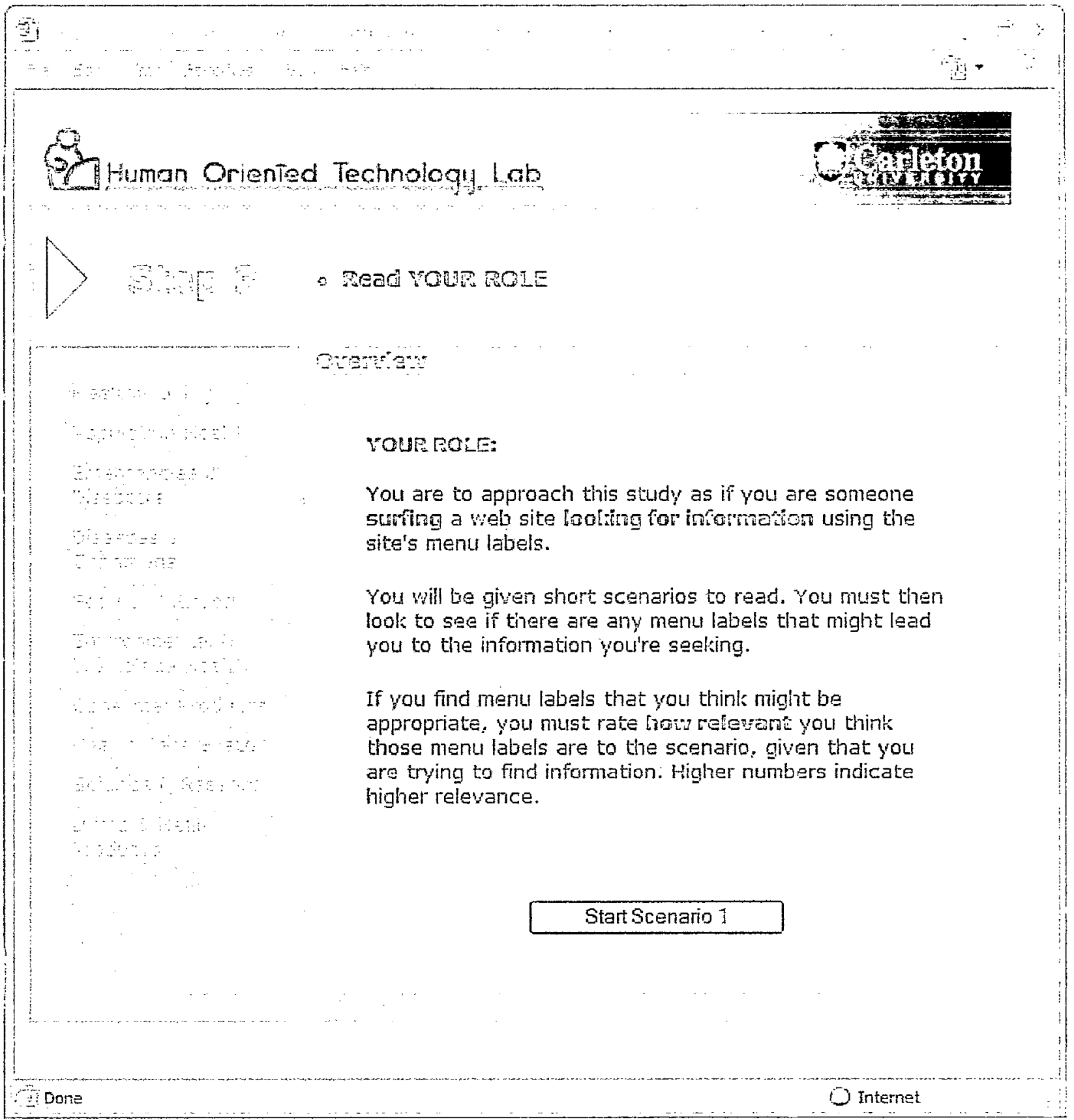


Step 3 - Reading YOUR Role

Developer's Role and Instructions

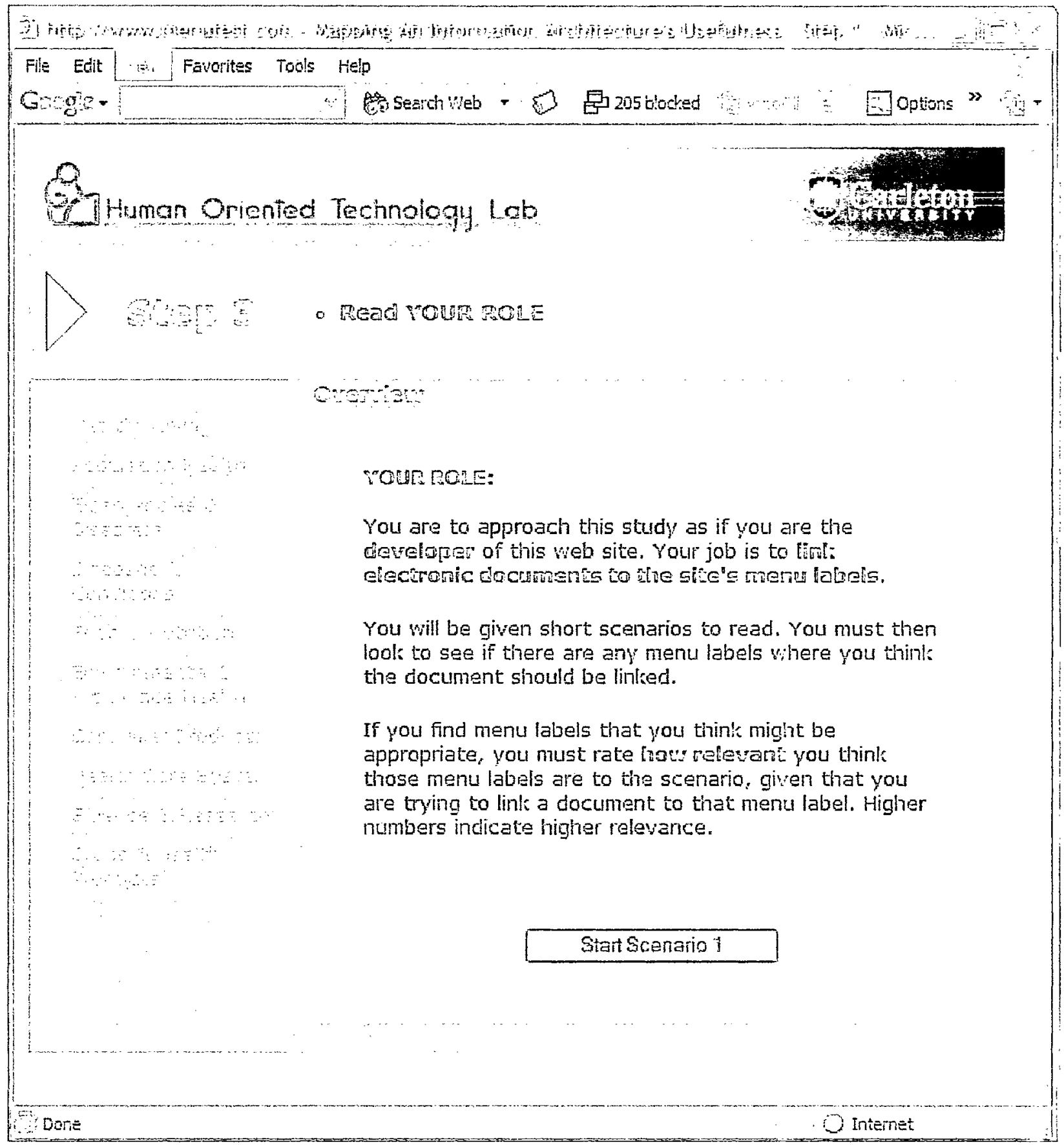


Appendix H-Practice Scenario 1 -All Four Experimental Conditions

Seeking Topical Information

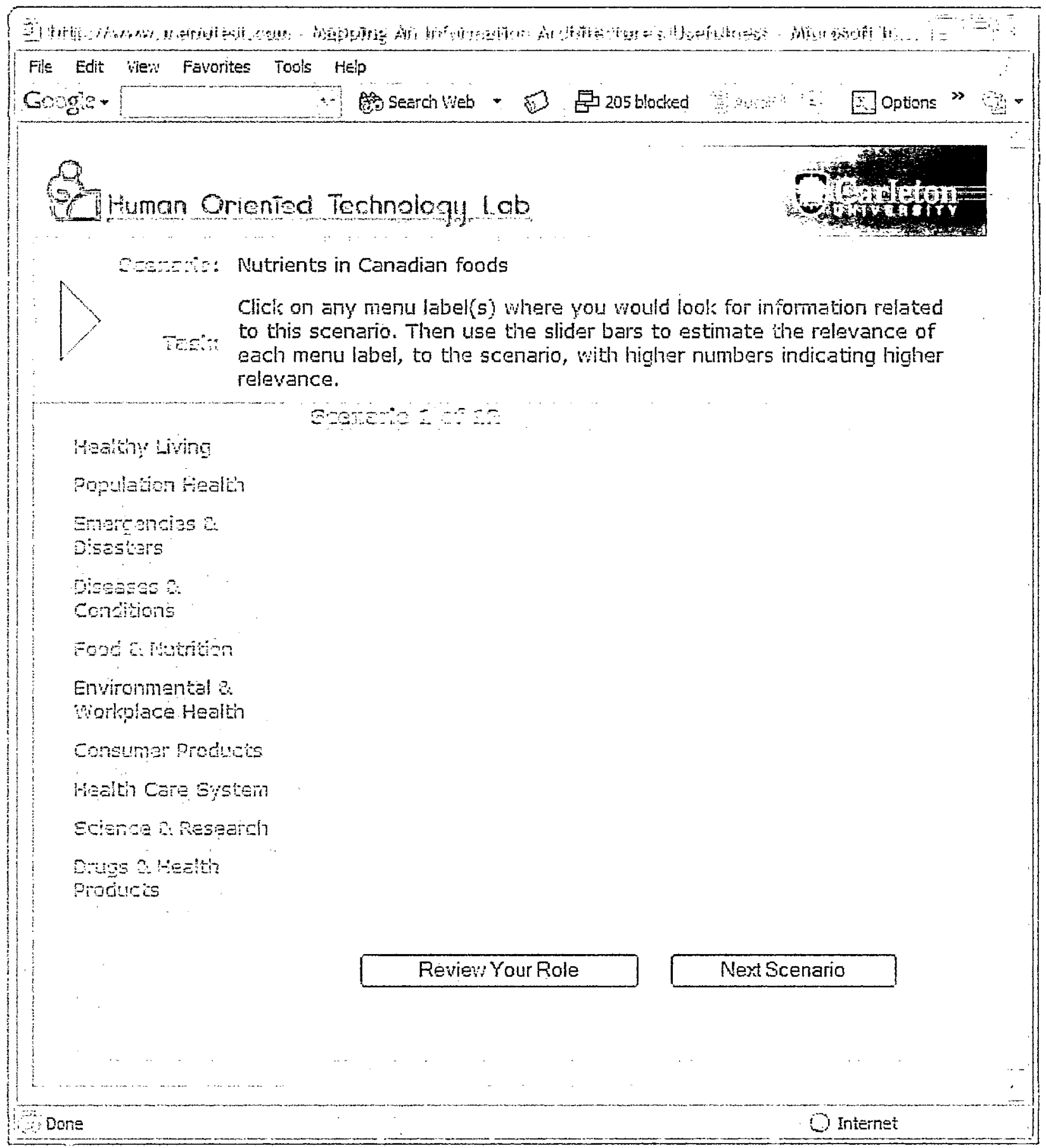


Classify Topical Information.

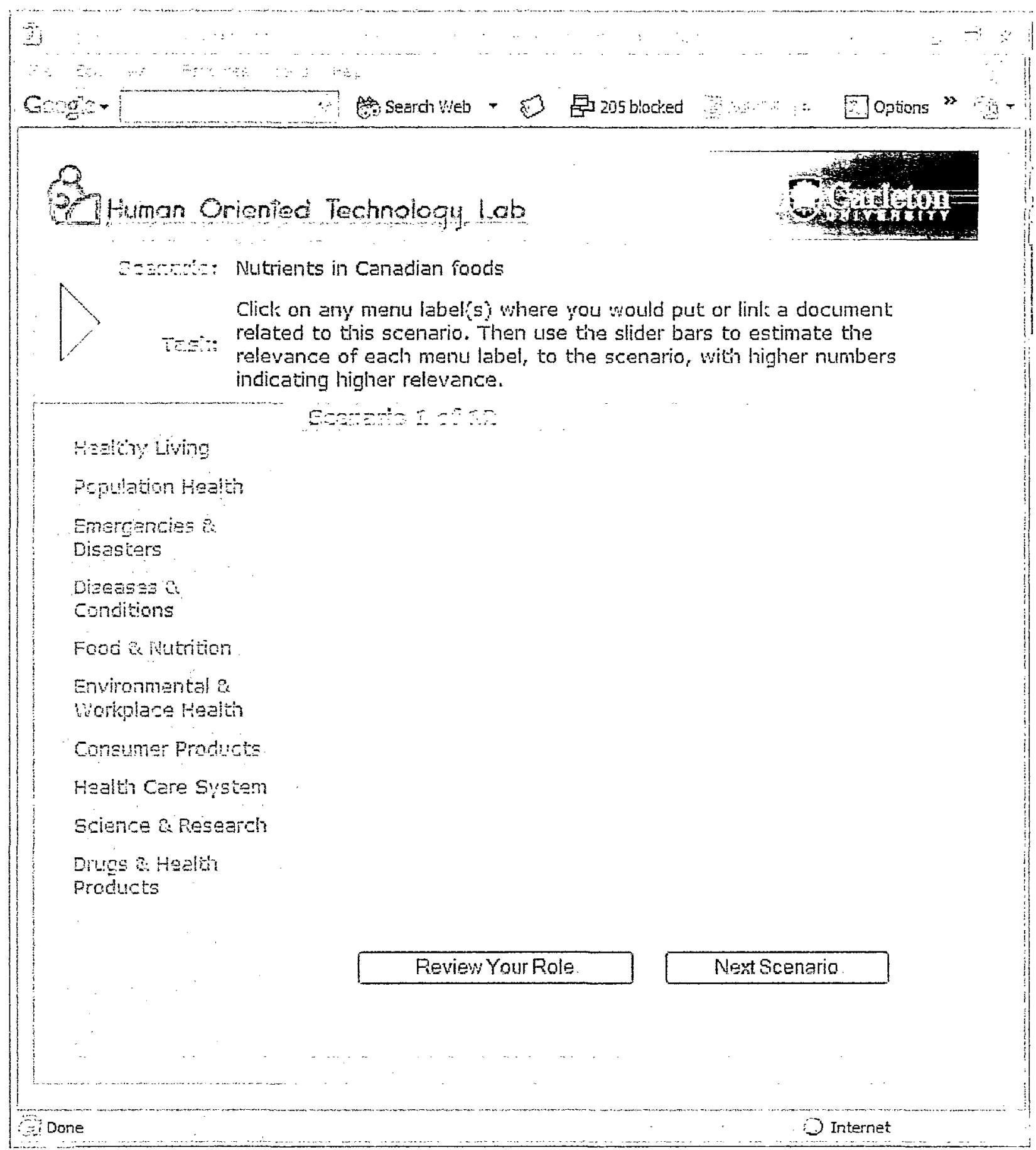




\section{Seelcing Situational Information.}

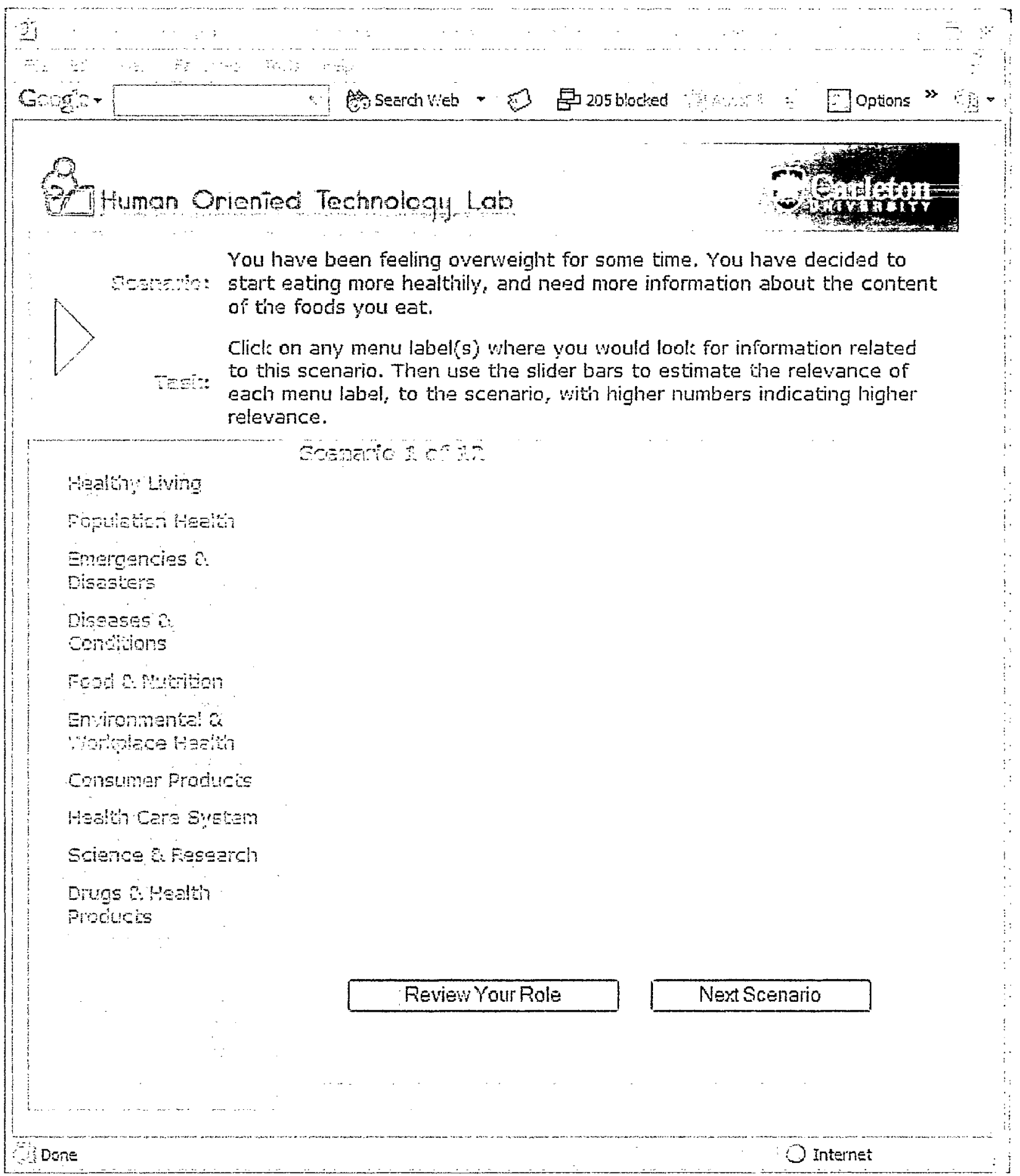


Classifying Situational Information

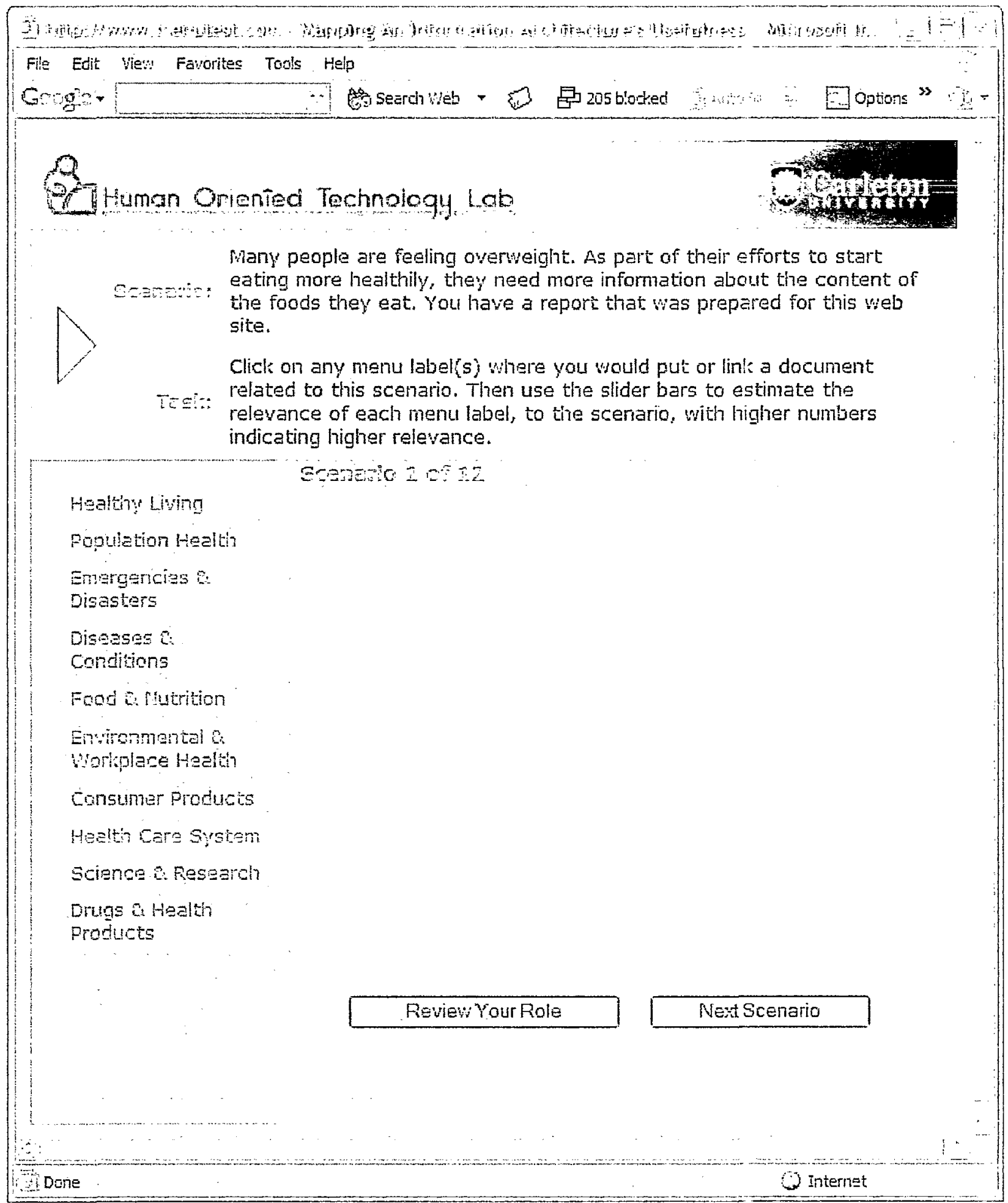


Sample Browsing Page-(Classify Topical Information)

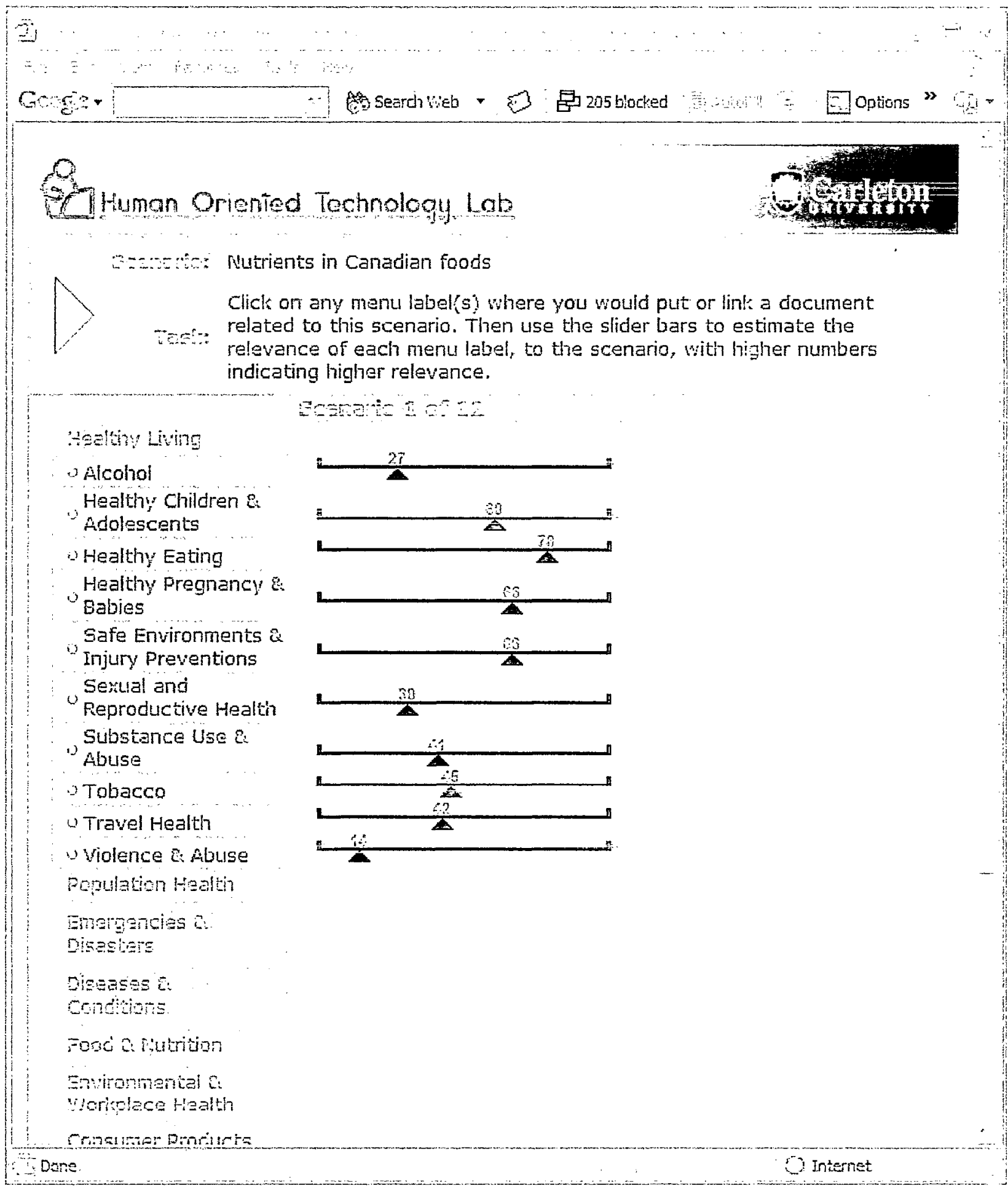


Appendix I - Final Question Page

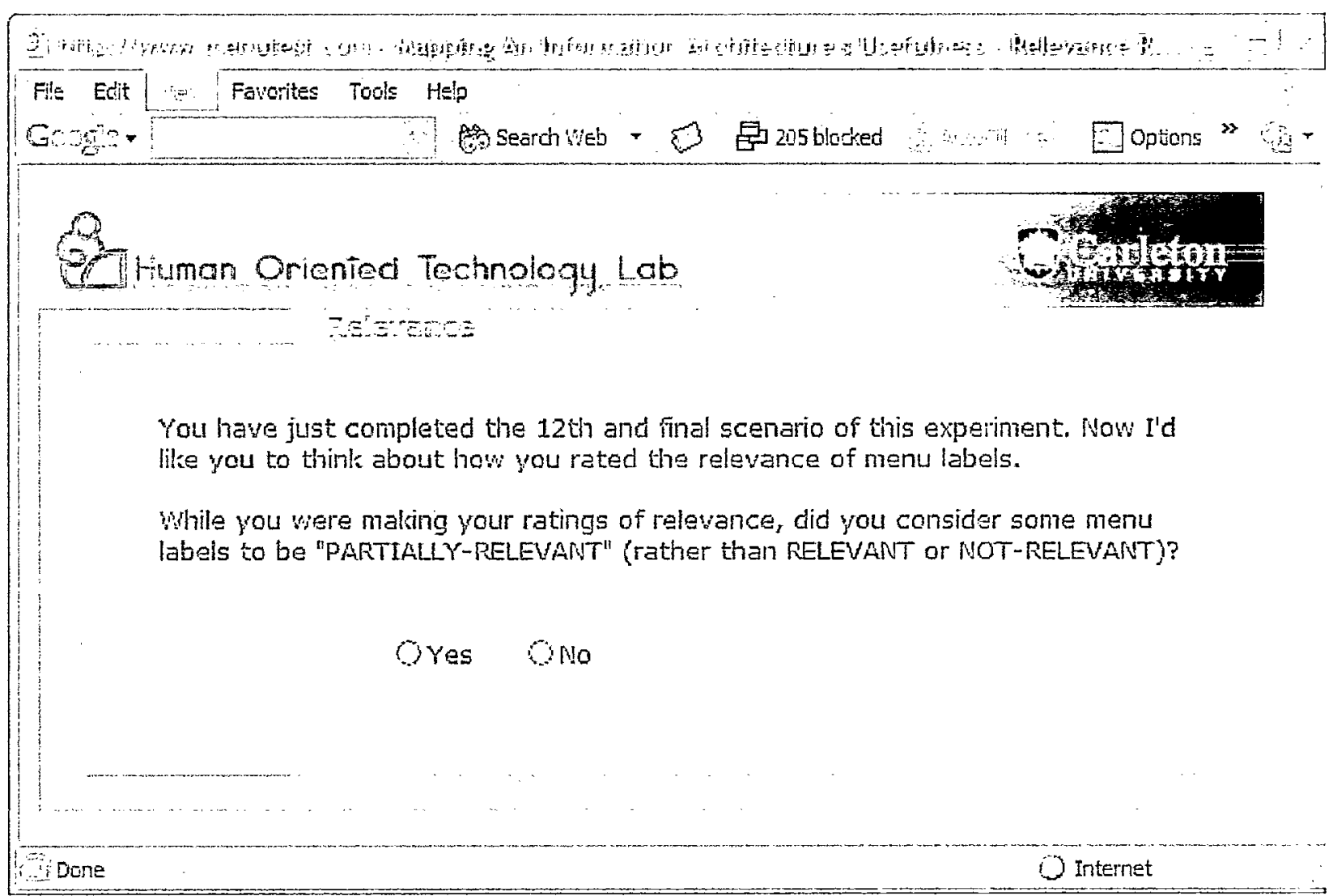


If question about Partial-Relevance was answered "NO" ......

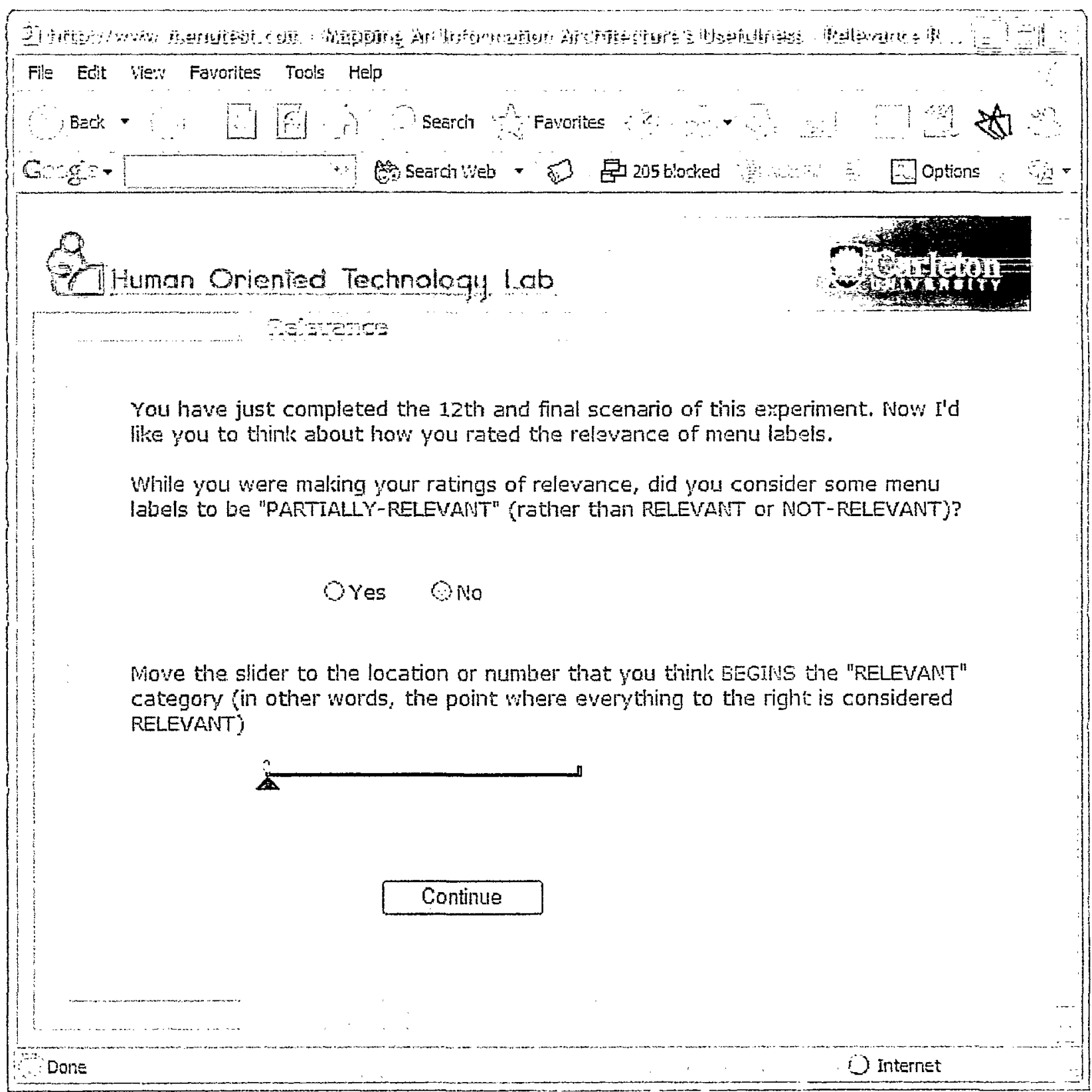


If question about Partial-Relevance was answered "YES".....

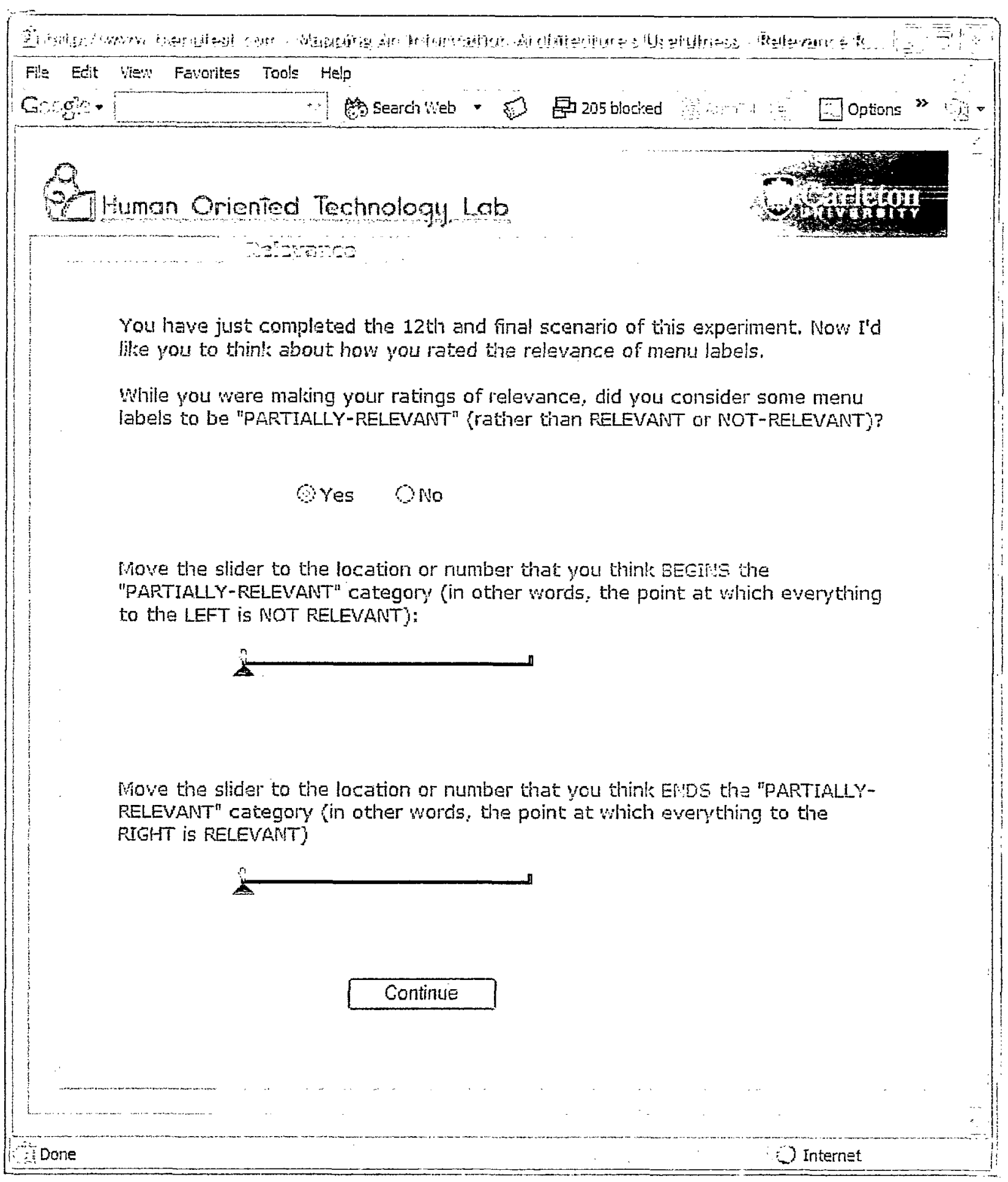


Appendix J-User Infomation Screen

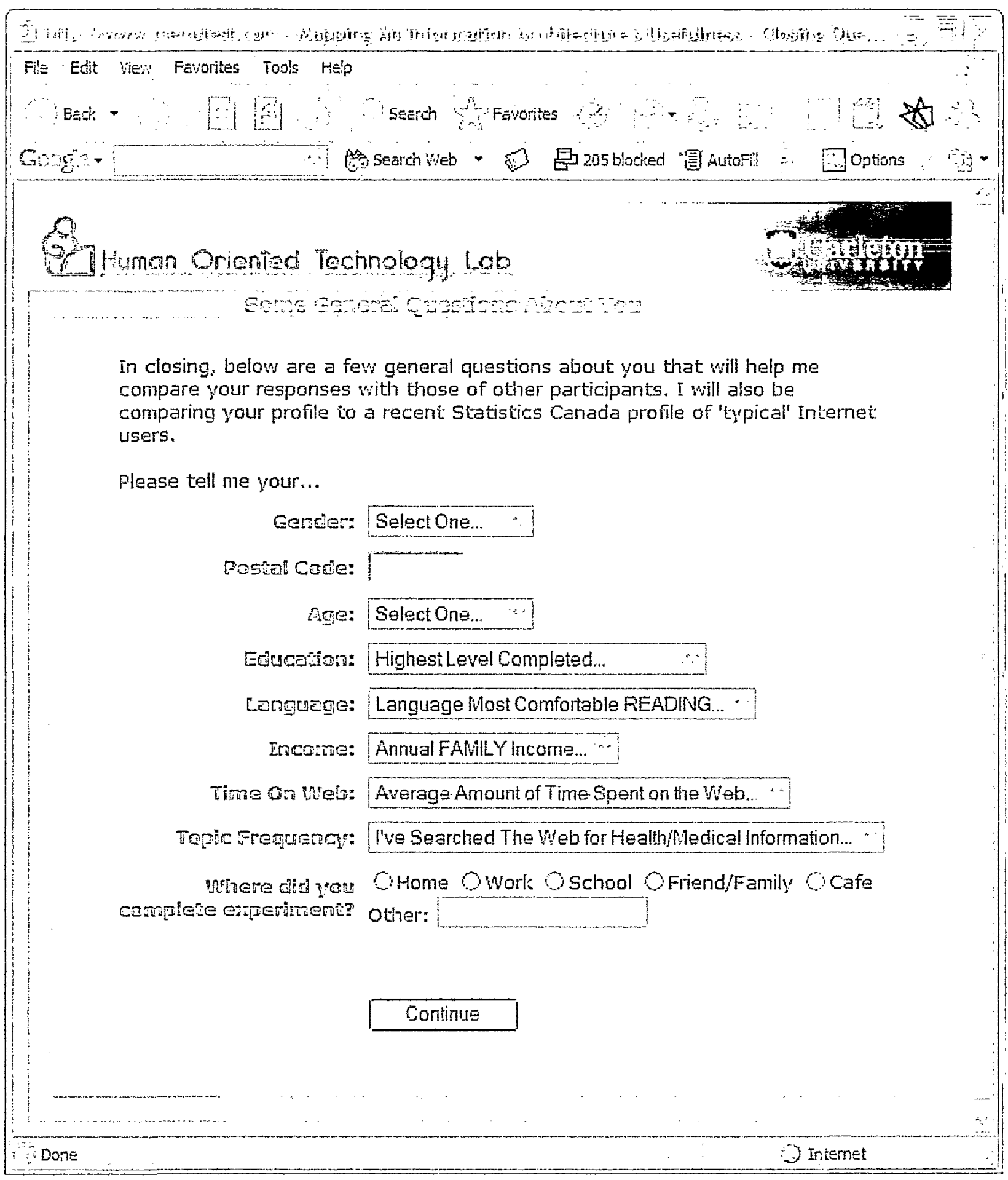


Appendix K - Text from Participant Debriefing Screen

\section{About this Research}

When a person arrives at a web site, they are usually confronted with a menu. If they are looking for information, they browse or scan the menu labels, try and identify which ones appear to be most relevant, and then click deeper into the menu hierarchy.

If they are developing a web site, they view menu labels as locations where information can be stored. In other words, people are either trying to find information on a web site or put information into one of its menu categories.

Part of this research is trying to understand if these different roles cause people to judge the relevance of a menu label differently.

Another part of this research looks at what happens to judgments of relevance when people view the information topic and their information needs differently.

For example, in the scenario about medical marijuana. A person looking for information may be in a great deal of pain and need relief as quickly as possible, yet be very concerned about exposing themselves to legal action if they don't obtain it correctly. In contrast, a web developer may look at a document about medical marijuana as being about the differences in its organic composition when compared to non-medical marijuana. If this results in the web developer putting the information in part of the web site where the person looking for relief from pain would not look, then this web site is less useful.

I'm interested in learning more about how to improve menu systems and make them more useful. I've developed the approach you just used to try and help web site designers see if their menus work, by having people like you try out some scenarios.

In this experiment you were given a role with a specific view to the information. Now your judgments of relevance will be compared to those of other participants who had different roles and different perspectives about the information.

Again I would like to thank you for your time and participation in this research.

\section{Any Questions?}

If you have further questions about this research, or you would like a summary of the results when they have been compiled, please send an e-mail to:

Mark Game, Principal Researcher, Human Oriented Technologies Lab, Psychology Department, Carleton University , (613) 520-2600 ext. 6628.

\section{Any Concerns?}

If you have any concerns about how this research was conducted, please contact one of the following faculty members:

Faculty Advisor: Professor Richard Dillon, Psychology Department, Carleton University, (613) 520-6629.

Chair, Research Ethics Committee for Psychological Research: Professor Mary Gick, Psychology Department, Carleton University, (613) 520-2600 ext. 2664.

Chair of the Psychology Department: Professor John Logan, Carleton University, (613) 5202600 ext. 2690. 
Many Thanks for help

Mark Game

Principal Researcher

markgame@menutest.com 
Appendix L-Face-to-Face Recruiting Scripts

\section{[Principal Researcher's Face-to-Face Script]}

Hello:

You [already] or [may not] know, I'm a graduate student associated with Carleton University's Human Oriented Technology Lab. Currently l'm conducting an experiment as partial fulfillment of Master's degree. I'm looking for people to participate in this experiment, and was wondering if you might be interested. The research is called:

"Mapping an Information Architecture's Usefulness"

This experiment will take about $\mathbf{3 0}$ minutes of your time, can be done over the Internet from the location of your choice.

In this experiment, your role will be to visit a mock web site, read 12 health-related scenarios, and then make judgments about how relevant the menu labels of the web site are to the scenarios you just read.

If your interested, I have a written copy of the invitation that I've been sending out that contains the web address you need to go to to complete the experiment.

Would you like a copy of the e-mail?

[If yes - I hand the individual a copy of the recruiting e-mail (Appendix D)]

[If no - I thank the candidate and end the discussion] 
Appendix M-Computing an IA's Usefulness

The usefulness of an information architecture can be seen as the probability with which a user will choose a valid scent trail that provides access to relevant information. For example, if a user seeking information perceives the target menu label leading to that information as having $100 \%$ relevance to an information need AND no other menu label is perceived as having any relevance (no other scent trails), then the probability of a user choosing that menu label is 1 . However, as soon as the relevance of the target label is perceived as being less than $100 \%$ and/or there are other menu labels that may have some relevance to the context in question (i.e. other scents are being emitted scent), then the probability of selecting a label is $<1$.

To assess the usefulness of an information architecture (the probability of the user choosing a valid scent trail) two evaluations must be completed: a) the degree of scent or relevance the target menu label commands given a specific context, and b) which other scent trails or relevant menu labels are most likely to be chosen when foraging for information within a specific context. The methodology used in this experiment allows a developer to complete both of these evaluations.

The metric used to estimate usefulness has been adapted from work reported by Nosofsky (1984) and based on Luce's (1963) choice theory. Equation 1 estimates the probability that the target menu label (leading to the desired information) will be chosen given the information scent of all other menu labels in the information architecture.

$$
P_{\left(L_{d}\right)}=\frac{R_{\left(L_{d}\right)}}{R_{\left(L_{1}\right)}+R_{\left(L_{2}\right)} \ldots R_{\left(L_{n}\right)}}
$$


The left side of this equation can be read as the probability $\boldsymbol{P}$ of choosing the target menu label $\left(\boldsymbol{L}_{\boldsymbol{d}}\right)$ in an information architecture (i.e., the menu label that corresponds to where the information is actually linked). The right side of the equation can be read as: the participant's relevance estimate $R$ of the target menu label $\left(\boldsymbol{L}_{\boldsymbol{d}}\right)$, divided by the sum of the participant's relevance estimates $R$ for all menu labels in the information architecture $\left(L_{l} \ldots L_{n}\right)$.

For example, of the 71 second-level menu labels used in this experiment, assume a participant identifies labels 4, 15 and 23 as having some degree of relevance. Assume also that the relevance estimates for these three labels were 80,100 and 75 respectively (all other labels have been given a relevance rating of zero). Label number four is the target menu label (actually linked to the information). Therefore, the probability of this participant choosing the target menu label is .31 or $31 \%$, given by:

$$
P_{\left(L_{4}\right)}=\frac{R_{\left(L_{4}\right)}}{R_{\left(L_{4}\right)}+R_{\left(L_{15}\right)}+R_{\left(L_{23}\right)}}=\frac{80}{80+100+75}=.31
$$

Notice that in the above example, the target menu label $\left(\boldsymbol{L}_{4}\right)$ was not the label judged most relevant. In other words, it was not the label with the strongest information scent. That estimate was given to menu label 15.

Even if the target menu label was changed to maximize its information scent (increase the relevance rating to 100 ), this would only increase the overall probability to .39 . Notice that the equation does not only factor the strength of the target menu label, but also the strength of the other scent trails emitting which have been identified (labels 15 and 23 in the above example).

Equation 2 is an extension of the first equation, and calculates the probability of a participant choosing one of two valid menu labels. The numerator includes both the target menu label $\left(\boldsymbol{L}_{\boldsymbol{d}}\right)$ and the user's top ranked menu label choice $\left(\boldsymbol{L}_{c 1}\right)$, i.e. the label with the strongest 
information scent. Therefore, the numerator lists those menu labels from which relevant information can be accessed.

$$
P_{\left(L_{d}\right)}=\frac{R_{\left(L_{d}\right)}+R_{\left(L_{c_{1}}\right)}}{R_{\left(L_{1}\right)}+R_{\left(L_{2}\right)} \ldots R_{\left(L_{n}\right)}}
$$

Using the values from the earlier example, the addition of the user's top ranked menu label increases the probability of choosing a valid scent trail from .31 to .80 . 
Appendix $N-$ Scenario Task \& Contexts Used During Experiment.

Seeking Task: Click on any menu label(s) where you would look for information related to this scenario. Then use the slider bars to estimate the relevance of each menu label, to the scenario, with higher numbers indicating higher relevance.

Classifying Task: Click on any menu label(s) where you would put or link a document related to this scenario. Then use the slider bars to estimate the relevance of each menu label, to the scenario, with higher numbers indicating higher relevance.

\begin{tabular}{|c|c|c|c|c|}
\hline \multirow{2}{*}{$\begin{array}{l}\text { Scenario } \\
\text { Number }\end{array}$} & \multicolumn{2}{|c|}{ Context (Topics) } & \multicolumn{2}{|c|}{ Context (Situations) } \\
\hline & $\begin{array}{c}\text { Task } \\
\text { (Seek) }\end{array}$ & $\begin{array}{c}\text { Task } \\
\text { (Classify) }\end{array}$ & Task (Seek) & Task (Classify) \\
\hline $\begin{array}{l}\text { Practice } \\
\text { Scenario1 }\end{array}$ & $\begin{array}{l}\text { Nutrients in } \\
\text { Canadian } \\
\text { foods }\end{array}$ & $\begin{array}{l}\text { Nutrients in } \\
\text { Canadian } \\
\text { foods }\end{array}$ & $\begin{array}{l}\text { You have been feeling } \\
\text { overweight for some time. } \\
\text { You have decided to start } \\
\text { eating more healthily, and } \\
\text { need more information } \\
\text { about the content of the } \\
\text { foods you eat. }\end{array}$ & $\begin{array}{l}\text { Many people are feeling } \\
\text { overweight. As part of their } \\
\text { efforts to start eating more } \\
\text { healthily, they need more } \\
\text { information about the content } \\
\text { of the foods they eat. You } \\
\text { have a report that was } \\
\text { prepared for this web site. }\end{array}$ \\
\hline $\begin{array}{l}\text { Practice } \\
\text { Scenario2 }\end{array}$ & $\begin{array}{l}\text { Misbehavior } \\
\text { and spanking }\end{array}$ & $\begin{array}{l}\text { Misbehavior } \\
\text { and spanking }\end{array}$ & $\begin{array}{l}\text { You're a frustrated parent } \\
\text { of young children who are } \\
\text { continually misbehaving. } \\
\text { You want to know how to } \\
\text { discipline your children } \\
\text { effectively and wonder if } \\
\text { there is anything wrong } \\
\text { with spanking. }\end{array}$ & $\begin{array}{l}\text { Community centers are } \\
\text { receiving phone calls from } \\
\text { frustrated parents of young } \\
\text { children who are continually } \\
\text { misbehaving. These parents } \\
\text { want to know how to discipline } \\
\text { their children effectively and } \\
\text { are wondering if there is } \\
\text { anything wrong with spanking. } \\
\text { You have access to newly } \\
\text { published material about this } \\
\text { issue and want to place it on } \\
\text { your web site. }\end{array}$ \\
\hline
\end{tabular}




\begin{tabular}{|c|c|c|c|c|}
\hline \multirow{2}{*}{$\begin{array}{l}\text { Scenario } \\
\text { Number }\end{array}$} & \multicolumn{2}{|c|}{ Context (Topics) } & \multicolumn{2}{|c|}{ Context (Situations) } \\
\hline & $\begin{array}{c}\text { Task } \\
\text { (Seek) }\end{array}$ & $\begin{array}{c}\text { Task } \\
\text { (Classify) }\end{array}$ & Task (Seek) & Task (Classify) \\
\hline $\begin{array}{c}\text { Scenario } \\
1\end{array}$ & $\begin{array}{l}\text { Canadian } \\
\text { Safety } \\
\text { Requirements } \\
\text { for Toys }\end{array}$ & $\begin{array}{l}\text { Industry } \\
\text { Guide to } \\
\text { Canadian } \\
\text { Safety } \\
\text { Requirements } \\
\text { for Toys and } \\
\text { Related } \\
\text { Products }\end{array}$ & $\begin{array}{l}\text { You're very excited because } \\
\text { you've made contact with } \\
\text { an Asian toy manufacturer } \\
\text { who is willing to give you a } \\
\text { large contract to sell their } \\
\text { product. You must provide } \\
\text { them with a substantial } \\
\text { deposit cheque and details } \\
\text { of your first order in the } \\
\text { next } 48 \text { hours. You are } \\
\text { concerned about whether } \\
\text { or not their products meet } \\
\text { Canadian toy safety } \\
\text { requirements and don't } \\
\text { want to react from pure } \\
\text { excitement. You need more } \\
\text { detailed information before } \\
\text { making a final decision. }\end{array}$ & $\begin{array}{l}\text { Trade with Asian toy } \\
\text { manufacturers has increased } \\
\text { causing renewed excitement } \\
\text { among Canadian retailers. } \\
\text { Large contracts are being } \\
\text { awarded which require the } \\
\text { retailer to pay for an initial } \\
\text { inventory within } 48 \text { hours of } \\
\text { the contract award. A } \\
\text { consultant has prepared an } \\
\text { industry guide to the Canadian } \\
\text { safety requirements for toys } \\
\text { and related products. It is } \\
\text { important that the guide be } \\
\text { placed on this web site so that } \\
\text { retailer's can make informed } \\
\text { decisions about toy purchases } \\
\text { and are not stuck with } \\
\text { inventory they can't sell or } \\
\text { return. }\end{array}$ \\
\hline $\begin{array}{c}\text { Scenario } \\
2\end{array}$ & $\begin{array}{c}\text { Garden } \\
\text { Safety Tips }\end{array}$ & $\begin{array}{c}\text { Garden } \\
\text { Safety Tips }\end{array}$ & $\begin{array}{l}\text { A few months ago you } \\
\text { bought your first home. } \\
\text { Spring has arrived and you } \\
\text { are eager to start working } \\
\text { in your own garden for the } \\
\text { first time. You have two } \\
\text { young children, a cat and a } \\
\text { dog. You want to know if } \\
\text { there are any general } \\
\text { safety tips you should } \\
\text { consider to protect your } \\
\text { children, pets and yourself } \\
\text { before beginning. }\end{array}$ & $\begin{array}{l}\text { Every year as spring arrives } \\
\text { people are eager to reopen } \\
\text { their gardens. There is a } \\
\text { growing awareness on the part } \\
\text { of gardeners for the need to } \\
\text { protect their children, pets and } \\
\text { themselves from the hazards } \\
\text { of gardening. You have some } \\
\text { material describing general } \\
\text { safety tips to be considered } \\
\text { when gardening. }\end{array}$ \\
\hline
\end{tabular}




\begin{tabular}{|c|c|c|c|c|}
\hline \multirow{2}{*}{$\begin{array}{l}\text { Scenario } \\
\text { Number }\end{array}$} & \multicolumn{2}{|c|}{ Context (Topics) } & \multicolumn{2}{|c|}{ Context (Situations) } \\
\hline & $\begin{array}{l}\text { Task } \\
\text { (Seek) }\end{array}$ & $\begin{array}{c}\text { Task } \\
\text { (Classify) }\end{array}$ & Task (Seek) & Task (Classify) \\
\hline $\begin{array}{c}\text { Scenario } \\
3\end{array}$ & $\begin{array}{c}\text { Facts about } \\
\text { chiropractic } \\
\text { care }\end{array}$ & $\begin{array}{c}\text { Facts about } \\
\text { chiropractic } \\
\text { care }\end{array}$ & $\begin{array}{l}\text { Changes in health care } \\
\text { legislation have removed } \\
\text { chiropractic care as an } \\
\text { eligible expense from your } \\
\text { compensation package. You } \\
\text { suffer from chronic back } \\
\text { pain, and now want to do } \\
\text { some research to compare } \\
\text { chiropractic care to other } \\
\text { forms of treatment. You } \\
\text { need more facts to } \\
\text { determine if you should pay } \\
\text { for these services yourself. }\end{array}$ & $\begin{array}{l}\text { Changes in health care } \\
\text { legislation have removed } \\
\text { chiropractic care as an eligible } \\
\text { insurable expense. Those } \\
\text { suffering from chronic back } \\
\text { pain are the biggest users of } \\
\text { this type of treatment. These } \\
\text { regulatory changes have lead } \\
\text { to an increased demand for } \\
\text { information comparing } \\
\text { chiropractic care to other } \\
\text { forms of treatment. People } \\
\text { need to decide if they should } \\
\text { pay for these services } \\
\text { themselves. You have a } \\
\text { document containing this } \\
\text { information. }\end{array}$ \\
\hline $\begin{array}{c}\text { Scenario } \\
4\end{array}$ & $\begin{array}{l}\text { How to } \\
\text { control your } \\
\text { blood } \\
\text { pressure }\end{array}$ & $\begin{array}{l}\text { How to } \\
\text { control your } \\
\text { blood } \\
\text { pressure }\end{array}$ & $\begin{array}{l}\text { Your doctor has just told } \\
\text { you that your blood } \\
\text { pressure is elevated. You } \\
\text { are concerned and worried } \\
\text { because there is a history } \\
\text { of high blood pressure in } \\
\text { your family. You want to } \\
\text { know more about the risks } \\
\text { associated with high blood } \\
\text { pressure and get some } \\
\text { detailed information about } \\
\text { changes you can make to } \\
\text { your life style to bring this } \\
\text { condition under control. }\end{array}$ & $\begin{array}{l}\text { Many people have elevated } \\
\text { blood pressure, and those with } \\
\text { a history of high blood } \\
\text { pressure in their family are } \\
\text { particularly concerned. People } \\
\text { want information about the } \\
\text { risks associated with high } \\
\text { blood pressure and detailed } \\
\text { information about lifestyle } \\
\text { changes that can be made to } \\
\text { control high blood pressure. } \\
\text { You have a document } \\
\text { containing this information } \\
\text { that you want to place on this } \\
\text { web site. }\end{array}$ \\
\hline $\begin{array}{c}\text { Scenario } \\
5\end{array}$ & $\begin{array}{l}\text { Exposure to } \\
\text { computer } \\
\text { monitor } \\
\text { electric and } \\
\text { magnetic } \\
\text { fields }\end{array}$ & $\begin{array}{l}\text { Exposure to } \\
\text { computer } \\
\text { monitor } \\
\text { electric and } \\
\text { magnetic } \\
\text { fields }\end{array}$ & $\begin{array}{l}\text { You spend a lot of time in } \\
\text { front of a computer } \\
\text { monitor. You've heard } \\
\text { conflicting reports about } \\
\text { the effects of exposure to a } \\
\text { computer monitor's electric } \\
\text { and magnetic fields. You } \\
\text { want to know what the real } \\
\text { story is and if there is } \\
\text { anything you should do to } \\
\text { protect yourself. }\end{array}$ & $\begin{array}{l}\text { More and more people are } \\
\text { spending larger amounts of } \\
\text { time each day in front of a } \\
\text { computer monitor. There are } \\
\text { conflicting reports about the } \\
\text { effects of this increased } \\
\text { exposure to a computer } \\
\text { monitor's electric and } \\
\text { magnetic fields. You have a } \\
\text { document that provides an } \\
\text { overview of the topic and what } \\
\text { if anything people should do to } \\
\text { protect themselves. }\end{array}$ \\
\hline
\end{tabular}




\begin{tabular}{|c|c|c|c|c|}
\hline \multirow{2}{*}{$\begin{array}{l}\text { Scenario } \\
\text { Number }\end{array}$} & \multicolumn{2}{|c|}{ Context (Topics) } & \multicolumn{2}{|c|}{ Context (Situations) } \\
\hline & $\begin{array}{c}\text { Task } \\
\text { (Seek) }\end{array}$ & $\begin{array}{c}\text { Task } \\
\text { (Classify) }\end{array}$ & Task (Seek) & Task (Classify) \\
\hline $\begin{array}{c}\text { Scenario } \\
6\end{array}$ & $\begin{array}{l}\text { Keeping } \\
\text { lawns } \\
\text { healthy }\end{array}$ & $\begin{array}{l}\text { Keeping } \\
\text { lawns } \\
\text { healthy }\end{array}$ & $\begin{array}{l}\text { The use of pesticides for } \\
\text { lawn care is an issue in } \\
\text { your community. You're a } \\
\text { little embarrassed every } \\
\text { time your lawn care } \\
\text { company comes by and } \\
\text { puts that "do not walk" sign } \\
\text { on your grass after each } \\
\text { treatment. Accepting that } \\
\text { it's probably healthier not } \\
\text { to use pesticides, you've } \\
\text { decided to try and find } \\
\text { alternate ways of keeping } \\
\text { your lawn healthy. }\end{array}$ & $\begin{array}{c}\text { The use of pesticides for lawn } \\
\text { care is an issue in many } \\
\text { communities. Pressure from } \\
\text { neighbours and an acceptance } \\
\text { of the inherent risks of } \\
\text { pesticides is driving more } \\
\text { people to look for alternate } \\
\text { methods of keeping their lawns } \\
\text { healthy. You have a document } \\
\text { with suggestions for } \\
\text { alternatives that you would } \\
\text { like published on your web } \\
\text { site. }\end{array}$ \\
\hline $\begin{array}{c}\text { Scenario } \\
7\end{array}$ & $\begin{array}{l}\text { Diet-related } \\
\text { health } \\
\text { claims for } \\
\text { osteoporosis }\end{array}$ & $\begin{array}{l}\text { Diet-related } \\
\text { health } \\
\text { claims for } \\
\text { osteoporosis }\end{array}$ & $\begin{array}{l}\text { Following a bone density } \\
\text { test, your mother has been } \\
\text { diagnosed with } \\
\text { osteoporosis. You are } \\
\text { wondering if diet } \\
\text { supplements might help her } \\
\text { to slow the effects of this } \\
\text { condition. You are looking } \\
\text { for information about the } \\
\text { diet-related health claims } \\
\text { between calcium, vitamin D } \\
\text { and osteoporosis. }\end{array}$ & $\begin{array}{l}\text { Bone density tests can identify } \\
\text { cases of osteoporosis, } \\
\text { particularly among women. } \\
\text { The use of diet supplements is } \\
\text { becoming popular to try and } \\
\text { slow the effects of this } \\
\text { condition. In particular, your } \\
\text { office has been receiving calls } \\
\text { about the diet-related health } \\
\text { claims between calcium, } \\
\text { vitamin D and osteoporosis. } \\
\text { You have a document that } \\
\text { outlines these relationships } \\
\text { that you wish to publish on } \\
\text { your web site. }\end{array}$ \\
\hline $\begin{array}{c}\text { Scenario } \\
8\end{array}$ & $\begin{array}{l}\text { Medical } \\
\text { Marijuana }\end{array}$ & $\begin{array}{c}\text { Medical } \\
\text { Marijuana }\end{array}$ & $\begin{array}{c}\text { You are currently in a great } \\
\text { deal of pain as a result of } \\
\text { your treatments for cancer. } \\
\text { You are looking for relief } \\
\text { and would like to try using } \\
\text { marijuana. Because of the } \\
\text { controversy and legal } \\
\text { issues you want to know } \\
\text { what the rules are for } \\
\text { obtaining marijuana for } \\
\text { medical purposes, and how } \\
\text { to get it. }\end{array}$ & $\begin{array}{l}\text { Many people who suffer a } \\
\text { great deal of pain following } \\
\text { cancer treatments are looking } \\
\text { for relief. One option is the } \\
\text { use of marijuana. However, } \\
\text { the controversy and legalities } \\
\text { surrounding its use has } \\
\text { created some confusion about } \\
\text { how and when marijuana can } \\
\text { be used for medical purposes. } \\
\text { You have information that } \\
\text { you've formatted for the web, } \\
\text { that acts as a primer on these } \\
\text { issues. }\end{array}$ \\
\hline
\end{tabular}




\begin{tabular}{|c|c|c|c|c|}
\hline \multirow{2}{*}{$\begin{array}{l}\text { Scenario } \\
\text { Number }\end{array}$} & \multicolumn{2}{|c|}{ Context (Topics) } & \multicolumn{2}{|c|}{ Context (Situations) } \\
\hline & $\begin{array}{c}\text { Task } \\
\text { (Seek) }\end{array}$ & $\begin{array}{c}\text { Task } \\
\text { (Classify) }\end{array}$ & Task (Seek) & Task (Classify) \\
\hline $\begin{array}{c}\text { Scenario } \\
9\end{array}$ & $\begin{array}{l}\text { Potential } \\
\text { radiation } \\
\text { effects of } \\
\text { cellular } \\
\text { phone } \\
\text { usage }\end{array}$ & $\begin{array}{l}\text { Potential } \\
\text { radiation } \\
\text { effects of } \\
\text { cellular } \\
\text { phone } \\
\text { usage }\end{array}$ & $\begin{array}{l}\text { A recent TV documentary } \\
\text { described potential } \\
\text { radiation effects of using } \\
\text { cellular phones. You are } \\
\text { constantly on your cell } \\
\text { phone for personal and } \\
\text { business reasons. You are } \\
\text { concerned about your } \\
\text { exposure to this potential } \\
\text { hazard and want to know } \\
\text { how to protect yourself. }\end{array}$ & $\begin{array}{l}\text { A recent TV documentary } \\
\text { described potential radiation } \\
\text { effects of cellular phone usage. } \\
\text { Cellular phone usage continues } \\
\text { to rise as people are using cell } \\
\text { phones for personal and } \\
\text { business reasons. You have a } \\
\text { document that can act as } \\
\text { supplement to the current } \\
\text { media coverage, and outlines } \\
\text { how people can protect } \\
\text { themselves from potentially } \\
\text { harmful effects. }\end{array}$ \\
\hline $\begin{array}{c}\text { Scenario } \\
10\end{array}$ & $\begin{array}{l}\text { Acupuncture } \\
\& \\
\text { Traditional } \\
\text { Chinese } \\
\text { Medicine }\end{array}$ & $\begin{array}{l}\text { Acupuncture } \\
\& \\
\text { Traditional } \\
\text { Chinese } \\
\text { Medicine }\end{array}$ & $\begin{array}{l}\text { Your reduced productivity } \\
\text { and feelings of chronic } \\
\text { fatigue have increased } \\
\text { lately. You've heard that } \\
\text { traditional Chinese } \\
\text { medicines and acupuncture } \\
\text { may be effective in treating } \\
\text { this type of condition. You } \\
\text { want to find out if there has } \\
\text { been any research } \\
\text { comparing these } \\
\text { treatments to traditional } \\
\text { North American treatments. }\end{array}$ & $\begin{array}{l}\text { Reduced productivity and } \\
\text { feelings of chronic fatigue are } \\
\text { increasing among adults. } \\
\text { There is interest in the } \\
\text { effectiveness of traditional } \\
\text { Chinese medicines and } \\
\text { acupuncture to treat this type } \\
\text { of condition. Recent research } \\
\text { has compared these } \\
\text { treatments to traditional North } \\
\text { American treatments, and you } \\
\text { would like to put a copy of this } \\
\text { material on your web site. }\end{array}$ \\
\hline
\end{tabular}


Appendix O-Data Cleaning Details.

Incomplete sessions were those that a participant began but failed to complete all 12 scenarios (two practice and 10 real) or did not complete the question regarding the relevance thresholds. The database rule established for the removal of an incomplete record was based on a 24 hour clock following the beginning of the session.

It was acknowledged early on in the experiment, that several participants would begin an experimental session, and then part way through, leave their computers (e.g. meetings, shopping etc.). They would return at a future point in time and complete the experiment. If the experiment was not completed within 24 hours, it was assumed the participant had quit and any accumulated data was automatically moved to an inactive area of the database. One check for incomplete data was performed manually. If a participant had clicked through all the questions (but did not make any relevance ratings) and then answered the relevance threshold questions in a logical manner, this session would not have been removed automatically as it met the criteria for completion. Therefore, there was also a manual inspection of each record, and instances such as the one described resulted in the removal of the data.

Illogical relevance thresholds were identified in 15 cases. The relevance threshold question asked users to identify the points where the partially relevant category began and ended. There were 15 sessions in which participant's beginning number was larger than or equal to the ending number. This illogical pairing of numbers became the second automated rule for removing data.

There were two instances of suspicious response patterns early in the experiment. In these two cases, the participant had opened each and every menu label and provided a near maximum rating to every menu label choice. The patterns of responses and the time taken to 
make each response (several responses per second) suggested that the participants responses were rote, automatic and not in good faith. The data from these sessions was also removed. A test session was defined as one conducted by someone that did not constitute a legitimate participant (e.g. an academic colleague, thesis advisor, technical support person) and was interacting with the site to explore or test some feature of the site. These individuals were identified by a unique postal code which was reserved for testing. Data from these sessions were removed. 


\section{Bibliography}

Blackmon, M. H., Polson, P. G., Kitajima, M., \& Lewis, C. (2002). Cognitive walkthrough for the web. In Proceedings of the SIGCHI conference on Human factors in computing systems: Changing our world, changing ourselves (pp. 463-470). Minneapolis, Minnesota: ACM Press.

Borlund, P. (2003). The concept of relevance in IR. Journal of the American Society for Information Science and Technology, 54(10), 913-925. Retrieved 8-22-2003, from http://resolver.scholarsportal.info/rcsolve/15322882/v54i0010/913 tcorii\&form $7 p d f \&$ file =file.pdf

Brooks, T. A. (1997). The relevance aura of bibliographic records. Information Processing and Management, 33(1), 69-80.

Bruce, H. (1994). A cognitive view of the situational dynamism of user-centered relevance estimation. Journal of the American Society for Information Science, 45 142-148.

Bruce, H. (1998). User satisfaction with information seeking on the Internet. Journal of the American Society for Information Science, 49(6), 541-556. Retrieved 8-22-2003, from http://resolver:scholarsportal.info/resolve/00028231/v49i0006/541 uswisoti\& form $=$ pdf\& $\underline{\text { file=file.pdf }}$

Brunswik, E. (1952). The conceptual framework of psychology. Chicago, IL: University of Chicago Press.

Charnov, E. L. (1976). Optimal foraging, the marginal value theorem. Theoretical Population Biology, 9(2), 129-136. 
Cohen, J. (1992). A power primer. Quantitative methods in psychology. Psychological Bulletin, $112155-159$.

Deerwester, S., Dumais, S. T., Furnas, G. W., Landauer, T. K., \& Harshman, R. (1990). Indexing by Latent Semantic Analysis. Journal of the American Society for Information Science, $41(6), 391-407$.

Eisenberg, M. B. (1986). Magnitude estimation and the measurement of relevance. Unpublished doctoral dissertation, Syracuse, NY: Syracuse University .

Eisenberg, M. B. (1988). Measuring relevance judgments. Information Processing and Management, 24(4), 373-389.

Gluck, M. (1996). Exploring the relationship between user satisfaction and relevance in information systems. Information Processing and Management, 32(1), 89-104.

Greisdorf, H. (2000). Relevance: An interdisciplinary and information science perspective. Informing Science, 3(2), 67-72.

Hassenzahl, M. (1999). Usability Engineers as Clinicians. Common Ground, 9(3), 12-14. Retrieved 11-22-2004, from http://www.tudarmstadt.de/fb/fb3/psy/soz/veroeffentlichungen_mh/Usability_engineers_are_clinicians. $\underline{\mathrm{pdf}}$

Howard, D. L. (1994). Pertinence as reflected in personal constructs. Journal of the American Society for Information Science, 45(3), 172-185. 
Janes, J. W. (1991). Relevance judgments and the incremental presentation of document representations. Information Processing and Management, 27(6), 629-646.

Katz, M. A. \& Byrne, M. D. (2003). Effects of scent and breadth on use of site-specific search on e-commerce web sites. ACM Transactions on Computer-Human Interaction, 10(3), 198220.

Landauer, T. K. (2002). On the computational basis of learning and cognition: Arguments from LSA. In N.Ross (Ed.), The psychology of learning and motivation (41, pp. 49-84). San Diego: Academic Press.

Landauer, T. K. \& Dumais, S. T. (1997). A solution to Plato's problem: the Latent Semantic Analysis theory of acquisition, induction and representation of knowledge. Psychological Review, 104 211-240.

Landauer, T. K., Foltz, P. W., \& Laham, D. (1998). An introduction to Latent Semantic Analysis. Discourse Processes, 25 259-284.

Leth-Steensen, C. (2003). Personal Communication.

Luce, R. D. (1963). Detection and recognition. In R.R.B.a.E.G.R.D.Luce (Ed.), Handbook of mathematical psychology (pp. 103-189). New York: Wiley.

Nosofsky, R. M. (1984). Choice, similarity, and the context theory of classification. Journal of Experimental Psychology: Learning, Memory and Cognition, 10(1), 104-114.

Pirolli, P. (1997). Computational models of information scent-following in a very large browsable text collection. In Proceedings from the SIGCHI'97 Conference on Human 
factors in computing systems, Atlanta, Georgia (pp. 3-10). ACM Press/Addison-Wesley Publishing Co.

Pirolli, P. (2004). The use of proximal information scent to forage for distal content on the world wide web. User Interface Research@PARC, Retrieved 10-5-0004, from http://www2.parc.com/istl/projects/uir/publications/all_pubs_abstracts.html\#UIR-200407-Pirolli-ProximallnformationScent

Pirolli, P. \& Card, S. (1995). Information foraging in information access environments. In Proceedings of the SIGCHI conference on Human factors in computing systems, Denver, Colorado. (pp. 51-58). ACM Press/Addison-Wesley Publishing Co.

Pirolli, P. \& Card, S. (1999). Information foraging. Psychological Bulletin, 106(4), 643-675.

Quesada, Jose. (2003). Personal communication.

Soto, R. (1998). Learning and performing by exploration - Label quality measured by latent semantic analysis. Proceedings of the 1999 SIGCHI Conference on Human Factors in Computing Systems, (1999), 418-425. Retrieved 4-8-2003, from $\underline{\text { http://lsa.colorado.edu/papers/soto1.pdf }}$

Statistics Canada (2002). Households using the Internet from home by purpose of use. Statistics Canada, CANSIM II, table 358-0006, catalogue no.56F0004MIE, Retrieved 8-13-2003, from http://www.statcan.ca/english/Pgdb/arts52a.htm

Stephens, D. W. \& Krebs, J. R. (1986). Foraging Theory. Princeton, NJ: Princeton University Press. 
Stevens, S. S. (1975). Pschophysics: Introduction to its perceptual, neural, and social prospects. New York, NY: Wiley.

W3Schools (2004). Browser Statistics. wuw.w3schools.com, Retrieved 6-22-0004, from http://www.w3schools.com/browsers/browsers_stats.asp

Zeno, S. M., Ivenz, S. H., Millard, R. T., \& Duwuri, R. (1995). The educator's word frequency guide. Brewster, NY: Touchstone Applied Science Associates (T A S A), Incorporated. 